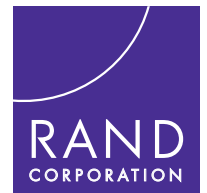

\title{
Review of Army Total Force Policy Implementation
}

Ellen M. Pint, Christopher M. Schnaubelt, Stephen Dalzell, Jaime L. Hastings, Penelope Speed, Michael G. Shanley 
For more information on this publication, visit www.rand.org/t/RR1958

Library of Congress Cataloging-in-Publication Data is available for this publication.

ISBN: 978-0-8330-9821-4

Published by the RAND Corporation, Santa Monica, Calif.

(C) Copyright 2017 RAND Corporation

RAND $^{\circledR}$ is a registered trademark.

\section{Limited Print and Electronic Distribution Rights}

This document and trademark(s) contained herein are protected by law. This representation of RAND intellectual property is provided for noncommercial use only. Unauthorized posting of this publication online is prohibited. Permission is given to duplicate this document for personal use only, as long as it is unaltered and complete. Permission is required from RAND to reproduce, or reuse in another form, any of its research documents for commercial use. For information on reprint and linking permissions, please visit www.rand.org/pubs/permissions.

The RAND Corporation is a research organization that develops solutions to public policy challenges to help make communities throughout the world safer and more secure, healthier and more prosperous. RAND is nonprofit, nonpartisan, and committed to the public interest.

RAND's publications do not necessarily reflect the opinions of its research clients and sponsors.

\section{Support RAND}

Make a tax-deductible charitable contribution at www.rand.org/giving/contribute 


\section{Preface}

This document reports the results of a research project entitled "Review of Army Total Force Policy Implementation.” The purpose of the project was to review the implementation of the Army Total Force Policy and to provide recommendations for sustaining and/or modifying its objectives to more effectively achieve a more integrated operational force.

In this report, we review the Army's progress in implementing the Army Total Force Policy across the domains of doctrine, organization, collective training, mobilization, materiel, leadership and education, personnel, and facilities. Our assessment is based on objective indicators as well as interviews with stakeholders in the Regular Army, Army National Guard, and U.S. Army Reserve. We also discuss related recommendations made by the National Commission on the Future of the Army, obstacles to integration, and additional steps the Army could take to move toward the goal of total force integration.

This research was sponsored by the Office of the Chief, Army Reserve, and conducted within the RAND Arroyo Center's Personnel, Training and Health program. RAND Arroyo Center, part of the RAND Corporation, is a federally funded research and development center sponsored by the United States Army.

The Project Unique Identification Code (PUIC) for the project that produced this document is RAN167282. 



\section{Contents}

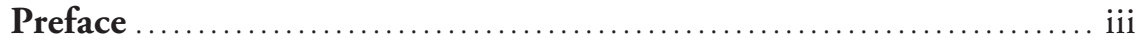

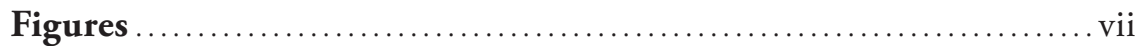

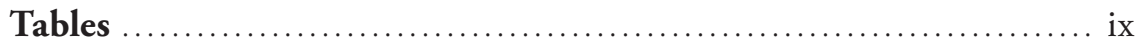

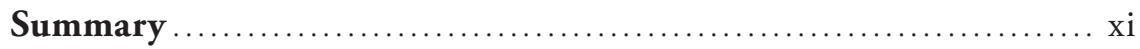

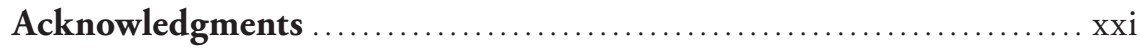

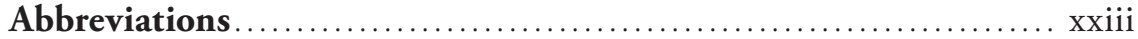

CHAPTER ONE

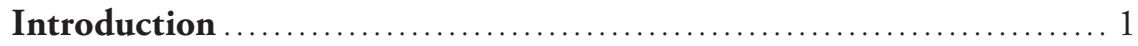

Methodology ................................................. 3

Organization of This Report...................................... 5

CHAPTER TWO

DoD and Army Total Force Policy ............................. 7

Evolution of Total Force Policy..................................... 7

The Army Total Force Policy ........................................ 11

National Commission on the Future of the Army ..................... 21

Summary .................................................. 22

CHAPTER THREE

ATFP Implementation Within DOTMLPF Functions .............. 25

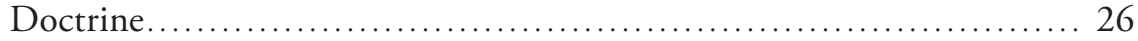

Organization ................................................. 31

Training ......................................................... 47

Mobilization ................................................. 55

Materiel.....................................................62 
vi Review of Army Total Force Policy Implementation

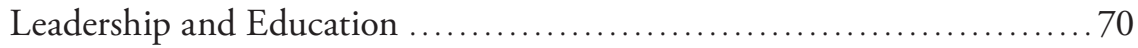

Personnel .................................................... 77

Facilities .................................................. 92

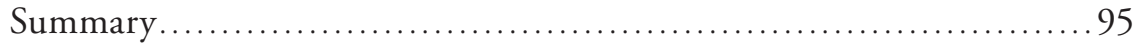

CHAPTER FOUR

Conclusions and Recommendations ........................... 97

Doctrine ..................................................... 98

Organization ................................................... 99

Training ......................................................... 99

Mobilization ................................................... 99

Materiel.................................................... 100

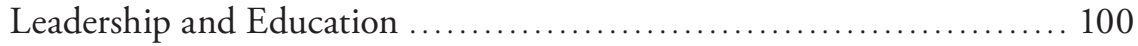

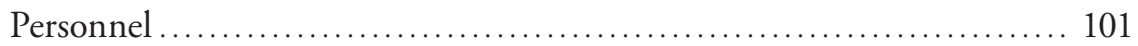

Facilities ................................................... 101

Related Research ............................................. 102

APPENDIXES

A. Interview Protocol ....................................... 105

B. Department of Defense Directive 1200.17, Managing the RCs as an Operational Force .................. 109

C. Army Total Force Policy .................................. 121

D. Additional Data on Equipping Rates for Selected Unit Types ... 127

E. Additional Data on Cross-Component Attendance at ALC and SLC .......................................... 133

References ................................................. 137 


\section{Figures}

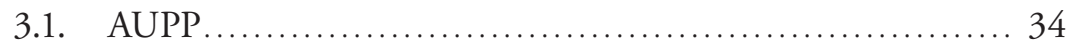

3.2. Median Percentage of Authorized Equipment on Hand, No Substitutes, by Dollar Value ..............................6 65

3.3. Trends in Cross-Component Attendance at Basic Leader Course .................................................. 73

3.4. Promotion Rates for Title XI Officers vs. All Army Officers .......................................... 80

D.1. Median Percentage of Authorized Equipment on Hand, No Substitutes, by Dollar Value for Different Types of MP Companies

D.2. Median Percentage of Authorized Equipment on Hand, No Substitutes, by Dollar Value for Different Types of Transportation Companies

D.3. Median Percentage of Authorized Equipment on Hand, No Substitutes, by Dollar Value for Infantry Battalions by DARPL BIN.

D.4. Median Percentage of Authorized Equipment on Hand, No Substitutes, by Dollar Value for MP Companies by DARPL BIN

D.5. Median Percentage of Authorized Equipment on Hand, No Substitutes, by Dollar Value for Transportation Companies by DARPL BIN. 



\section{Tables}

S.1. Remaining Challenges to Be Addressed .................. xix

1.1. List of Army Organizations Included in Interviews ............ 4

2.1. Summary of ATFP Implementation Guidance .............. 15

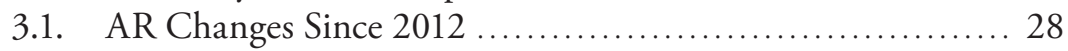

3.2. Multicomponent MTOE Units ....................... 43

3.3. RC Participation in FY 2016 NTC Rotations................ 51

3.4. Army Utilization of 10 U.S.C. $12304 \mathrm{~b}$ Mobilization Authority........................................ 60

3.5. Installation Funding by Command ..................... 94

E.1. Trends in Cross-Component Attendance at ALC and SLC ...................................... 134 



\section{Summary}

Over the past four decades, the Army has developed policies and programs to address the complex task of integrating its active and reserve forces. Despite those efforts, two key, and often contentious, issues remain:

1. how best to integrate the Army's active components (ACs) and reserve components (RCs)

2. how best to apportion roles, missions, force structure, and other resources among the components.

The Secretary of the Army issued the Army Total Force Policy (ATFP) on September 4, 2012, to define further the steps that should be taken to integrate all components as a total force. Since 2012, changes in the Army budget, force structure, operational environment, and future operating concepts have been made that could affect the Army's ability to implement the ATFP. However, while significant progress has been made in meeting ATFP objectives, much work still must be done to achieve a fully integrated, operational total force that can leverage the strengths of each of its components. This is reflected in the National Commission on the Future of the Army (NCFA) report; many of its 63 recommendations are related to ATFP objectives.

The Office of the Chief, Army Reserve asked the RAND Arroyo Center to examine the extent to which the Army has implemented the policies and actions directed by the ATFP; how these efforts have benefited the different components and enhanced the total force; whether they have any negative unintended consequences; and how the Army might improve the ATFP to achieve a more cost-effective, integrated, 
and capable total force. As part of this research, we reviewed Army regulations, policies, and doctrine as well as related literature on the ATFP and total force integration, including the NCFA's report. We also developed indicators for assessing progress toward achieving ATFP objectives based on available data sources, and interviewed key stakeholders in the Regular Army, Army National Guard (ARNG), and U.S. Army Reserve (USAR). Based on these efforts, we make recommendations on further actions the Army should take to strengthen the integration of its $\mathrm{AC}$ and $\mathrm{RC}$ forces.

\section{Overview of Army Total Force Policy}

The ATFP specifies several policy and regulatory changes that must be implemented by various organizations in the Army.

- Integrate AC and RC forces and capabilities at the tactical level (division and below), including some predeployment collective training of units that will routinely deploy as multicomponent forces.

- Establish uniform procedures and processes for validating the predeployment readiness of AC and RC units and soldiers. Standards for qualification and professional development will be the same for AC and RC personnel.

- Streamline the voluntary and involuntary call to active duty of RC personnel and units.

- Ensure that the Army's equipping strategy enables the total force to perform its missions.

- Employ an integrated personnel management and pay system with standardized business processes and authoritative data for military personnel. Personnel policies shall facilitate continuum of service and opportunities for joint experiences.

- Amend Army Regulation (AR) 71-11, AR 525-29, and AR 500-5 to conform with the ATFP (Department of the Army, 1995, 2011, 2015b). 
- Consolidate or eliminate Army publication Series 135 (Army National Guard and Army Reserve), Series 140 (Army Reserve), Series 350 (Training), and Series 600 (Personnel-General).

- Use the new authority in 10 U.S.C. $12304 \mathrm{~b}$, which allows the Secretary of the Army to order RC units to active duty under certain conditions.

The Army issued additional implementation guidance in 2013, 2014, and 2015 that designated Army organizations as leads for specific implementation tasks; established deadlines for completing certain tasks; and required formation of working groups, with participation from each component. As of this writing, the Army was preparing new guidance to be issued in 2017.

\section{Findings and Recommendations}

The Army has made progress in implementing ATFP objectives across the Doctrine, Organization, Training, Materiel, Leadership, Personnel, and Facilities (DOTMLPF) domains, but more work remains to be done. In many areas, the NCFA has provided more-specific recommendations and has created a new impetus for the Army to move forward with ATFP implementation. However, budget constraints have limited implementation of some objectives. In addition, several initiatives focus on brigade combat teams (BCTs), placing less emphasis on the enabler units needed to conduct contingency operations. Many stakeholders also stated that a change in culture was particularly needed to promote better AC-RC integration within the Army. Finally, some interviewees noted that ATFP implementation emphasizes policy changes, not executing and enforcing those changes.

Even if proposed increases to the defense budget come to pass, the Army's budget is likely to remain constrained. Therefore, innovative solutions are needed to achieve the intent of the ATFP. For example, the Army can reduce the cost of multicomponent training through initiatives such as the Nationwide Move program, multicomponent vehicle loans, and positioning modernized equipment at regional training 
and mobilization sites. Another example is consolidating and integrating individual training and professional military education under the One Army School System (OASS).

To continue moving forward, the Army should set goals for force integration and establish metrics to monitor progress toward achieving those goals, such as the number of units and soldiers participating in multicomponent training events; the use of $12304 \mathrm{~b}$ mobilization authority; the equipping of early-deploying enabler units; and the fielding schedule and functionality of the Integrated Personnel and Pay System-Army (IPPS-A). In addition, the Army has started several pilot programs that will need to be evaluated to determine whether they are meeting the intent of the ATFP and whether combining functions across components results in the neglect of ARNG and USAR interests. These programs include the Associated Units Pilot Program (AUPP), multicomponent headquarters organizations, the One Army recruiting pilot, and combining marketing functions.

We organized our more detailed findings and recommendations using the Army's DOTMLPF framework, with an additional section on mobilization. In each domain, we examined the Army's progress in implementing ATFP objectives and obstacles to integration, and developed recommendations for the Army to further strengthen integration of $\mathrm{AC}$ and $\mathrm{RC}$ forces.

\section{Doctrine}

To assess the Army's progress in implementing required regulatory changes, we examined changes made to each regulation since 2012. We found that only a few had been updated in recent years and, in some cases, the changes did not address ATFP requirements. Stakeholders reported satisfaction with their input into rewriting some regulations, but minimal involvement in rewriting others. The ARNG, more than the other components, continues to maintain component-specific regulations, in some cases because proponents of Army-wide regulations are reluctant to incorporate ARNG-specific items. Therefore, we recommend that the Army assess the status of the regulatory changes required by the ATFP and set a firm timeline to publish the remaining changes. However, stakeholders from all three components reported 
to us that, even if all the required regulation changes are made, Army culture and practices must change to increase trust and integration between the components.

\section{Organization}

The Army has several initiatives related to multicomponent units. For example, the AUPP establishes formal relationships between designated $\mathrm{AC}$ and $\mathrm{RC}$ units so that they can train and potentially deploy together. The multicomponent headquarters program creates RC detachments to augment $\mathrm{AC}$ corps and division headquarters to offset a recent downsizing of these organizations. The Army has also created other multicomponent sustainment and support units that account for about 1 percent of total Army end strength. Most of these programs have only recently been implemented and have yet to be evaluated to determine whether they are meeting the intent of the ATFP. Some are similar to past initiatives that were intended to increase AC-RC integration but fell into neglect or were abandoned when $\mathrm{RC}$ forces were not deemed ready to deploy with their AC counterparts. Therefore, we recommend that the Army develop goals and metrics for these programs and adjust policies and practices as necessary to meet those goals.

\section{Training}

Initiatives to increase multicomponent collective training include the Total Force Partnership Program, which partners ARNG division headquarters with AC corps headquarters and RC brigades and higherlevel units with like-designed AC brigades based on geographic location. The Army has also increased participation of RC units in Combat Training Center (CTC) rotations and other multicomponent training exercises and developed a new execution order on validating predeployment readiness. However, no additional funding has been provided to transport RC units to CTCs or AC installations or AC units to $\mathrm{RC}$ training facilities. In addition, some initiatives focus on BCTs and tend to exclude enabler units or provide only limited opportunities for enabler units to participate. Innovative solutions, such as the Nationwide Move program, multicomponent vehicle loans, and positioning equipment at training centers, can reduce transportation costs, but the 
Army should also consider increasing transportation funding to support multicomponent training.

\section{Mobilization}

The ATFP and the NCFA both call for greater use of $12304 \mathrm{~b}$ mobilization authority, which allows the service secretaries to involuntarily mobilize up to 60,000 RC personnel for a maximum of 365 days. The NCFA found that the Army has not made much use of this authority due to budget constraints. As a result, some AC units with less than two years of dwell time (time that service members spend at home station between deployments to war zones) performed missions that could have been done by similar ARNG and USAR units. Based on recent Army budget materials, we found that the Army is gradually ramping up toward the 3,000 person-years of $12304 \mathrm{~b}$ utilization recommended by the NCFA. The Army should monitor the types of operations designated for RC units under this authority, and the contributions of these missions to relieving stress on $\mathrm{AC}$ forces and maintaining an operational reserve.

\section{Materiel}

The U.S. Department of Defense's (DoD's) annual National Guard and Reserve Equipment Report provides an overview of RC equipment shortages and the services' equipment procurement plans for their RCs. The most recent report indicates overall shortages of \$23.9 billion in ARNG equipment and $\$ 8.9$ billion in USAR equipment, not including authorized substitutions (DoD, 2016b). It also notes that budget constraints are causing a decline in $\mathrm{RC}$ equipment procurement funding, and the practice of transferring aging equipment from $\mathrm{AC}$ to $\mathrm{RC}$ units creates capability and interoperability gaps. Our analysis of Army equipping data found some evidence of discrepancies in assignment of modernized equipment. The Army's procurement funding is likely to remain constrained, but it could set higher priorities for earlydeploying RC units and measurable goals for equipping those units. An improved process for equipment transparency reporting would also help ensure that equipment designated for RC units is eventually delivered to them. In addition, greater multicomponent sharing of equip- 
ment or positioning of equipment at training centers could increase RC access to modernized equipment.

\section{Leadership and Education}

The OASS is consolidating individual training facilities across components, standardizing programs of instruction, and integrating the flow of soldiers to the closest location offering needed courses, regardless of component. For soldiers in selected unit types, we found that $\mathrm{RC}$ attendance at AC-run Basic Leader Courses (BLCs) had increased in recent years, but not $\mathrm{AC}$ attendance at RC-run BLCs. There was also relatively little cross-component attendance at Advanced Leader Courses or Senior Leader Courses, except for combined ARNG and USAR attendance at RC-run courses. As recommended by the NCFA, the Army should continue to implement OASS and monitor crosscomponent attendance. Pursuing broader multicomponent attendance at training and leadership courses could help break down cultural barriers between components. This pursuit could include increasing the number of fully funded slots allocated to RC officers at the National Defense University, senior war colleges, and the Joint Professional Military Education in-residence course.

\section{Personnel}

The ATFP directs the Army to employ an integrated personnel management and pay system and to facilitate continuum of service and opportunities for joint experiences. The NCFA added recommendations to increase cross-component assignments, establish a multiyear pilot program to consolidate recruiting across components, and consolidate marketing functions across components. The Army is making progress in implementing IPPS-A, but full implementation is not expected until 2020. So far, initiatives to promote a continuum of service have focused on reducing the paperwork requirements limiting transfers between components. These initiatives have not yet moved toward a broader vision of an Army human capital strategy that allows soldiers to move more flexibly between components, depending on their personal circumstances and the needs of the Army. The Defense Officer Personnel Management Act and Reserve Officer Personnel Manage- 
ment Act create additional constraints and disincentives for continuum of service and cross-component assignments. Other concerns that will need to be monitored and evaluated include whether multicomponent assignments will have negative effects on promotion opportunities and whether combining recruiting and marketing functions across components will have equitable outcomes for all three components.

\section{Facilities}

The ATFP objectives and NCFA recommendations do not directly address facilities, but they are important enablers for training and mobilization. AC and RC installations are very different. The typical $\mathrm{AC}$ installation is a sprawling city, providing a wide range of services to resident Army personnel and surrounded by acres of maneuver space, whereas many ARNG armories and USAR training centers are embedded in local communities. Even large RC training facilities are lightly manned for much of the year. Concerns in this area focus on equitable funding for facility operations and maintenance and military construction. Facility management may be a case where "one size fits all" policies are inappropriate, and the components should be given some latitude on how best to maintain and invest in facilities.

\section{Remaining Challenges}

We summarize key remaining challenges to total force integration and ways the Army can address them in Table S.1. 
Table S.1

Remaining Challenges to Be Addressed

\begin{tabular}{|c|c|}
\hline Challenges & Approaches \\
\hline $\begin{array}{l}\text { Reduce cultural barriers } \\
\text { and distrust between } \\
\text { components }\end{array}$ & $\begin{array}{l}\text { - Increase cross-component interactions through } \\
\text { unit associations, multicomponent training events, } \\
\text { individual training and education, multicomponent } \\
\text { units, and cross-component assignments } \\
\text { - Use strategic communications to reinforce need for } \\
\text { change }\end{array}$ \\
\hline $\begin{array}{l}\text { Improve RC access to } \\
\text { modernized equipment }\end{array}$ & $\begin{array}{l}\text { - Increase multicomponent equipment-sharing } \\
\text { - Position modernized equipment at RC training } \\
\text { centers } \\
\text { - Set timelines for providing modernized equipment } \\
\text { to early-deploying RC units }\end{array}$ \\
\hline $\begin{array}{l}\text { Create a true continuum } \\
\text { of service }\end{array}$ & $\begin{array}{l}\text { - Facilitate transfers between components that meet } \\
\text { the needs of individual soldiers and the Army } \\
\text { - Ensure that nontraditional career paths and cross- } \\
\text { component assignments are not penalized by the } \\
\text { promotion process }\end{array}$ \\
\hline
\end{tabular}





\section{Acknowledgments}

We thank our action officers in the Office of the Chief, Army Reserve, COL Toney Filostrat and Mr. Daniel George, for their guidance and assistance throughout this project. COL Timothy D. Connelly, initially while assigned to the Office of the Assistant Secretary of the Army, Manpower and Reserve Affairs, and later as the Executive Officer to the Chief of Army Reserve, provided important data and helped us to identify useful points of contact. We also thank the many Regular Army, Army National Guard, and U.S. Army Reserve stakeholders who participated in our not-for-attribution interviews and gave us their candid opinions on the Army's progress in implementing the Army Total Force Policy.

Our RAND colleagues Laurie McDonald and Rodger Madison provided programming assistance with the analysis of Army training data, and Lisa Colabella helped us obtain Army equipping data. Greg Schumacher contributed valuable observations on the Associated Units Pilot Program and the multicomponent headquarters program. Jerry Sollinger provided editorial assistance, and Rosie Velasquez helped format this document.

We also thank our colleagues Bernard Rostker and Daniel Ginsburg for their thoughtful reviews, which have helped improve this report. 



\section{Abbreviations}

AC

AE2S

AGR

ALC

APD

AR

ARNG

ASA (M\&RA)

ATFP

ATRRS

AUPP

BCT

BLC

$\mathrm{CoC}$

CTC active component

Army Equipping Enterprise System

Active Guard and Reserve

Advanced Leader Course

Army Publishing Directorate

Army Regulation

Army National Guard

Assistant Secretary of the Army, Manpower, and Reserve Affairs

Army Total Force Policy

Army Training Requirements and Resource System

Associated Units Pilot Program

brigade combat team

Basic Leader Course

Council of Colonels

Combat Training Center 


\begin{tabular}{|c|c|}
\hline DAMO-FM & $\begin{array}{l}\text { Department of the Army Management } \\
\text { Office, Force Management }\end{array}$ \\
\hline DAMO-OD & $\begin{array}{l}\text { Department of the Army Management } \\
\text { Office, Operations }\end{array}$ \\
\hline DAMPS & $\begin{array}{l}\text { Department of the Army Mobilization } \\
\text { Processing System }\end{array}$ \\
\hline DARPL & Dynamic Army Resourcing Priority List \\
\hline DIMHRS & $\begin{array}{l}\text { Defense Integrated Military Human } \\
\text { Resources System }\end{array}$ \\
\hline DoD & U.S. Department of Defense \\
\hline DoDD & Department of Defense Directive \\
\hline DODI & Department of Defense Instruction \\
\hline DOPMA & Defense Officer Personnel Management Act \\
\hline DOTMLPF & $\begin{array}{l}\text { Doctrine, Organization, Training, Materiel, } \\
\text { Leadership, Personnel, and Facilities }\end{array}$ \\
\hline DOTMMLPF & $\begin{array}{l}\text { Doctrine, Organization, Training, } \\
\text { Mobilization, Materiel, Leadership, } \\
\text { Personnel, and Facilities }\end{array}$ \\
\hline $\mathrm{EAB}$ & echelons above brigade \\
\hline EXORD & Execution Order \\
\hline FORSCOM & U.S. Army Forces Command \\
\hline FY & fiscal year \\
\hline GAO & U.S. Government Accountability Office \\
\hline GOSC & General Officer Steering Committee \\
\hline $\mathrm{HR}$ & human resources \\
\hline HRC & U.S. Army Human Resources Command \\
\hline IMA & Individual Mobilization Augmentation \\
\hline
\end{tabular}




\begin{tabular}{|c|c|}
\hline IMCOM & Installation Management Command \\
\hline iPERMS & $\begin{array}{l}\text { Interactive Personnel Electronic Records } \\
\text { Management System }\end{array}$ \\
\hline IPPS-A & Integrated Personnel and Pay System-Army \\
\hline MCP-OD & $\begin{array}{l}\text { Main Command Post Operational } \\
\text { Detachment }\end{array}$ \\
\hline MOS & Military Occupational Specialty \\
\hline MP & Military Police \\
\hline MTOE & $\begin{array}{l}\text { Modified Table of Organization and } \\
\text { Equipment }\end{array}$ \\
\hline NCFA & $\begin{array}{l}\text { National Commission on the Future of the } \\
\text { Army }\end{array}$ \\
\hline $\mathrm{NCO}$ & noncommissioned officer \\
\hline NDAA & National Defense Authorization Act \\
\hline NGB & National Guard Bureau \\
\hline NGREA & $\begin{array}{l}\text { National Guard and Reserve Equipment } \\
\text { Appropriation }\end{array}$ \\
\hline NGRER & $\begin{array}{l}\text { National Guard and Reserve Equipment } \\
\text { Report }\end{array}$ \\
\hline NTC & National Training Center \\
\hline OASS & One Army School System \\
\hline OCAR & Office of the Chief, Army Reserve \\
\hline $\mathrm{OCO}$ & Overseas Contingency Operations \\
\hline RA & Regular Army \\
\hline $\mathrm{RC}$ & Reserve Component \\
\hline ROPMA & Reserve Officer Personnel Management Act \\
\hline
\end{tabular}


xxvi Review of Army Total Force Policy Implementation

SLC Senior Leader Course

TFPP Total Force Partnership Program

TRADOC U.S. Army Training and Doctrine Command

USAR

U.S. Army Reserve

USARC

U. S. Army Reserve Command 


\section{Introduction}

The concept of a "total force" has been a topic of discussion by the Department of Defense (DoD) and the Army for at least four decades. The key, and often contentious, issues have been:

1. how best to integrate the active components (AC) and reserve components (RCs)

2. how best to apportion roles, missions, force structure, and other resources among the components.

The DoD defines the total force as

The organizations, units, and individuals that comprise DoD resources for implementing the National Security Strategy. It includes DoD Active and Reserve military personnel, DoD civilian personnel (including foreign national direct- and indirecthires, as well as non-appropriated fund employees), contracted support, and host-nation support personnel (DoD, 2014a, p. 7).

This definition lists a collection of organizations but does not describe how their various roles fit with one another, particularly in the case of each service's AC and RCs.

Since the end of the Cold War, the RCs have been transformed from a strategic to an operational force. These changes began with operations in Bosnia and Kosovo in the 1990s, but particularly increased to support the rotational demand for forces in Afghanistan and Iraq. Between September 2001 and July 2015, more than 900,000 Guard 
and Reserve service members were activated for these operations, including 385,000 members of the Army National Guard (ARNG) and 223,000 members of the U.S. Army Reserve (USAR) (Office of the Assistant Secretary of Defense, Reserve Affairs, undated). ${ }^{1}$ DoD and Army policies have been evolving to support this transformation, as exemplified by DoD Directive (DoDD) 1200.17 (DoD, 2008) and DoD Instruction (DoDI) 1235.12 (DoD, 2016).

The Secretary of the Army signed the Army Total Force Policy (ATFP) in September 2012 to establish policy for integrating the AC and RC into an operational total force (McHugh, 2012). Since 2012, there have been changes in the Army budget, force structure, operational environment, and future operating concepts that could affect the Army's ability to implement the ATFP. In addition, the National Commission on the Future of the Army (NCFA) was established by the National Defense Authorization Act (NDAA) for fiscal year (FY) 2015 to undertake a comprehensive study of the structure of the Army and policy assumptions related to its size and force mixture. In its January 2016 report, the NCFA made 63 recommendations, many related to total force integration.

The Office of the Chief, Army Reserve (OCAR) asked RAND Arroyo Center to examine the extent to which the Army has implemented the policies and actions directed by the ATFP, how these efforts have benefited the different components and enhanced the total force, whether they have caused any negative unintended consequences, and how the Army might improve the ATFP to achieve a more costeffective, integrated, and capable total force. In subsequent discussions, the research sponsor also asked us to consider how the NCFA's recommendations are influencing the Army's implementation of the ATFP.

1 For additional information on the concept of an operational reserve force, see Nagl and Sharp, 2010; Winkler, 2010; and Schnaubelt et al., 2017. 


\section{Methodology}

To answer these questions, the RAND Arroyo Center research team took the following approach. First, we examined the context of the ATFP, including DoDD 1200.17 and ATFP implementation guidance, to use as a basis for assessing implementation. We also conducted a literature review of the relevant Army regulations, policies, and doctrine on ATFP and AC-RC integration, as well as other reports, studies, press releases, and articles on this topic. In addition, we reviewed the final report from the NCFA; although the NCFA examined issues beyond the scope of our study, many of its recommendations are relevant to the ATFP and are influencing its ongoing implementation.

Second, we developed indicators for assessing progress toward achieving the stated ATFP objectives and used them to assess that progress toward achieving objectives and completing required actions. For example, we used the Army Equipping Enterprise System (AE2S) to compare equipping across components and the Army Training Requirements and Resource System (ATRRS) to examine crosscomponent attendance at training courses for enlisted soldiers. In some cases, our assessments were binary: For example, if the Army was directed to develop a new regulation, had that regulation been promulgated? In many cases, however, the assessments required analysis regarding the sufficiency and effectiveness of implementation tasks.

To inform these assessments, we interviewed key stakeholders, including personnel at OCAR; U.S. Army Reserve Command (USARC); the Office of the Director, Army National Guard; the Office of the Assistant Secretary of the Army, Manpower and Reserve Affairs (ASA [M\&RA]); Office of the Deputy Chief of Staff, G-3/5/7; U.S. Army Forces Command (FORSCOM); Office of the Deputy Chief of Staff, G-1; U.S. Army Human Resources Command (HRC); and U.S. Army Training and Doctrine Command (TRADOC). A complete list of the organizations represented by our interviewees is provided in Table 1.1. Since each organization was typically involved only in a few aspects of ATFP implementation, we provided interviewees a list of ATFP policies and implementing actions and asked them to indicate which changes they were involved with implementing and their assess- 
4 Review of Army Total Force Policy Implementation

Table 1.1

List of Army Organizations Included in Interviews

\begin{tabular}{lc}
\hline Army Organization & Offices Represented \\
\hline OCAR & Assistant Chief of Staff \\
G-1 & G-35 \\
& Army Reserve Communications \\
Comptroller \\
Installation Management \\
Legislative Affairs
\end{tabular}

ment of the steps the Army had taken to date. We also asked them to describe any barriers to implementation and whether they would suggest any changes to the ATFP to better meet the objective of a more integrated total force. A copy of our interview protocol is provided in Appendix A. 
We organized our assessments using a modified version of the Doctrine, Organization, Training, Materiel, Leadership, Personnel, and Facilities (DOTMLPF) framework. DOTMLPF analysis is part of the Joint Capabilities Integration and Development System and is used to identify changes that are needed to develop required warfighting capabilities. More broadly, it is used by the Army as a framework to manage change (U.S. Army War College, 2015, pp. 1-1-1-3). ${ }^{2}$ We added the topic of mobilization because it is an important $\mathrm{RC}$ issue that does not fit neatly into the DOTMLPF framework, creating a "DOTMMLPF" framework. In each domain, we identified related ATFP policies and actions and NCFA recommendations, examined the Army's progress in implementing required changes, and discussed obstacles to total force integration. Finally, we developed recommendations for sustaining or modifying the ATFP to strengthen AC-RC integration.

\section{Organization of This Report}

The remainder of this report is organized as follows. Chapter Two discusses the context of DoD and Army Total Force Policy and provides a detailed description of the ATFP and subsequent implementation guidance. In Chapter Three, we expand on the policy, related NCFA recommendations, and the indicators we developed to assess implementation and its impact. We also provide our resulting assessments. In the final chapter, we summarize our conclusions and recommendations.

2 For more information on DOTMLPF analysis, see AcqNotes, 2014a, 2014b, and 2014c. It has also been used in other contexts, such as the Army Mission Command Strategy (U.S. Army Chief of Staff, 2013), an Army War College thesis on operationalizing the Army National Guard (Pressnell, 2013), and private-sector strategic planning (Knotts, 2014). 



\section{DoD and Army Total Force Policy}

In this chapter, we review some of the antecedents of the ATFP, including DoDD 1200.17. We then describe the ATFP and subsequent implementation guidance, including the specific policies and actions the Army is required to implement. ${ }^{1}$ The chapter concludes with a brief discussion of the NCFA, which explored the relationships among the Army's components and the specific roles that each should play. Congress also asked the NCFA to evaluate the Army's proposed transfer of attack helicopters from the ARNG to the AC-which was a contentious issue representative of what the NCFA described as an "unhealthy competitive tension among the Army's components” (NCFA, 2016).

\section{Evolution of Total Force Policy}

The roots of today's efforts at integrating the three components can be traced to 1970, when then-Secretary of Defense Melvin Laird proposed the total force concept as one of the steps to prepare for the end of the draft and the creation of an all-volunteer force (Correll, 2011). Subsequent Secretaries of Defense issued policies directing the services to provide the manning, equipping, training, and facilities necessary to assure that RC units could meet the deployment times and readiness required by contingency plans (Office of the Secretary of Defense, Public Affairs, 1997, p. 3). Although the terms for the total force have

1 The full texts of DoDD 1200.17 and the Army Total Force Policy are provided in Appendixes B and C (DoD, 2008; McHugh, 2012). 
varied, even before the post-9/11 period of sustained combat operations, former Army Chiefs of Staff Generals Dennis Reimer, Gordon Sullivan, and Eric Shinseki all emphasized the need for a "total Army" (Owens, 2001, p. 1).

The evolution toward a total Army has involved several integration initiatives, recent operationalization of the RCs, and guidance to break down any existing structural, attitudinal, or cultural barriers to success. ${ }^{2}$ For example, in 1997, then-Secretary of Defense William Cohen issued a memorandum requiring integration to go beyond structural needs to also address cultural barriers to the total force:

I ask each of you to create an environment that eliminates all residual barriers-structural and cultural — for effective integration within our Total Force. By integration, I mean the conditions of readiness and trust needed for the leadership at all levels to have well-justified confidence that Reserve Component units are trained and equipped to serve as an effective part of the joint and combined force within whatever timelines are ser [sic] for the unit-in peace and war ... Our goal, as we move into the 21st century, must be a seamless Total Force that provides the National Command Authorities the flexibility and interoperability necessary for the full range of military operations. We cannot achieve this as separate components (Office of the Secretary of Defense, Public Affairs, 1997, p. 3).

Total force integration is important to the Army because it relies on its two RCs for more than half of its forces. The Army routinely task-organizes units from all three Army components to accomplish assigned missions. According to Michael S. Tucker, commanding general of First U.S. Army, "We never go to war as one component. We go to war as a multicomponent force, always" (Cronk, 2014). In response to discussion about fiscal constraints and reductions in Army

2 Integration initiatives have included the following: integrated combat divisions, the Bosnia Task Force, multicomponent units, integrated light infantry battalions, Training Support XXI, AC Associate Unit Mentoring, and the AC/RC Battalion Command Exchange Program. See Owens, 2001, p. 28. 
end strength, in September 2015, General Mark A. Milley, Army Chief of Staff, asserted:

There is only one Army . . . we are not 10 divisions, we are 18 divisions. We're not 32 brigades; we're 60 brigades. And we're not 490,000 Soldiers; we are 980,000 Soldiers. . . . We cannot conduct sustained land warfare without the Guard and the Reserve ... It is impossible for the United States of America to go to war today without bringing Main Street-without bringing Tennessee and Massachusetts and Colorado and California. We just can't do it ... It is one Army, and we're not small—we're big. We're very capable. And we're very capable because of the reserves, we're capable because of the National Guard (Greenhill, 2015).

\section{DoD Directive 1200.17}

In 2008, then-Secretary of Defense Robert Gates issued DoDD 1200.17, which established nine policies for management of the RCs:

- The RCs provide operational capabilities and strategic depth to meet U.S. defense requirements across the full spectrum of conflict.

- The ACs and RCs are integrated as a total force based on the attributes of the particular component and individual competencies.

- Homeland defense and defense support to civil authorities are total force missions.

- The RCs are connected amd committed to the U.S. public.

- The continuum of service enhances the effectiveness of and sustains the all-volunteer force with flexible service options that are attractive to a broad population.

- Utilization rules are implemented to govern frequency and duration of activations. Since expectation management is critical to managing the RCs as an operational force, these rules enhance predictability and judicious and prudent RC use.

- Voluntary duty is encouraged to meet mission requirements.

- The RCs are resourced by the military services to meet readiness requirements. $\mathrm{RC}$ resourcing plans shall ensure visibility to 
track resources from formulation, appropriation, and allocation through execution.

- Outreach services are established and available for RC members, their families, and their employers from preactivation through reintegration (DoD, 2008).

DoDD 1200.17 also assigns responsibilities to the secretaries of the military departments as follows:

- Manage their respective RCs as an operational force so that RCs provide operational capabilities while maintaining strategic depth to meet U.S. military requirements across the full spectrum of conflict.

- Ensure that the RCs participate across the full spectrum of missions at home and abroad. To the extent practicable and consistent with the services' organizational constructs, ensure unit integrity is maintained, including unit leadership positions, when RC units fulfill operational requirements.

- Ensure that RC units and individuals train and are available for missions in accordance with the national defense strategy.

- Ensure the total force and nonfederalized National Guard forces have capabilities useful for domestic disaster response and are utilized in accordance with applicable federal rules, without interference with defense missions.

- Ensure RC forces meet operational readiness requirements as identified by the President and the Secretary of Defense.

- Ensure sufficient depth of RC unit and individual capabilities to meet established DoD force utilization goals.

- Ensure force rebalancing is conducted on a continuing basis to adjust force structure and individual skill inventories to meet fullspectrum operations while moderating excessive utilization of the total force.

- Integrate $\mathrm{AC}$ and $\mathrm{RC}$ organizations to the greatest extent practicable, including the use of cross-component assignments (both $\mathrm{AC}$ to RC and RC to AC). Such assignments should be considered as career-enhancing, not detrimental, to career progression. 
- Align, to the extent practicable, force structure with established DoD goals for frequency and duration of utilization for units and individuals.

- Ensure the appropriate level of full-time support personnel-AC, Active Guard and Reserve, military technicians, and other federal civilian employees - to meet the readiness requirements of the RCs.

- Implement the continuum of service construct in ways that sustain the all-volunteer force and the willingness of individuals to serve.

- To facilitate the sustainment of volunteerism, provide flexible participation options and opportunities for the performance of military duty beyond minimum participation requirements, consistent with service needs.

- Program and execute resources where required to support a "trainmobilize-deploy" construct. Funds for training and equipment must be provided to coincide with the services' force planning cycle and enable an effective pre- and postmobilization training and deployment process.

- Accelerate modernization while balancing the need for restoring immediate readiness through recapitalization with the imperative to prepare for future conflicts with more advanced adversaries.

- Ensure RC forces are considered for sourcing combatant commands' requests for forces (DoD, 2008).

\section{The Army Total Force Policy}

To implement the provisions of DoDD 1200.17, in 2012, then-Secretary of the Army John McHugh issued Army Directive 2012-08 to establish policy for the integration of the Army's AC and RC as a total force. The ATFP states that

DoD policies require the military departments to organize, man, train and equip their active and reserve components as an integrated operational force to provide predictable, recurring, and 
sustainable capabilities. The Total Force must be part of Army strategy and planning to fulfill national military needs (McHugh, 2012).

To achieve a total force, Army Directive 2012-08 sets forth seven policy statements:

1. As one total force, the Active Army, ARNG, and USAR provide operating and generating forces to support the National Military Strategy and Army commitments worldwide.

2. The Army will ensure that the total force is organized, trained, sustained, equipped, and employed to support combatant commander requirements.

3. As appropriate, the Army will integrate AC and RC forces and capabilities at the tactical level (division and below). Integration includes, but is not limited to, predeployment collective training of tactical-level organizations, including those routinely deploying as multicomponent forces.

4. Army commands and Army service component commands will ensure that the procedures and processes for validating the predeployment readiness of assigned forces are uniform for $\mathrm{AC}$ and $\mathrm{RC}$ units and soldiers. Army commanders will be responsible for certification of personnel readiness and individual training. Standards for qualification and professional development will be the same for AC and RC personnel.

5. The Army will streamline the voluntary and involuntary call to active duty of RC personnel and units.

6. The Army's equipping strategy will ensure that procurement and equipping processes enable the total force to perform Army missions.

7. The Army will employ an integrated personnel management and pay system that contains standardized business processes and authoritative data for military personnel, enabling access to secure and reliable data. Personnel policies shall incorporate total force values and facilitate continuum of service and joint opportunities (McHugh, 2012). 
In addition to establishing total force policy, Army Directive 2012-08 required five implementation actions to amend and use existing Army Regulations (ARs), Army publications, and other authorities to help achieve the total force. The five implementation actions are:

1. Amend AR 71-11 (Department of the Army, 1995) to include an annual analysis of force structure options, including the mix of operating and generating force capabilities between the AC and RCs, for the Secretary of the Army to consider and approve in support of the Army's future force and to meet Secretary of Defense planning objectives. In conjunction with this requirement, the ASA (M\&RA), in coordination with the Deputy Chief of Staff, G-3/5/7, must report any military capabilities that are insufficient either in numbers or type to achieve Secretary of Defense planning objectives. The Secretary of the Army and Chief of Staff, Army, must also annually approve the Army Program Objective Memorandum Force.

2. Amend AR 525-29 (Department of the Army, 2011) to direct that available forces (mission and surge) are prepared to deploy as integrated expeditionary forces in accordance with Global Force Management requirements. The amended regulation must require the ASA (M\&RA), in coordination with the Deputy Chief of Staff, G-3/5/7, to develop a common set of standards and procedures for the validation of readiness. To the maximum extent possible under security conditions and combatant commander requirements, the Army also must use a common deployment cycle for named operations to facilitate integration of AC and RC forces. The Secretary of the Army must approve the common deployment cycle, and the Chief of Staff, Army must provide advice on such plans and implement them once approved.

3. Amend AR 500-5 (Department of the Army, 2015b) and the Army Mobilization Operations, Planning and Execution System. The ASA (M\&RA), in coordination with the Deputy Chief of Staff, G-3/5/7, must streamline the mobilization process to rapidly provide $\mathrm{RC}$ capabilities to support the total force. 
4. Consolidate or eliminate Army publications Series 135 (Army National Guard of the United States and Army Reserve), Series 140 (Army Reserve), Series 350 (Training), and Series 600 (Personnel-General) to conform to ATFP policy guidance. In revising these publications, Army Directive 2012-08 requires all three components to collaborate on development and execution in order to capitalize on subject-matter expertise and address component-specific needs, but is silent both on the degree of collaboration and on the weight to be given to the components' viewpoints.

5. Use $12304 \mathrm{~b}$ statutory authority to make greater use of the RCs. Section $12304 \mathrm{~b}$ of Title 10 of the U.S. Code permits the secretary of a military department (subject to the availability of funding and some other limitations) to involuntarily order RC units to active duty to augment AC forces for preplanned missions in support of combatant commands (McHugh, 2012).

Since 2012, the Army issued annual ATFP implementation guidance and taskings on remaining steps needed to fully implement the ATFP. ${ }^{3}$ We summarize this guidance in the sections below and in Table 2.1. In addition to policy memoranda, the Army holds a variety of meetings to guide the ATFP implementation process. Throughout FY 2016, there were monthly ATFP Implementation CoCs, quarterly two-star General Officer Steering Committees (GOSCs), quarterly Secretary of the Army updates on ATFP implementation, and annual ATFP three-star GOSCs. In October 2015, the ASA (M\&RA) identified completion of ATFP implementation as her number one goal for the year ahead (Wada, 2015).

\section{ATFP Implementation Plan}

On September 25, 2013, the Army issued its first memorandum on ATFP implementation (McHugh, 2013). The 2013 implementation

3 The Army did not issue any additional ATFP implementation guidance in 2016, but as of this writing, it planned to issue updated guidance in 2017. 
Table 2.1

Summary of ATFP Implementation Guidance

\begin{tabular}{|c|c|c|c|}
\hline $\begin{array}{l}\text { Army } \\
\text { Organization }\end{array}$ & $\begin{array}{c}\text { Taskings from } 2013 \\
\text { Guidance }\end{array}$ & $\begin{array}{c}\text { Changes in } 2014 \\
\text { Guidance }\end{array}$ & $\begin{array}{c}\text { Changes in } 2015 \\
\text { Guidance }\end{array}$ \\
\hline \multirow[t]{4}{*}{ ASA (M\&RA) } & $\begin{array}{l}\text { Establish quarterly } \\
\text { GOSC and submit } \\
\text { quarterly progress } \\
\text { reports to Secretary } \\
\text { of the Army }\end{array}$ & $\begin{array}{l}\text { Quarterly reports } \\
\text { to be approved by } \\
\text { GOSC } \\
\text { Convene annual } \\
\text { Principal GOSC } \\
\text { (3-Star/Senior } \\
\text { Executive Service } \\
\text { level) }\end{array}$ & $\begin{array}{l}\text { Delegated to Deputy } \\
\text { Assistant Secretary } \\
\text { of the Army, } \\
\text { Training, Readiness, } \\
\text { and Mobilization, } \\
\text { reporting quarterly } \\
\text { to ASA (M\&RA) }\end{array}$ \\
\hline & $\begin{array}{l}\text { Establish committee } \\
\text { on uniform training } \\
\text { and readiness } \\
\text { oversight }\end{array}$ & $\begin{array}{l}\text { Monitor progress } \\
\text { of Total Army } \\
\text { Training Validation, } \\
\text { Integrated Progress } \\
\text { Team } \\
\text { Recommend any } \\
\text { necessary legislative } \\
\text { or policy changes }\end{array}$ & $\begin{array}{l}\text { Delegated to Deputy } \\
\text { Assistant Secretary } \\
\text { of the Army, } \\
\text { Training, Readiness, } \\
\text { and Mobilization }\end{array}$ \\
\hline & $\begin{array}{l}\text { Review and revise } \\
\text { Army policy on use } \\
\text { of mobilization } \\
\text { authority }\end{array}$ & & \\
\hline & $\begin{array}{l}\text { Develop a plan } \\
\text { to program and } \\
\text { implement a } \\
\text { continuum of service }\end{array}$ & $\begin{array}{l}\text { Create Army } \\
\text { definition of } \\
\text { continuum of service } \\
\text { and implement any } \\
\text { related policy or } \\
\text { regulatory changes }\end{array}$ & $\begin{array}{l}\text { Delegated to Deputy } \\
\text { Assistant Secretary } \\
\text { of the Army, } \\
\text { Military Personnel } \\
\text { and Quality of Life }\end{array}$ \\
\hline \multirow[t]{2}{*}{$\begin{array}{l}\text { Deputy Chief } \\
\text { of Staff, } \\
\text { G-1 }\end{array}$} & $\begin{array}{l}\text { Oversight of } \\
\text { Integrated } \\
\text { Personnel and } \\
\text { Pay System- } \\
\text { Army (IPPS-A) } \\
\text { implementation }\end{array}$ & $\begin{array}{l}\text { Provide annual } \\
\text { progress update to } \\
\text { GOSC }\end{array}$ & $\begin{array}{l}\text { Provide estimated } \\
\text { dates for initial and } \\
\text { full operational } \\
\text { capability by May } \\
29,2015\end{array}$ \\
\hline & $\begin{array}{l}\text { Prioritize } \\
\text { consolidation, } \\
\text { revision or } \\
\text { elimination of AR } \\
\text { Series 135, 140, and } \\
600\end{array}$ & $\begin{array}{l}\text { Extended completion } \\
\text { deadline from } \\
\text { September } 30,2014 \text {, } \\
\text { to December } 21 \text {, } \\
2014\end{array}$ & $\begin{array}{l}\text { Extended deadline to } \\
\text { December 31, } 2016\end{array}$ \\
\hline $\begin{array}{l}\text { Deputy Chief } \\
\text { of Staff, } \\
\text { G-3/5/7 }\end{array}$ & $\begin{array}{l}\text { Ensure that Army } \\
\text { Strategic Planning } \\
\text { Guidance supports } \\
\text { ATFP }\end{array}$ & $\begin{array}{l}\text { Provide annual } \\
\text { progress report to } \\
\text { GOSC }\end{array}$ & \\
\hline
\end{tabular}


Table 2.1-Continued

\begin{tabular}{|c|c|c|c|}
\hline $\begin{array}{l}\text { Army } \\
\text { Organization }\end{array}$ & $\begin{array}{c}\text { Taskings from } 2013 \\
\text { Guidance }\end{array}$ & $\begin{array}{c}\text { Changes in } 2014 \\
\text { Guidance }\end{array}$ & $\begin{array}{c}\text { Changes in } 2015 \\
\text { Guidance }\end{array}$ \\
\hline & $\begin{array}{l}\text { Revise the } \\
\text { Department of the } \\
\text { Army Mobilization } \\
\text { Processing System } \\
\text { (DAMPS) }\end{array}$ & & \\
\hline & $\begin{array}{l}\text { Revise ARs 71-11, } \\
525-29,500-5 \text {, and } \\
\text { Series } 350\end{array}$ & $\begin{array}{l}\text { Extended completion } \\
\text { deadline from } \\
\text { March } 31,2014 \text {, to } \\
\text { June } 1,2015\end{array}$ & \\
\hline & & $\begin{array}{l}\text { Establish a } \\
\text { directorate to } \\
\text { coordinate ATFP } \\
\text { tasks }\end{array}$ & \\
\hline & & & $\begin{array}{l}\text { Incorporate } \\
\text { Execution Orders } \\
\text { (EXORDs) 042-14 and } \\
150-08 \text { into Army } \\
\text { regulations }\end{array}$ \\
\hline & & & Revise AR 71-32 \\
\hline $\begin{array}{l}\text { Deputy Chief of } \\
\text { Staff, G-8 }\end{array}$ & $\begin{array}{l}\text { Ensure that Army } \\
\text { equipping guidance } \\
\text { complies with ATFP }\end{array}$ & $\begin{array}{l}\text { Provide annual } \\
\text { progress report to } \\
\text { GOSC }\end{array}$ & \\
\hline
\end{tabular}

plan designated Army organizations as leads for specific implementation tasks, established deadlines for completion of certain tasks, and required formation of working groups with participation from each component. Additionally, it required the ASA (M\&RA) to submit quarterly progress reports to the Secretary of the Army on ATFP implementation.

The 2013 implementation plan established deadlines for the ASA (M\&RA) to take certain implementation actions. The ASA (M\&RA) was required to take the following actions no later than February 1, 2014:

1. Establish a committee to review and (if necessary) recommend legislative proposals and/or policy changes required to implement uniform training and readiness oversight and certify, vali- 
date, and confirm predeployment training and readiness of RC forces, in compliance with the ATFP.

2. Establish a quarterly GOSC to review progress toward identified ATFP implementation tasks and identify any issues impeding ATFP implementation.

3. Review and revise Army policy for use of the involuntary activation authorities in Sections 12304a and 12304b of Title 10 of the U.S. Code (McHugh, 2013).

In addition, the ASA (M\&RA) was required to develop a plan to program and implement a continuum of service by March 31, 2014. The identified purpose of a continuum of service was to optimize the Army's investment in all of its soldiers by facilitating a seamless transition among the three components and veteran status.

The Deputy Chief of Staff, G-1, was tasked with oversight of implementation of the IPPS-A. The 2013 implementation plan also required, no later than September 30, 2014, the Deputy Chief of Staff, G-1, to prioritize the Army publications in Series 135, 140, and 600 to be consolidated, revised, and/or eliminated. The Deputy Chief of Staff, G-3/5/7, was in charge of ensuring that Army Strategic Planning Guidance supported ATFP. This oversight required development of DAMPS templates for Sections 12304a and 12304b, issuance of a memorandum of instruction for training DAMPS users, and revision of ARs 71-11, 525-29, and 500-5 (Department of the Army, 1995, 2011, 2015b) as well as Army publication Series 350 (Training) to conform with ATFP requirements and policies. The Deputy Chief of Staff, G-8, was tasked with coordinating with ASA (M\&RA), other Army headquarters staff, the National Guard Bureau (NGB), and OCAR to ensure that Army equipping guidance complies with ATFP requirements, senior leader priorities, governing regulations, and Army fiscal constraints.

The 2013 implementation plan required all lead Army organizations to coordinate their tasks with subject-matter experts from all three components in order to capitalize on their expertise and capture the needs of each component. The Chief, NGB, and Chief, Army Reserve, were charged with designation of their components' subject- 
matter experts. As with Army Directive 2012-08, the 2013 implementation plan was silent on the level of collaboration and weight given to the respective components' viewpoints.

\section{ATFP Implementation Plan}

Issued on October 16, 2014, the 2014 implementation plan superseded the 2013 guidance and adjusted the tasks of the leading Army organizations (McHugh, 2014). The 2014 implementation plan maintained the original tasks and coordination requirements, but it added specific reporting requirements and revised deadlines for task completion.

Although the 2014 implementation plan did not alter the ASA (M\&RA)'s obligation to provide quarterly progress reports, it added the requirement that submission of those reports and management of suspension dates would be done upon recommendation by the ATFP GOSC. Additional ASA (M\&RA) tasks included:

- monitoring the progress of the Total Army Training Validation, Integrated Progress Team

- recommending any necessary legislative proposals or policy changes to ensure uniform Training and Readiness Oversight implementation and processes for certifying, validating, and confirming the predeployment training and readiness of $\mathrm{RC}$ forces

- convening an annual Principal GOSC (3-Star/Senior Executive Service level) to review ATFP implementation progress on tasks in both Army Directive 2012-08 and implementation memoranda and identify any issues impeding ATFP implementation

- creating an Army definition for continuum of service and implementation of any policy and regulatory changes incorporating this definition (McHugh, 2014).

The revised tasks of the Deputy Chief of Staff, G1, included continued oversight of IPPS-A and prioritization of regulations requiring revision or elimination within Series 135 (Army National Guard of the United States and Army Reserve), 140 (Army Reserve), and 600 (Personnel-General). G-1's IPPS-A oversight included providing the ATFP GOSC with an annual progress update on the program and 
its functional milestones. Further IPPS-A progress included release of Increment I: "Trusted Database with Reporting Capabilities" and full deployment of a standardized Soldier Record Brief for the Total Force. Although the 2013 implementation plan also had tasked the G-1 with prioritizing the Army publications for revision, the completion deadline was moved back by three months.

The Deputy Chief of Staff, G-3/5/7, remained in charge of ensuring that the Army Strategic Planning Guidance supported the ATFP and revising Army regulations. The 2014 implementation plan added the requirement of providing an annual progress report on Army Strategic Planning Guidance and Army regulation revision milestones to the ATFP GOSC. The 2014 implementation plan also pushed back the G-3/5/7's Army regulation revision deadlines by 14 months, from March 31, 2014, to June 1, 2015. The Deputy Chief of Staff, G-8, was tasked with providing annual updates on Army equipping guidance to the ATFP GOSC.

Original coordination requirements within the 2013 implementation plan required lead organizations to coordinate their tasks with subject matter experts from all three components. Appointment of ARNG and USAR subject matter experts remained within the purview of the Chief, NGB, and Chief, Army Reserve, respectively. However, the 2014 implementation plan added requirements for the Deputy Chief of Staff, G-3/5/7 to appoint subject-matter experts to work at the $\mathrm{CoC}$ level and to establish a directorate as the primary office for coordination of all G-3/5/7 tasks applicable to ATFP (McHugh, 2014).

\section{ATFP Implementation Plan}

Unlike the 2014 implementation plan, the 2015 ATFP implementation guidance did not supersede previous ATFP implementation guidance. Instead, it further revised existing implementation guidance to enable lead organizations to manage suspense dates on tasks and required monthly status updates to the ATFP CoC, quarterly updates to the ATFP 2-Star GOSC, and annual updates to the ATFP 3-Star GOSC. The 2015 implementation plan also shifted some responsibilities from 
the ASA (M\&RA) level to Deputy Assistant Secretaries of the Army. Deadlines on completion of tasks were pushed back, especially those related to prioritization and revision of existing Army regulations and other Army publications previously identified in Army Directive 201208 and other implementation guidance.

The Deputy Assistant Secretary of the Army, Training, Readiness, and Mobilization, became responsible for convening an annual ATFP 3-Star GOSC and quarterly ATFP 2-Star GOSC. Additional requirements included: (1) quarterly ATFP implementation progress reports to ASA (M\&RA) to inform his/her quarterly updates to the Secretary of the Army, (2) management of suspension dates on tasks, (3) status updates and recommendations to the ATFP 2-star and ATFP 3-star GOSCs, and (4) monitoring of the progress of the Total Army Training Validation task, including submission of any required legislative proposals or policy changes.

The Deputy Assistant Secretary of the Army, Military Personnel and Quality of Life, became responsible for developing an Army continuum of service initiative to achieve: (1) development of the ASA (M\&RA) definition of continuum of service, (2) development and presentation of a formal problem statement for Army continuum of service, (3) development and presentation of a recommended course of action for implementation of Army continuum of service, and (4) upon approval of any course of action by the ASA (M\&RA), implementation of any legislative, policy, and institutional changes necessary to incorporate the Army continuum of service principles.

The Deputy Chief of Staff, G-1, remained responsible for oversight of IPPS-A implementation and updates on milestones achieved. The 2015 implementation plan also added the requirement that the Deputy Chief of Staff, G-1, provide the ASA (M\&RA) with estimated dates for IPPS-A initial operational capability and full operational capability no later than May 29, 2015. The deadline prioritization of Army publications requiring consolidation, revision, and/or elimination within Series 135, 140, and 600 was pushed back again, to December 31, 2016.

The Deputy Chief of Staff, G-3/5/7, remained responsible for ensuring that the annual Army Strategic Plan complies with ATFP. 
Additional responsibilities included: (1) codification of the directives within EXORD 042-14 and EXORD 150-08 into existing Army regulations, (2) revision of AR 71-32 (Department of the Army, 1997), (3) revision of AR 525-29 to incorporate the Army's new force generation policy, and (4) review and revision of Army publication Series 350 to ensure compliance with ATFP.

\section{National Commission on the Future of the Army}

Shortly after the ATFP was introduced in September 2012, the Army faced more severe budget constraints than had been expected due to the drawdown of operations in Iraq and Afghanistan. The Budget Control Act of 2011 and subsequent caps on defense spending that were imposed by sequestration beginning in 2013 put pressure on DoD and the Army to reduce costs while maintaining the capability to meet ongoing missions. From FY 2010 to FY 2015, the Army's base budget fell by 14 percent, and it reduced its AC end strength from more than 560,000 to 490,000 (NCFA, 2016, pp. 39, 122-123). In October 2013, the Army proposed an Aviation Restructuring Initiative that would have retired aging Kiowa helicopters and transferred all Apache helicopters from the ARNG to the AC, with estimated savings of $\$ 1$ billion annually. The U.S. Government Accountability Office (GAO) reported that the NGB was opposed to the transfer of the Apache helicopters (GAO, 2015). Bureau officials said that this action would "degrade the Army National Guard's role as a combat reserve, establish a precedent for removing other combat capabilities from the Army National Guard, and disrupt Army National Guard units and force structure across 20 states." ${ }^{4}$

In May 2014, Senators Patrick Leahy and Lindsey Graham introduced a bill to establish a National Commission on the Future of the

\footnotetext{
4 For more information on the establishment of the NCFA, see Feickert, 2016; Dunn, 2015; and Henry, 2015. Feickert also suggests that the decision to establish the NCFA was influenced by the perceived success of two previous commissions, the 2014 National Commission on the Structure of the Air Force and the 2015 Military Compensation and Retirement Modernization Commission.
} 
Army, which became part of the National Defense Authorization Act for FY 2015. Their reasoning was as follows:

\begin{abstract}
The Army's budget for Fiscal Year 2015 sets a path toward major, irreversible changes to Army capacity and capability, particularly in the Army National Guard and Army Reserves that cannot be ignored by the Congress ... The changes would also render the Nation's operational reserve insufficient in its ability to retain gains in experience and readiness that the reserve has achieved over a decade of continuous deployment. Most dramatically, these changes would transfer all of the National Guard's AH-64 Apaches to the active component, leaving the Nation without any combat reserves for one of the aircraft most essential to ground operations (U.S. Senate, 2014).
\end{abstract}

Congress directed the NCFA to conduct a comprehensive study of the size and force mixture of the AC and RCs of the Army, taking into account "anticipated mission requirements for the Army at acceptable levels of national risk and in a manner consistent with available resources and anticipated future resources." Congress also directed the Commission to study the proposed transfer of the Apache helicopters and to report its findings and recommendations no later than February 1, 2016 (NCFA, 2016, pp. 14, 107-109).

The NCFA published its final report on January 28, 2016, which included a detailed discussion of its findings and 63 recommendations for the Army, DoD, Congress, and the President. Many cover the same issues as the ATFP, such as manning, equipping, training, and readiness of the total force.

\title{
Summary
}

This chapter has charted the evolution of the Total Force Policy and how the Army has attempted to implement that policy. It reveals the difficult issues that must be overcome and the steps that must be taken to overcome them; many of these steps have important resource implications. It also shows that evolving to a total force is not just a matter 
of policy, directives, and resources, but involves reconciling fundamentally different views of the roles and missions of the components.

In the next chapter, we review the Army's implementation of the ATFP, based on both objective indicators and interviews with subjectmatter experts from the Army's AC and RCs. We also discuss related NCFA recommendations and their relationships to the ATFP. 



\section{ATFP Implementation Within DOTMLPF Functions}

As we discussed in the previous chapter, the Army has deliberately laid out a series of initiatives and tasks intended to further the creation of the Total Force and has regularly examined progress on these efforts. Moreover, the NCFA has recommended a number of changes to accomplish the same ends. This chapter provides an independent look at these efforts and gives at least preliminary assessments of whether these initiatives and recommended actions are likely to achieve the desired effects. It is organized according to the DOTMLPF framework, with an additional section on mobilization (thus DOTMMLPF). Each section begins with tasks specifically identified in the ATFP and related recommendations from the NCFA. ${ }^{1}$ Next, we discuss the status of those recommendations in subsections labeled "What's Being Done," based on our literature review, interviews, and available metrics. In some cases, existing initiatives predated the ATFP but are being continued "in the spirit of ATFP." In other cases, NCFA recommendations entail more-specific actions intended to move the Army toward the goal of a more integrated total force. Next, we summarize obstacles to integration, as expressed by various stakeholders we interviewed, and additional steps the Army could take. We conclude by sketching out what needs to be done to move forward.

1 We do not attempt to classify all NCFA recommendations, only those that appear to be related to ATFP objectives. In particular, we do not discuss recommendations related to the transfer of Apache attack helicopters from the ARNG to the AC. 


\section{Doctrine}

The first element of DOTMMLPF refers to doctrine. In joint terminology, the doctrine function refers to "Fundamental principles by which the military forces or elements thereof guide their actions in support of national objectives" (Chairman of the Joint Chiefs of Staff, 2015, p. A-1.) In this case, that function is performed by the Army field manuals, regulations, and directives that give formal shape to the programs and principles included in the ATFP.

The ATFP specifically mentions several ARs that should be changed, as follows:

- Amend AR 71-11 (Department of the Army, 1995) to include an annual analysis of force structure options and the mix of operating and generating force capabilities between the AC and RC and to require the Army to report any military capabilities that are insufficient in numbers or type to meet Secretary of Defense planning objectives for the total force.

- Amend AR 525-29 (Department of the Army, 2011) to direct that available forces (mission force and surge force) are prepared to deploy as integrated expeditionary forces and to require a common set of standards and procedures for the validation of readiness. The Army shall use a common deployment cycle to facilitate the integration of $\mathrm{AC}$ and $\mathrm{RC}$ forces in support of operations.

- Amend AR 500-5 (Department of the Army, 2015b) to conform with the ATFP and to streamline the mobilization process to rapidly provide RC capabilities to perform Army missions.

- Consolidate or eliminate Army publications Series 135 (Army National Guard and Army Reserve), Series 140 (Army Reserve), Series 350 (Training), and Series 600 (Personnel-General) to conform with ATFP guidance. All components will collaborate in the development, administration, and execution of publications (McHugh, 2012b).

The NCFA also made several recommendations related to changes in strategic and budget guidance and Army regulations: 
- Recommendation 13: The President should revise strategic and budget guidance based on changes in the security environment. DoD should use this revised guidance as the basis for revising its planning guidance, and the Army should adjust its structure, readiness, and modernization plans accordingly. ${ }^{2}$

- Recommendation 47: The Army should reduce mandatory training prescribed in AR 350-1 (Army Training and Leader Development). Changes should include developing a formal process for reviewing mandatory training requirements annually, giving local commanders more latitude on the frequency and duration of some requirements, and converting the RCs from an annual cycle to a two-year cycle.

- Recommendation 61: The Army should codify the delegation of authority from the chief of the NGB to the director of the Army National Guard for force structure allocation among the states, territories, and the District of Columbia in AR 71-32.

- Recommendation 62: The Army should codify in AR 71-32 the existing ARNG Force Program Review process as the formal way to manage change in the ARNG (NCFA, 2016).

\section{What's Being Done}

To determine the status of required regulatory changes, we reviewed the dates of the most-recent versions of the listed regulations posted on the Army Publishing Directorate (APD) website (undated). For those that had been changed since 2012, we also examined the summary of changes made since the previous version. In addition, we obtained information on the status of NCFA recommendations from briefings developed by the NCFA CoC. The status of AR changes is summarized in Table 3.1.

As Table 3.1 indicates, relatively few of the required regulatory changes listed in the ATFP had been completed as of October 2016.

2 The commission expressed a concern that the current guidance does not account for changes in the security environment, including the rise of Islamic State of Iraq and the Levant and Russian actions in Crimea, Ukraine, and Syria. Thus, the Army's planned total force may lack key capabilities and capacity to meet or deter some potential threats (NCFA, 2016, p. 52). 
Table 3.1

AR Changes Since 2012

\begin{tabular}{|c|c|c|}
\hline Required Action & Dates Last Modified & Status \\
\hline Amend AR 71-11 & December 29, 1995 & Not completed \\
\hline Amend AR 500-5 & April 16, 2015 & $\begin{array}{l}\text { Not completed (Revision } \\
\text { does not address ATFP } \\
\text { requirements) }\end{array}$ \\
\hline Amend AR 525-29 & March 14, 2011 & Not completed \\
\hline $\begin{array}{l}\text { Consolidate/eliminate } \\
\text { Series } 135 \text { (Army } \\
\text { National Guard and } \\
\text { Reserve) }\end{array}$ & $\begin{array}{l}20 \text { publications, } \\
4 \text { updated* } \\
\text { (Dates range from } \\
\text { February 15, 1984, to } \\
\text { March } 14,2016 \text { ) }\end{array}$ & $\begin{array}{l}\text { Not completed (Revisions } \\
\text { do not address ATFP } \\
\text { requirements) }\end{array}$ \\
\hline $\begin{array}{l}\text { Consolidate/eliminate } \\
\text { Series } 140 \text { (Army } \\
\text { Reserve) }\end{array}$ & $\begin{array}{l}10 \text { publications, } \\
2 \text { updated* } \\
\text { (Dates range from } \\
\text { August } 1,1984 \text {, to March } \\
21,2016 \text { ) }\end{array}$ & Not completed \\
\hline $\begin{array}{l}\text { Consolidate/eliminate } \\
\text { Series } 350 \text { (Training) }\end{array}$ & $\begin{array}{l}16 \text { publications, } \\
5 \text { updated* } \\
\text { (Dates range from March } \\
15,1987, \text { to October } 6, \\
2015 \text { ) }\end{array}$ & Partially completed \\
\hline $\begin{array}{l}\text { Reduce mandatory } \\
\text { training requirements } \\
\text { in AR } 350-1\end{array}$ & $\begin{array}{l}\text { Review of training } \\
\text { requirements initiated in } \\
\text { FY 2015; AR 350-1 update } \\
\text { scheduled December } \\
2016\end{array}$ & Not completed \\
\hline $\begin{array}{l}\text { Consolidate/eliminate } \\
\text { Series } 600 \text { (Personnel) }\end{array}$ & $\begin{array}{l}42 \text { publications, } \\
13 \text { updated* (Dates } \\
\text { range from July 1, 1978, } \\
\text { to September 14, 2016) }\end{array}$ & Partially completed \\
\hline Amend AR 71-32 & $\begin{array}{l}\text { Secretary of the Army } \\
\text { approved changes in } \\
\text { June } 2016, \text { but current } \\
\text { regulation dated July 1, } \\
2013\end{array}$ & Not completed \\
\hline
\end{tabular}

SOURCE: APD, undated.

NOTE: Bold text indicates changes related to NCFA recommendations.

* Most changes are not specifically related to ATFP.

One interviewee told us that, in some cases, the organizational proponents of the regulations determined that no changes were needed to 
conform to the ATFP, but we were not able to find any documentation of these decisions.

\section{Obstacles to Integration}

Whether Army doctrine is "total force friendly" involves multiple perspectives. First, one can assess the process of writing, reviewing, and approving doctrine. Second, one can assess the degree to which components have separate regulations and policy documents for the same processes. Finally, one can review the text of documents that are intended to speak to all three components and judge whether they do so in a way that promotes total force principles and objectives.

In our interviews with ATFP stakeholders, some RC participants reported satisfaction with their input into rewriting some regulations, but minimal involvement in rewriting others. In some cases, they reported that proponents were resistant to incorporating RCrecommended changes. One of the challenges in documenting this involvement, as much for those inside the Army as for outside observers, is the lack of transparency in the particular mechanics for reviewing proposed regulations. The staffing process is not fully automated, which means one needs to see a scanned or printed review form to know which individual responded on behalf of a given office. Depending on how the office assigns the task, not only may it be answered by someone without deep experience on RC issues, but it also might not even be evident who was the action officer. The lack of an automated staffing system makes it difficult for higher-level reviewers, such as the regulation sponsor or the APD, to see who has reviewed the changes. In some cases, the APD has had to pull back published regulations because they were not fully staffed by all components.

One interviewee noted that the ATFP requirement to consolidate or eliminate component-specific regulations may be as important as modifying Army-wide regulations. More than the other components, the ARNG continues to maintain some regulations specific to its own units and personnel, in some cases because the proponents of Armywide regulations are reluctant to incorporate ARNG-specific items.

In addition, stakeholders from all three components said that, even if all the required regulation and policy changes are made, Army 
culture and practices must also change to increase trust and integration between the components. For example, the NCFA noted that

\begin{abstract}
A cultural divide exists between the components ... Some of that is good, healthy unit pride and esprit de corps; unfortunately, some of that is the result of a long-standing - and, the Commission contends, outdated-prejudice regarding the skills and dedication of one component over the others. These differences among the components continue to be manifested in a wide range of administrative policies and traditional practices, from promotion standards and training opportunities to personnel management and human resources stove piping. These work against developing one Army (NCFA, 2016, pp. 59-60).
\end{abstract}

\title{
Moving Forward
}

The Army should assess the status of each regulatory change required by the ATFP and identify reasons why changes have not yet been made. Proponents should indicate remaining steps in the review and approval process that need to be completed and set a firm timeline to publish remaining regulatory changes. Successive versions of the ATFP implementation guidance indicate that timelines for completed changes set in the past have been extended. If a proponent has determined that changes are not necessary to meet ATFP requirements, it should inform the ASA (M\&RA) of its determination in writing and request an exception to the guidance to amend, consolidate, or eliminate as prescribed by the ATFP and subsequent implementation memorandums.

Assuming that the Army will continue to have three components for the foreseeable future, some doctrine and regulations may need to be specific to each. However, the goal should be to eliminate unnecessary distinctions between components and obstacles to integration that hinder the components from working together as a total force. As the Army continuously updates its doctrine and regulations, it should look for additional opportunities, beyond the regulations specified in the ATFP, to promote integration. 
In addition to changes in doctrine and regulations, strategic communications from senior leaders can help break down cultural barriers between components and facilitate bureaucratic changes that need to be made. For example, when Mark Milley was appointed as Chief of Staff of the Army, he made a commitment to work more closely with the National Guard and the Army Reserve to improve their readiness. He has also endorsed the findings and recommendations of the NCFA. ${ }^{3}$

\section{Organization}

The second part of DOTMMLPF is organization-i.e., force structure. Force structure presents one of the most problematic areas for total force integration. Most other areas are generally subjectiveculture, equity, and changing processes to increase efficiency or improve support to all components. Organization is relentlessly objectiveModified Tables of Organization and Equipment (MTOEs) are either single- or multiple-component. Chains of command run to either an $\mathrm{AC}$ commander or an $\mathrm{RC}$ one. And because the Army goes to war as organizations, it has a complex organizational design process to ensure that its organizations have the capability to accomplish the Army's mission and are affordable, supportable and sustainable (U.S. Army War College, 2015, pp. 3-20-3-21).

Regarding organization, the ATFP simply states that, "As appropriate, the Army will integrate $\mathrm{AC}$ and $\mathrm{RC}$ forces and capabilities at the tactical level (division and below), consistent with the Secretary of Defense's policies for use of the Total Force." The NCFA made several more-specific organizational recommendations, with a goal of increasing the number of positions designated for multicomponent use and substantially increasing the incentives for service in multicomponent units: ${ }^{4}$

3 See, for example, Greenhill, 2015, and Freedberg, 2016.

4 In the strictest sense, it can be argued that a multicomponent unit is one with personnel from more than one component on a single authorization document that trains and deploys together. However, in this report we use the term more broadly as defined by the NCFA: "multicomponent units ... have members and organizations from the Regular Army along with members and organizations of the Army National Guard or Army Reserve" (NCFA, 
- Recommendation 27: The Army should review and assess officer and noncommissioned officer (NCO) positions from all components for potential designation as integrated positions, to foster a total force culture and expand knowledge about other components.

- Recommendation 32: The Army should continue using multicomponent units and training partnerships to improve total force integration and overall Army effectiveness.

- Recommendation 33: The Army should add goals for future use of multicomponent units and related initiatives to the FY 2017 ATFP Implementation Guidance.

- Recommendation 34: The Army should develop a pilot program to test multicomponent approaches in its aviation units.

- Recommendation 48: The Army should resource First Army's ARNG and USAR active guard and reserve (AGR) positions at the aggregate manning level provided for each component (NCFA, 2016).

While some of these recommendations could also be considered to be related to "personnel" or "training" policies, we will address initiatives related to multicomponent units and positions in this section.

\section{What's Being Done}

The Army has several initiatives to move its organizations toward the goals articulated in the ATFP. Multicomponent units make up one of these initiatives, including the Associated Units Pilot Program (AUPP), the Corps and Division Multicomponent Headquarters program, and other multicomponent sustainment and support units. In this section, we also discuss the status of NCFA recommendations related to multicomponent positions and resourcing of First Army positions.

\section{AUPP}

The AUPP pairs AC units with ARNG and USAR units to train together and, potentially, deploy together. It is similar to some past total force 
initiatives, such as the Cold War Roundout Program, which designated ARNG maneuver brigades as one of the three combat brigades in several AC divisions. The AUPP took shape in 2015 and was implemented by Acting Secretary of the Army Patrick Murphy's 2016 memorandum, which set out the definitions of the program and identified the units to be involved in the pilot program (Figure 3.1). The program primarily involves brigade combat teams (BCTs) but also includes some engineer, quartermaster, and transportation units (Murphy, 2016).

While the ultimate aim of the AUPP is presumably to field a multicomponent unit for operations, that aspect of the program is barely discussed in the 2016 memorandum. The memorandum focuses on the nature of the peacetime administrative control of the associated units, shared between the "gaining headquarters" and "controlling headquarters." The memorandum gives the following authorities to the gaining unit commander:

- approving the training program of the associated unit

- reviewing readiness reports

- assessing resource requirements

- validating compatibility; this is the authority that moves farthest from the established concept of AC commanders simply assessing readiness and resourcing, as it specifies that compatibility will be assessed using "integrated training exercises" (Murphy, 2016).5

Figure 3.1 illustrates how the program works at three levels: brigade, battalion, and company. For example, at the top of the left column of the figure, the 48th Infantry BCT from the Georgia ARNG is associated with the 3rd Infantry Division located at Fort Stewart, Georgia. In the next-to-last row of the middle column, Task Force 1-28 of the 3rd Infantry Division is associated with the 48th Infantry BCT from the Georgia ARNG. If an RC battalion is associated with an AC

5 However, it echoes language from Section 1131 of the Army National Guard Combat Readiness Reform Act (Title XI of the National Defense Authorization Act for FY 1993, commonly referred to as "Title XI"), which states that the commander of the associated active duty unit shall be responsible for validating the compatibility of the RC unit with active duty forces (Pint et al., 2015, pp. 85-86). 
Figure 3.1

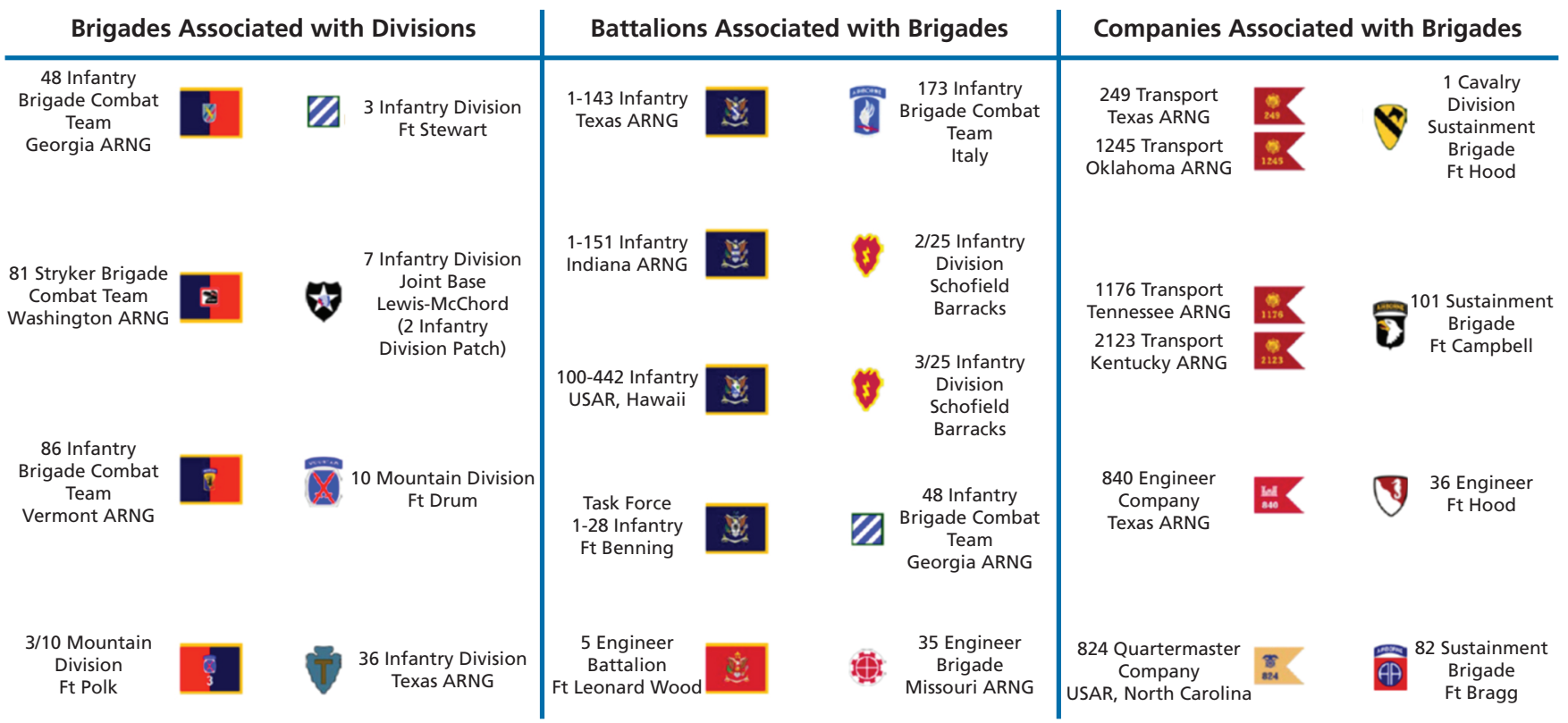

SOURCE: Office of the Deputy Chief of Staff, G-3/5/7, 2016.

NOTE: The 100th Battalion, 442nd Infantry Regiment, has been removed from the program (Fanning, 2016).

RAND RR1958-3.1 
$\mathrm{BCT}$, the BCT commander approves the training of the $\mathrm{RC}$ unit. If an $\mathrm{AC}$ battalion is associated with an $\mathrm{RC}$ brigade, the $\mathrm{RC}$ commander approves the training schedule of the $\mathrm{AC}$ battalion. The higher-level unit commander assesses the compatibility and capability of the lower-echelon unit. Additionally, a small number of AC officers and NCOs go to the $\mathrm{RC}$ unit and vice versa.

The memorandum is inconsistent in its specification of authorities and responsibilities given to AC and RC commanders. In some places, it specifies that authorities or responsibilities are given only to $\mathrm{AC}$ commanders, while in other places it explicitly states that the same authorities apply to gaining unit commanders, regardless of component. Additionally, public announcements about the program have noted that associated units will wear the uniform patches of the gaining headquarters, but such details are not specified in the memorandum.

\section{Obstacles to AUPP Implementation}

One issue to consider is whether the program has been successfully implemented. Many of the initial steps for this pilot program have been taken, including the memorandum cited above and the passage of responsibility for the program from DAMO-FM to DAMO-OD. However, as of July 1, 2016, none of the units scheduled for inclusion in the AUPP had been documented as moving to the designated higher unit (within the FMS web platform, the website of the Army Force Management system, which documents and authorizes the personnel and equipment resources required to for Army operations [U.S. Army Force Management Support Agency, undated]).

A second question is whether the pilot program has been implemented in a way that promotes the total force. As of this writing, it is too early to judge the effect of the pilot program on total force integration. However, as the outlines of the program have become evident, we gathered initial thoughts from various stakeholders and observers about the likely impact of this program on its own terms.

- A common concern among RC leaders is the lack of resources dedicated to the AUPP, especially considering the distances between some of the units involved (shown in Figure 3.1). To highlight the 
most challenging example, it is one thing to task the commander of the 173rd BCT in Vicenza, Italy, with assessing the compatibility of his European battalions with the 1-143rd infantry battalion in Texas, but if the Texas National Guard has only enough annual training funds to send that battalion 250 miles from home station, it is hard to see how that responsibility will be met.

- The Army Reserve's 100th Battalion, 442nd Infantry Regiment, originally intended to be associated with the 25th Infantry Division (both are headquartered in Hawaii), has been removed from the program. While this particular association relationship could reasonably seem to be challenged by the dispersion of both units, the USAR did not advocate removing the battalion, which suggests this was an AC-driven change to the initial plan. ${ }^{6}$ Additionally, while distances between units were a particularly high hurdle in this case, they will be an obstacle in most cases of such AC-RC pairings.

- One obstacle to leveraging this pilot program is the lack of an experimental design in its execution. Our interviews with stakeholders confirmed that units were not selected for inclusion using factors that would allow for rigorous analysis of the potential impacts of the program. For example, while two USAR units are associated to Regular Army (RA) commands, no RA units are associated to USAR commands, limiting the program's ability to generate generalizable findings about the range of association options.

As noted above, the current AUPP is similar to past initiatives to integrate $\mathrm{AC}$ and $\mathrm{RC}$ forces over the decades. The essential premise of these programs has been that, if the Army is structured so a deploying unit knows it will be made up of AC and RC components, the staff and subunits will have a vested interest in training together, evaluating readiness holistically, and ensuring effective operations on the ground. By

6 While many USAR and ARNG units are geographically dispersed at the brigade, battalion, and even company levels, RA units are used to being collocated at the brigade level and below. This situation might be an example of cultural differences between the AC and the RCs as well as logistical and funding challenges. 
being identified in advance as partners in the higher unit, subunits will also have increased opportunities to train together, test interoperability of equipment and procedures, and build interpersonal relationships.

The history of these efforts has been well documented and sheds light on the issues involved in carrying out the AUPP.7 For example, the CAPSTONE program, launched in 1979, was intended to align $\mathrm{RC}$ units with the AC or other RC units with which they would likely be employed in wartime. Three years later, a GAO report found that many RC units had neither been contacted by their wartime gaining commands nor received training and planning guidance (GAO, 1982). The Round-Out Strategy, which designated ARNG maneuver brigades as one of the three combat brigades in several AC divisions, was put to the test in Operation Desert Storm. In August 1990, AC brigades were substituted for the ARNG round-out brigades that were supposed to deploy with the 1st Cavalry and 24th Infantry Divisions. Three roundout brigades were activated later in 1990, but required 90 or more days of postmobilization training, which was not completed until after the cease-fire with Iraq. As a result, Congress passed Title XI. Among its provisions was a requirement that each ARNG combat unit be associated with an AC combat unit whose commander would have similar authorities to those described in the AUPP. By 1997, the role of the $\mathrm{AC}$ units in supporting the training of their associated $\mathrm{RC}$ units was transferred to First and Fifth Army, thus attenuating the connection between the $\mathrm{AC}$ and $\mathrm{RC}$ units.

In contrast, the U.S. Air Force has a more successful history of associating AC and RC units going back to the 1960s. ${ }^{8}$ Initially, these associations followed the pattern of matching a parent unit from one component with a subordinate unit from another. In the early 2000s, the Air Force began to experiment with integrated associate unitsblended units that included both AC and RC members. A few years later, this initiative was expanded as part of the Total Force Integration concept. In these blended units, one component has principal responsibility for a weapon system or systems, which it shares with a unit

\footnotetext{
7 See, for example, Pint et al. (2015, pp. 7-15).

8 See Schnaubelt et al. (2017).
} 
from another component, and each unit retains command authority over its own forces and separate organizational structures. In 2014, the National Commission on the Structure of the Air Force recommended that the Air Force increase the number of associate units to the extent that most units have an associate relationship with an element from another component, and to create a single, integrated chain of command for associate units, called an Integrated Wing or " $\mathrm{i}-\mathrm{Wing}$."

Some of the factors contributing to the success of Air Force associate units are:

- The Air Force has published an Air Force Policy Directive and Air Force Instruction on Total Force Integration and established a governance structure including a Chief of Total Force Integration under the Director of Strategic Plans in A-8. In recent years, it has developed more-detailed guidance, including templates and worksheets for preliminary documentation of associated units.

- Each unit association has an integration plan, developed at the major command level, that explains the purpose of the proposed association, the major command requirement it supports, how it supports the major command's long-range plan to integrate the force, and benefits to be achieved by the integration. It is supplemented by supporting documents that describe how the associated units will work together on a day-to-day basis.

- Because the personnel within associated units are under the command and disciplinary authority of their unit commander and respective chain of command, the Air Force developed a new concept called Operational Direction, which enables commanders to assign tasks, designate objectives, and give authoritative direction to forces not administratively assigned to them.

- Air Force units often do not deploy intact, and active duty tours are relatively short for RC personnel (e.g., a 120-day rotation may be split between three or four reservists for 30 or 40 days each). As a result, the typical associated unit is able to provide an $\mathrm{AC}$ unit with an available supply of RC personnel for relatively short activations, while sharing capital-intensive weapon systems between units (Schnaubelt et al., 2017). 
While it may not be feasible for the Army to fully emulate the Air Force's model (because of differences in the way its forces are employed), there may be opportunities to share expensive systems across components, particularly in aviation units. The Army might also be able to learn from the Air Force's experience in developing policy and guidance, as well its documentation of integration plans and supporting agreements and its concept of Operational Direction.

\section{Corps and Division Multicomponent Headquarters Program}

The Multicomponent Headquarters program is another example of a recent program designed to integrate $\mathrm{AC}$ and $\mathrm{RC}$ soldiers into multicomponent units. It began with two pilot programs at the corps and division levels in 2015. Under the corps headquarters pilot, the USAR provides 56 soldiers to be organic to the staff and colocated with the XVIII Airborne Corps headquarters at Fort Bragg. The Division headquarters pilot integrates 123 ARNG soldiers located in Utah and Wisconsin with the 101st Airborne Division headquarters, along with five USAR soldiers colocated with the division at Fort Campbell. It has since been expanded to develop RC augmentation for the remaining corps and division headquarters (NCFA Operation Subcommittee, 2015). The RC portion of the headquarters is called a Main Command Post Operational Detachment (MCP-OD).

The two pilot programs are governed by memoranda of agreement specifying the authorities, roles, responsibilities, and operational procedures between the FORSCOM commander and the Chief of the Army Reserve (in the case of the corps headquarters pilot) and among the FORSCOM commander, USARC commander, ARNG director, and the adjutants general of the Wisconsin and Utah National Guard (for the division headquarters pilot). Notably, these agreements specify how RC personnel will be evaluated and establish an expectation of 53-54 involuntary training days for RC personnel, plus an additional 28 days of voluntary training to achieve the 81-day training requirement for the corps headquarters pilot (FORSCOM, 2015 and 2016a). ${ }^{9}$

9 According to the memoranda of agreement, soldiers who are unwilling to perform the additional days of duty will not be assigned to these units, and should they become unwilling after assignment, they will be reassigned. 
The Multicomponent Headquarters program was also designed to compensate for earlier reductions in the size of headquarters organizations. According to our interview subjects, the origin of the program was in the Focus Area Review Group of 2012, which led to DoD guidance to reduce authorizations in all two-star headquarters by 20 percent; the Army changed this to a 25-percent reduction. This decision directly affected the ARNG because its division structure is the same as the AC. It was not only a reduction in total positions, but also a grade-plate reduction (downgrading a position from major to captain, for example). Strength for a division staff was cut from the high 600 s to around 500 spaces. Following these decisions, TRADOC concluded that the new division headquarters organization was too small and began looking for ways to regain capacity. The decision was made to create a second "AA"-level unit identification code, with separate chains of command and reporting requirements. In general, Division MCP-ODs were to be sourced in the ARNG and corps MCP-ODs in the USAR.

\section{Obstacles to Corps and Division Multicomponent Headquarters Program Implementation}

A variety of obstacles affect the implementation of the multicomponent headquarters program. According to our interviewees, the USAR had two major concerns with this plan.

- The USAR was adamant on the need for a MCP-OD to have a commander, a G3 section, an organic supply section, etc. ${ }^{10}$ This position was overruled, so the unit is largely a collection of pieces to be plugged into a corps structure.

10 The USAR's reasoning was that it does not have organizations like the ARNG's state Joint Force Headquarters to provide administrative support. Its units' daily administrative functions are performed by functional unit structure (as in the 377th Theater Sustainment Command, for example). The USAR would have to burden other organizations, such as the 76th Operational Response Command, to provide administrative support to the MCP-OD. 
- The USAR also called for three MCP-ODs for each supported corps headquarters, to allow for rotational support. ${ }^{11}$ This request was eventually dropped in exchange for a concession on another force structure issue, but it raises the question whether these RC detachments will need to be on the same readiness cycle as the rest of the associated $\mathrm{AC}$ headquarters.

Another potential difficulty is finding locations with enough senior personnel available for assignment to the MCP-ODs and willing to commit to an expanded number of training days. For example, the Hawaii National Guard said it could not support the MCP-OD associated with the 25th Infantry Division, so the mission was passed to the USAR. The USAR feels that it can staff the unit, but U.S. Army Pacific thinks the limitations of geography will impede its ability to find the required personnel. This problem is not unique to the Hawaii unit. There have been other adjustments in alignments, as with MCPODs in Illinois and Wisconsin being assigned to support the 101st and 10th Divisions. A separate issue arose with the 2nd Infantry Division, which stated that it did not need an RC MCP-OD because it had an equivalent force in host-nation support personnel assigned to the headquarters.

An additional concern is that there remains a lack of doctrine and operating concept for this new structure. For example, the memorandum of agreement for the division headquarters pilot does not specify how the ARNG soldiers who are not colocated will train with the rest of the unit. As Chief of Staff of the Army, Raymond T. Odierno provided refined guidance that MCP-ODs would provide the structure to ensure there is an AC expeditionary command post with early entry capabilities and utilize the RC for the main command post, both to provide reach-back support and depth at the home-station location and to deploy with the headquarters if the entire element is required (NCFA Operation Subcommittee, 2015). This is a plausible approach in that corps headquarters recently have deployed not as a whole but

11 The ARNG did not raise this issue, because it had no spaces to offer as billpayers for the additional units. 
with sections going "forward" while a considerable part of the headquarters remains at home station. However, this approach raises questions about how the units will train. For example, would the MCP-OD go with the headquarters for its Battle Command Training Program and/or the trainup for it? ${ }^{32}$

This question is particularly relevant because, without doctrine and an operating concept, it is hard to develop standards by which a MCP-OD will be evaluated for readiness. One interview subject suggested that this might come from the Mission Command Center at Fort Leavenworth.

\section{Other Multicomponent Structures}

The Army also has a number of other multicomponent MTOE units, as shown in Table 3.2. Unlike the AUPP and the multicomponent headquarters programs, these units combine $\mathrm{AC}$ and $\mathrm{RC}$ soldiers on a single authorization document for a unit that trains and deploys together. As of FY 2017, these units have a total of 9,238 AC and RC personnel, which accounts for just under 1 percent of total Army end strength. Aviation units account for 42 percent of personnel in multicomponent units (measured by the number of authorized personnel), the division/ corps headquarters discussed above account for another 14 percent, and 15 percent are in logistics headquarters. The remaining 29 percent are spread among a range of branches, including Military Intelligence, Engineers, Space, Signal, Maneuver Enhancement, Information Operations, Acquisition, Medical, and Adjutant General. In Table 3.2, we group these multicomponent units by their Standard Requirements Code and provide information on the number of soldiers required by their authorization documents and the number of units of each Standard Requirements Code type.

One example of newly created multicomponent aviation units is a pilot program started in October 2015 to attach a small group of AC and RC pilots to existing fixed-wing aerial intelligence, surveillance and reconnaissance battalions at Fort Bliss and Hunter Army Airfield

12 A possible precedent for MCP-ODs are Army Reserve Elements, which are designed to augment combatant commands and other headquarters organizations and DoD agencies. See, for example, U.S. Army Reserve (undated) and Randolph (2014). 
Table 3.2

Multicomponent MTOE Units

\begin{tabular}{|c|c|c|}
\hline Unit Type & Soldiers Required & Number of Units \\
\hline Aviation & 3,841 & 6 \\
\hline Engineers & 459 & 1 \\
\hline Medical & 188 & 1 \\
\hline Signal & 360 & 2 \\
\hline Adjutant General & 84 & 1 \\
\hline Military Intelligence & 532 & 7 \\
\hline Maneuver Enhancement & 255 & 1 \\
\hline Space & 408 & 3 \\
\hline Corps Headquarters & 675 & 1 \\
\hline Information Operations & 240 & 3 \\
\hline Logistics Headquarters & 1,372 & 3 \\
\hline $\begin{array}{l}\text { Heavy Division (Division/ } \\
\text { Brigade Headquarters) }\end{array}$ & 608 & 1 \\
\hline Acquisition & 216 & 9 \\
\hline Total & 9,238 & 39 \\
\hline
\end{tabular}

SOURCE: U.S. Army Force Management Support Agency, undated, and NCFA, 2016. NOTE: Table 3.2. does not include RC logistics companies that are "aligned" but not "assigned" to AC sustainment commands. These units have their own MTOEs, whereas the other multicomponent units in the table have one authorization document.

(Judson, 2016). Pooling AC and RC pilots to fly a small number of high-demand aircraft is helping to meet a near-constant need in theater. It also allows the Army to increase capability without increasing the number of aircraft and other equipment it owns, similar to the Air Force's associated units program discussed above.

The NCFA (2016, p. 68) cites the 100th Missile Defense Brigade, based in Colorado Springs, Colorado, as an example of both the strengths and challenges of multicomponent units and thus the issues to be dealt with in carrying out the ATFP. The brigade com- 
mands a battalion in Alaska and a detachment in California. The brigade's headquarters and headquarters battery have a multicomponent MTOE, with approximately 85 percent of the soldiers in the ARNG and 15 percent in the RA. Its sole subordinate unit, the 49th Missile Defense Battalion (Ground-Based Midcourse Defense) is completely ARNG.

The brigade has met all readiness requirements, including assigned strength, but interviewees noted that challenges have included lifecycle career management for ARNG personnel with limited promotion opportunities within the brigade headquarters and the battalion because of the specialized skills required by these units. Virtually all of the ARNG soldiers assigned to the brigade are full-time AGRs, in either a Title 10 or Title 32 status. Its firing crews and leadership in the "kill chain" must possess the T3 additional skill identifier, which qualifies them to operate the Ground-Based Midcourse Defense System. The 100th Missile Defense Brigade (including the 49th Missile Defense Battalion) is the only U.S. Army unit with an MTOE that has positions requiring the T3 additional skill identifier (Bailey and Crane, 2014). According to some RA officers, additional challenges are posed because the states retain Uniform Code of Military Justice authority for ARNG soldiers when in a Title 32 status. Alaska did not enact a version of the Uniform Code of Military Justice into state law until August 7, 2016.

The Army also has some multicomponent Table of Distribution and Allowances organizations, such as First Army and U.S. Army Human Resources Command. These two organizations face different types of integration challenges. First Army is currently undergoing a major reorganization, known as Bold Shift II, to shift its primary mission focus from supporting postmobilization training of RC units for operations in Iraq and Afghanistan back to its former role of providing premobilization training support. As of 2013, First Army was authorized approximately 3,300 AC soldiers under Title XI, as well as 400 USAR and 200 ARNG full-time AGR positions (Pint et al., 2015, pp. 68-69). However, there have been some problems ensuring that these positions are filled. The NCFA (2016) reports that the USAR was filling about 80 percent of its authorized positions, but the ARNG was 
only filling about 16 percent in FY 2014. Hence, it recommended that the Army fully resource First Army's AGR positions. The Army has postponed changes in AGR assignments until a formal staffing study of First Army's requirements is made in FY 2019, after the Bold Shift initiatives have been implemented. In the meantime, the NGB is working with FORSCOM to identify an interim solution, such as using Active Duty for Operational Support to increase the number of assigned personnel (NCFA CoC, 2016).

The consolidation of the AC and USAR human resource commands into one HRC headquarters at Fort Knox, Kentucky, is a case study in structure change-probably the biggest multicomponent structure the Army has created to date. As such, it merits study for what it may reveal about the challenges in such actions. In theory, one might have expected the command to integrate components throughout the structure-i.e., creating a single office for managing all RA/ USAR nurses, for example, filled by a mix of RA, USAR, and civilian personnel. In practice, the organization remains significantly segmented into AC and USAR divisions and branches, with each managing its own forces. We discuss the effects of HRC consolidation on the function of personnel management in greater detail below.

\section{Obstacles to Implementing Other Multicomponent Structures}

One of the biggest philosophical challenges in terms of total force organization is the balance between creating support organizations that serve all three components and allowing separate offices to focus on a specific AC, ARNG, or USAR "customer" or perspective. While this can be seen most dramatically in the merger of AC and USAR personnel commands, it has been seen throughout the Army. Each component has had, now or at some point, its own offices for legislative affairs, public affairs, recruiting, marketing, installation management, training management, operational planning, etc. Periodically, there are efforts to consolidate them in the name of efficiency, but RC interviewees argued that, in some cases, the combined organization ignored the interests of the RCs and used the manpower gained in the merger not for RC-related tasks but to support the total Army (and, implicitly, the AC most of all). While this would seem to be another case of the 
bureaucratic competition common to all large organizations, it also seems to raise deeper questions of Army culture. For example, is there a way to eliminate the accumulated layers of bias and mistrust to reach a point where an $\mathrm{AC}$ officer supporting an $\mathrm{RC}$ initiative, or vice versa, would not only know as much about it as an officer from that component would, but would also be as effective an advocate? Or are there fundamental differences between the components that require separate supporting organizations?

\section{Standardizing Organization Designs}

Interview subjects in the ARNG gave the opinion that post-9/11 deployments placed a premium on standardizing units across components so they could more easily follow each other in meeting overseas rotational missions. These interviewees were concerned that, as the deployment pace declined, the longer-term tendency to allow divergence in MTOEs would reassert itself.

However, standard organization designs can have a negative impact on the RCs in some cases, particularly when changes are driven not by doctrine or common equipment but by AC-specific issues. As noted above, the reductions in corps and division staff were not driven solely by assessment of workload and requirements, but a desire to transfer authorizations to other units. In the case of the ARNG, headquarters organizations may have served a human resource-management function by providing positions for field grade officers and senior NCOs who otherwise would run out of promotion opportunities and would either stagnate in lower-ranking positions or be lost to the state's Guard force. Force structure changes driven by one component's manning or equipping concerns will always run the risk of negatively affecting the other components.

While not directly affecting total force culture, maintaining the expectation that similar units share a common organization does support their equal utilization in operations.

\section{Moving Forward}

Because most of these programs have just recently been implemented, it is too early to say whether associated units and other types of multi- 
component units will successfully increase total force integration or fail due to the same difficulties as past initiatives. New organizational structures may not be fully tested until more multicomponent units face a deployment. If an AC-flagged multicomponent unit is deployed, will the RC portion or individual RC personnel be ready to deploy with it? If additional peacetime RC training days are needed to maintain readiness (as seems to be the case with the MCP-ODs), could these demands harm RC retention because of conflicts with civilian employment, education programs and/or family obligations? It will be important for the Army to develop goals and metrics for its pilot programs so that it can evaluate their effects and adjust policies and practices as necessary to meet those goals. Based on these evaluations, future actions could include making the pilot program arrangements permanent, expanding the program to new units of the same or other types, or creating, testing, and implementing other organizational options that will promote the ATFP goals in different ways.

\section{Training}

The third part of DOTMMLPF is training. As with the doctrine function, we break slightly with the customary definition of training and here focus on collective training and readiness: i.e., the process of developing units from home station, through ranges, training centers, and exercises, to mobilization platforms and the point of deployment. Individual training is considered in the Leadership and Education function.

Most readers will be familiar with the long, contentious history of this process. Reserve forces are built on the premise that, with enough training, RC units and individuals can reach the readiness level needed to deploy alongside regular forces. How long it will take to achieve the required level of readiness and how to resource and manage these $\mathrm{RC}$ elements before deployment has been the challenge and has often been the source of concerns, accusations, and acrimony among the components. 
The ATFP states that integration of AC and RC forces will include some predeployment collective training of tactical-level organizations, including those that will routinely deploy as multicomponent forces (such as sustainment brigades and other multifunctional support brigades). It also requires Army commands and Army service component commands to ensure that the procedures and processes for validating the predeployment readiness of assigned forces are uniform for $\mathrm{AC}$ and $\mathrm{RC}$ units and soldiers.

The NCFA made two recommendations related to collective training:

- Recommendation 45: The Army should implement the Objective$\mathrm{T}$ methodology for assessing the progression of training readiness and revise readiness reporting using the quantifiable criteria.

- Recommendation 46: The Army should increase the number of annual rotations for ARNG BCTs at combat training centers without decreasing the number of AC BCT rotations (NCFA, 2016).

\section{What's Being Done}

In this section, we review several initiatives related to ATFP directives and NCFA recommendations on collective training, including the Total Force Partnership Program (TFPP), participation of RC units in combat training center (CTC) rotations and other multicomponent training exercises, a new Army EXORD on validating predeployment readiness, and implementation of the Objective- $T$ methodology for assessing training readiness.

\section{Total Force Partnership Program}

The TFPP was established by FORSCOM in December 2013. Under the program, all eight ARNG division headquarters are partnered with an AC corps headquarters, and all RC brigades and higher-level units are partnered with like-designed AC brigades based on geographic location. First Army is responsible for integrating RC forces into major collective training exercises and facilitating other partnership training opportunities (Barrows, 2016; Vergun, 2016). However, our interview- 
ees indicated that no additional funding is provided for transportation of $\mathrm{AC}$ or $\mathrm{RC}$ units to multicomponent training exercises.

The draft ATFP guidance for FY 2017 (Office of the ASA [M\&RA], 2016, p. 3) tasks FORSCOM to "seek opportunities to expand the FORSCOM developed and led TFPP in areas where it improves readiness and AC-RC interoperability." These partnerships differ from the structural approaches discussed above (such as the AUPP) in that they involve larger numbers of units and are explicitly informal relationships, ${ }^{13}$ "and not intended to be prescriptive, disruptive or replace existing relationships." The guidance further manages expectations by noting "Partnered units should take the opportunity of training together when and where able; it is understood that units will not be able to conduct partnered training at all events." However, the informal nature of these partnerships may make them more difficult to document and assess than more formal, multicomponent organizations.

We found some anecdotal evidence that these partnerships seem to be moving ahead. Vergun (2016) highlights the participation of a California National Guard battalion and an AC unit from Fort Hood in partnered training at the USAR's Camp Roberts and Fort Hunter Liggett. The NCFA Operation Subcommittee (2015) also cites a partnership training exercise held by the Mississippi National Guard's 155th Armored BCT and the 3rd Brigade, 1st Cavalry Division at Camp Shelby. First Army has organized two Multiechelon Integrated Brigade Training exercises for ARNG BCTs that did not get a CTC rotation during training year three of their readiness cycle. These exercises also incorporated AC units as the opposing force and the USAR's 75th Training Command, as well as additional ARNG and USAR units (Marlow, 2015; Howlett, 2016).

Interviewees mentioned the USAR's Nationwide Move program as a way to reduce the costs of transporting equipment to multicomponent

13 Tan (2016) indicates that the AUPP takes selected partnerships a step farther by adding training and readiness authorities and responsibilities and prioritizing resources. Guard and Reserve units included in the pilot may conduct up to 15 additional days of training each year. The Army plans to test the AUPP concept for three years and decide whether to implement it more broadly in 2019 . 
training exercises. Under this program, USAR transportation companies move equipment for other units as a functional training exercise, which provides them with realistic training as well as saving on commercial transportation costs for the supported units. (See Price, 2015; Ochoa, 2016). Other initiatives to reduce transportation costs include multicomponent vehicle loans and stationing equipment sets at training centers, which we discuss in greater detail in the section on materiel.

Our interviews brought up other examples of partnerships that may not be included in the TFPP but that could contribute to its goals, such as when a sustainment command from Joint Base Dix-LakehurstMaguire participated in RC exercises, or when a commander and command sergeant major from the 82 nd Airborne Division provided coaching and mentoring to RC units.

\section{Combat Training Center Participation}

Starting in the 1980s, the Army's CTCs (located at Fort Irwin, California, and Fort Polk, Louisiana) have been established as the cornerstone of Army collective training, and they have become an essential part of the predeployment training process for combat arms units going to Afghanistan and Iraq, when time permitted. They have also been one of the more problematic venues for Total Army integration, owing to their specific geographic locations, limited capacity for trainee units, and lengthy training rotations. The Army recognizes this challenge, specifying in the FY 2017 draft ATFP implementation guidance that

EAB [echelons above brigade] support and sustainment elements for each CTC rotation will be multicomponent, and heavily dominated by the RC based on our force structure and available funding. FORSCOM, the ARNG and USAR will seek to optimize AC-RC integration at CTC and CTC-like exercises whenever possible and where it maximizes readiness and supports sustainable cross-component familiarity, interoperability and integration (Office of the ASA [M\&RA], 2016).

We examined the FY 2016 rotation schedule at the National Training Center (NTC) to identify reserve units that participated in $\mathrm{AC}$ and ARNG BCT rotations, shown in Table 3.3. We found that at 
least one $\mathrm{RC}$ engineer or logistics unit participated in each AC BCT rotation, while the ARNG BCT rotation also included an ARNG opposing force and aviation units. A second ARNG BCT rotation was added to the NTC schedule for FY 2018, in accordance with NCFA recommendation 46 .

\section{Pre-Employment Training Validation}

The ATFP requires the Army to establish uniform procedures and processes for validating the predeployment readiness of AC and RC units and soldiers. In January 2014, the Army published a new execution order (EXORD 042-14) on the Certification, Confirmation, and Vali-

Table 3.3

RC Participation in FY 2016 NTC Rotations

\begin{tabular}{|c|c|}
\hline Month & RC Units \\
\hline October 2015 & $\begin{array}{l}\text { Headquarters and Headquarters Company, 1297th Combat } \\
\text { Sustainment Support Battalion (Maryland ARNG) }\end{array}$ \\
\hline November 2015 & 387th Engineer Company (USAR) \\
\hline January 2016 & 649th Engineer Company (California ARNG) \\
\hline February 2016 & 323rd Engineer Company (USAR) \\
\hline April 2016 & $\begin{array}{l}\text { 444th Engineer Company (USAR); 746th Combat } \\
\text { Sustainment Support Battalion (California ARNG) }\end{array}$ \\
\hline May 2016 & $\begin{array}{l}\text { 883rd Engineer Company (North Carolina ARNG); 428th } \\
\text { Engineer Company (USAR); 687th Combat Sustainment } \\
\text { Support Battalion (USAR) }\end{array}$ \\
\hline $\begin{array}{l}\text { June } 2016 \\
\text { (ARNG BCT) }\end{array}$ & $\begin{array}{l}\text { 1-285th Attack Reconnaissance Battalion (Arizona ARNG); } \\
\text { 1-135th Attack Reconnaissance Battalion (Missouri ARNG); } \\
\text { 174th Mobility Augmentation Company (South Carolina } \\
\text { ARNG); 850th Engineer Company (Minnesota ARNG); 630th } \\
\text { Combat Sustainment Support Battalion (North Carolina } \\
\text { ARNG) } \\
\text { OPFOR: 1-144th Field Artillery Battalion (California ARNG); } \\
\text { 2-135th Infantry Battalion (Minnesota ARNG) }\end{array}$ \\
\hline August 2016 & $\begin{array}{l}\text { 171st Engineer Company (North Carolina ARNG); 375th } \\
\text { Combat Sustainment Support Battalion (USAR) }\end{array}$ \\
\hline September 2016 & $\begin{array}{l}\text { 818th Engineer Company (North Dakota ARNG); 450th } \\
\text { Engineer Company (USAR); 176th Combat Sustainment } \\
\text { Support Battalion (Tennessee ARNG) }\end{array}$ \\
\hline
\end{tabular}

SOURCE: NTC, 2016. 
dation Process for Employing Army Forces (Active Component and Reserve Component) (Headquarters, Department of the Army, 2014). The EXORD states that unit commanders (at the company level and above) certify that their units are trained to standard and capable of executing the deployment mission, whether operational or for training. The first O-6 (colonel) in the chain of command (or first general officer for employments defined as entailing high risk or sensitivity) is responsible for confirming the unit's readiness to execute the mission. For Army conventional forces in the continental United States that are not assigned to a combatant command, FORSCOM is responsible for validating the readiness of those forces for federal active duty. FORSCOM delegates its validation authority to First Army for RC units, according to interviewees at First Army (NCFA Force Generation Subcomittee, 2015). For Army forces assigned to an Army Service Component Command, the Army Service Component Command commander is responsible for validating the readiness of those forces for federal active duty employment. ${ }^{14}$ Validation is required for all active-duty operational missions, including homeland operations, designated contingency force packages, and preplanned federal missions under $12304 \mathrm{~b}$ mobilization authority. Validation is not required for employments that are principally for training, unless designated as high risk or sensitive by the requesting command.

\section{Objective-T Methodology for Training Readiness}

The NCFA recommended that the Army should implement the Objective-T methodology for assessing the progression of training readiness and revise readiness reporting using the quantifiable criteria. As the Army transitions from more than a decade of preparing forces for counterinsurgency operations, it is shifting its training focus to prepare units for the entire range of Decisive Action tasks in support of Unified Land Operations. It is also developing more objective and uniform readiness standards to assess and report training readiness, known as "Objective-T" (U.S. Army Chief of Staff, 2016). Under this

\footnotetext{
14 Note that although EXORD 042-14 does not explicitly distinguish between AC and RC units, the term "federal active duty employment" seems to refer to RC units.
} 
initiative, the Army is developing standardized Mission Essential Task Lists for all types of units at company level and above, as well as task proficiency standards and task proficiency criteria that unit leaders will use when evaluating unit proficiency on a task. To achieve the highest proficiency ratings, Fully Trained (T) or Trained (T-), units need to have at least 80 percent of authorized unit personnel and 85 percent of leaders present at training (for a rating of $\mathrm{T}$ ) or 75-84 percent of leaders present (for a rating of T-), as well as an external evaluation of the training exercise by the commander two levels above the unit (FORSCOM, 2016b).

As of August 2016, the Army was in the process of adapting its training and readiness reporting systems to implement Objective-T. RA units were scheduled to begin reporting monthly training readiness using the Object-T methodology in March 2017, and USAR and ARNG units to begin quarterly reporting in April 2017 (NCFA CoC, 2016).

\section{Obstacles to Integration}

The stakeholders we interviewed noted some concerns about the Army's implementation of collective training initiatives, including a focus on BCTs, lack of additional funding to transport units to multicomponent training exercises, and the process for validating units for employment.

\section{BCT-Focused Planning}

Some interviewees mentioned that programs such as TFPP, as well as the current process for planning and resourcing training, tend to focus on BCTs, which puts USAR units at a disadvantage. The Army has training centers and well-defined training programs for BCTs. The USAR, which has almost no combat arms units, has defined training programs for enabler and sustaining units, which could be adopted Army-wide. The Army should ensure that multicomponent training exercises designed for BCTs also incorporate sustaining units.

\section{Transportation Funding}

One of the most commonly mentioned obstacles to effective multicomponent training is a lack of funding for transportation. In the interest of efficiency, the default is often for units to conduct training 
at their home station when possible, or at the closest feasible location. Almost by definition, multicomponent training requires either $\mathrm{AC}$ or $\mathrm{RC}$ units (or both) to travel longer distances. For example, AC units generally have adequate ranges and maneuver space to conduct training at their home installation, or receive funds specifically to conduct training at one of the CTCs, which are on AC installations. Funding for travel to an RC training site, even if it is a partner or associated unit, is not generally provided.

Conversely, even though the CTCs have the capacity to include $\mathrm{EAB}$ or enabler units in $\mathrm{AC}$ rotations, no additional funding is provided for $\mathrm{RC}$ units to participate in these critical training events. Interviewees told us that RC units are only funded for a 502-mile round trip to attend training events, with very few units within 251 miles of major sites such as Fort Irwin, California, or Fort Polk, Louisiana. Another complicating factor is that RC installations are funded to support planned RC training on them, so if a commander moved an RC exercise to an $\mathrm{AC}$ installation to improve $\mathrm{AC}-\mathrm{RC}$ integration, the $\mathrm{RC}$ installation would lose funding. In addition, $\mathrm{RC}$ units typically plan training events 18 months in advance, but AC units may sometimes plan as little as six months in advance, so it can be difficult to integrate these plans and line up the necessary resources.

This challenge illustrates a common obstacle to total force integration: The necessary doctrines and policies may be in place to allowand even encourage-multicomponent training, but the Army must also make changes to its business practices to provide the necessary funding.

\section{Training Validation}

Some stakeholders we interviewed thought that reaching cross-component agreement on EXORD 042-14 was a success story for total force integration, but others, particularly in the National Guard, expressed the concern that differences in validation processes persisted. They asserted that $\mathrm{RC}$ units had to be validated by an external organization (First Army), whereas AC units could be validated by their own chain of command. For the processes to be truly equivalent, either RC units 
should be validated by their own chain of command, or AC units should be validated by external organizations.

\section{Moving Forward}

Although it may be difficult in the current budget environment, the Army should consider allocating more transportation funding to support multicomponent training. Innovative solutions, such as the Nationwide Move program, multicomponent vehicle loans, and positioning equipment at training centers, could also reduce transportation costs. However, even if equipment transportation costs are reduced, soldiers will need to travel to the training location. The Army should also ensure that enabler and support units are included in TFPP and other multicomponent training opportunities. A key challenge to overcome may be the difference in training planning cycles between the $\mathrm{AC}$ - which generally operates on a quarterly training cycle-and the RCs - which generally operates on a yearly training cycle. In sum, RC units generally require greater notification time to plan and budget for major collective training events.

Funding for collective training opportunities will also be needed to support the AUPP, if commanders are to be able to validate the compatibility of RC associated units through integrated training exercises. The challenge seems to be identifying multicomponent training as a value that can be weighed against the additional cost of transporting units to more-distant training sites.

\section{Mobilization}

The fourth part of our DOTMMLPF framework is mobilization. Although mobilization is not considered one of the DOTMLPF domains, it is an important issue for RC units that is addressed by both the ATFP and the NCFA report. Therefore, we discuss it in this section. Before discussing the specific ATFP policies and NCFA recommendations, we provide some background information on the mobilization process. 
The need to mobilize large numbers of RC service members for operations in Iraq and Afghanistan exposed problems with DoD's and the Army's mobilization processes. GAO (2003) found that, because existing operation plans did not adequately address the mobilization requirements needed to deal with terrorist attacks in the United States and uncertain overseas deployments, DoD began using a modified mobilization process that relied on additional management oversight and multiple layers of coordination. This process was slower and less efficient than the traditional process of synchronized mobilizations and deployments based on existing operation plans. At the time, the Army did not have a standard operating cycle for RC units, and many lowpriority units were mobilized with relatively little advance notice. In addition, information systems were unable to track the readiness of personnel and other resources within the small units that were frequently needed to deploy. ${ }^{15}$

The Commission on the National Guard and Reserve (2008, pp. 238-241) found that the mobilization process was still too slow and cumbersome because of the large number of organizations involved and the numerous document packets needed to make a mobilization request and recommended that the service secretaries be allowed to exercise their statutory authority to conduct the functions of mobilizing and demobilizing their respective forces.

DoD revised its Directive 1235.10 in November 2008 to update policy and guidance for mobilizing the RCs. It set a standard of 90 days from mobilization approval to mobilization date, with a goal of 180 days, and notification of RC units up to 24 months prior to the mobilization date. It also set a maximum involuntary mobilization period of one year at a time and a planning objective of one year mobi-

15 A second GAO report (2004) found that the Army was not able to efficiently execute its mobilization and demobilization plans because of outdated assumptions. Specifically, the plans assumed that (1) active forces would deploy away from mobilization and demobilization sites before reserve forces arrived, and (2) specialized RC support units would be able to provide medical, training, logistics, and processing support during mobilization and demobilization. In practice, some active forces had not deployed away from the mobilization sites, so RC units had to be diverted to other locations, and because the RC support units could not be involuntarily mobilized more than 24 months under existing legal authority, the Army began to replace them with civilians and contractors. 
lized to five years of dwell time. DoDI 1235.12, was revised in February 2010 to streamline the RC alert/mobilization decision process in order to ensure a standardized approach that enhances the timely release of orders. Among other things, it delegated authority to the service secretaries to approve alert/mobilization requests for involuntary mobilizations under certain conditions ${ }^{16}$ and for all voluntary mobilizations.

The National Defense Authorization Act for FY 2012 created a new mobilization authority in Section $12304 \mathrm{~b}$ of Title 10. It allows the service secretaries to involuntarily mobilize up to $60,000 \mathrm{RC}$ personnel at any one time for a maximum of 365 days. To use this authority, the services are required to detail manpower and costs in budget materials submitted to Congress, including the intended missions and length of activation periods, so that the funding can be approved in the programming cycle at least two years in advance of the intended mobilization (Office of the Assistant Secretary of Defense, Reserve Affairs, 2014). ${ }^{17}$

Within this context, the ATFP makes two policy statements related to mobilization:

1. Streamline the voluntary and involuntary mobilization of RC personnel and units to rapidly expand and sustain Total Army capabilities.

2. Use the mobilization authority in 10 U.S.C. $12304 \mathrm{~b}$, which allows the Secretary of the Army to order RC units to active duty under certain conditions (McHugh, 2012b).

The NCFA also made four related recommendations:

\footnotetext{
16 These conditions are (1) the mobilizations are of conventional forces; (2) the mobilization period is less than or equal to 12 months; (3) the individual or unit mobilization-to-dwell ratio is greater than or equal to one to four; (4) the individual or unit has been given 180 or more days between mobilization order approval and mobilization date; and (5) the unit is commanded by an officer in the grade of O-5 or below, or the deploying force consists of personnel not being deployed as part of a unit.

17 DoDI 1235.12 was subsequently revised in June 2016 to incorporate and cancel DoDD 1235.10 and to address the new mobilization authority in 10 U.S.C. $12304 \mathrm{~b}$.
} 
1. Recommendation 29: Congress should expand 12304b authority to include operational requirements that emerge within the programmed timeline, including the year of execution.

2. Recommendation 30: The Army should budget and Congress should authorize and fund at least 3,000 person-years annually for $12304 \mathrm{~b}$ utilization. DoD should also provide for the use of Overseas Contingency Operations and supplemental funding for RC utilization under $12304 \mathrm{~b}$.

3. Recommendation 31: DoD should relax the one-year limit on mobilizations to achieve common boots-on-the-ground periods for all components.

4. Recommendation 49: DoD should conduct a comprehensive review of the nation's ability to mobilize its existing reserves as well as its preparedness for the potential of national mobilization (NCFA, 2016).

\section{What's Being Done}

Interviewees did not mention streamlining the mobilization process as a salient issue, so we examined changes made to AR 500-5 (Army Mobilization) in 2015 and the Army's progress in developing an automated mobilization processing system. AR 500-5 does not specifically mention any efforts to streamline the mobilization process, but it provides for an Army Mobility Review CoC and periodic General Officer Mobilization Reviews to identify and resolve mobilization-related issues. It designates FORSCOM as the responsible agent for the mobilization, deployment, redeployment, and demobilization of RC units in the continental United States and directs FORSCOM, TRADOC, U.S. Army Materiel Command, and the Army Service Component Commands to prepare mobilization and demobilization plans (Department of the Army, 2015b).

After the terrorist attacks of September 2001, the Army began developing DAMPS, which electronically processes and tracks mobilization request packets through all necessary approval levels and stages, enabling the rapid issuance of mobilization orders and improving the Army's ability to account for and track units and individuals through- 
out the mobilization process. One of its modules, DAMPS-U, produces and maintains First Army unit mobilization orders. These orders provide the funding and authority for the mobilized unit to move from home station to the mobilization station. After the DAMPS-U order is issued, other commands can issue the individual mobilization orders for the members of the unit. Other modules produce and maintain the individual orders for RC soldiers on Contingency Operations-Active Duty for Operational Support tours and allow commands to advertise active duty opportunities and soldiers to volunteer for these opportunities (U.S. Army War College, 2015, p. 5-12; Office of the Deputy Chief of Staff, G-3/5/7, 2008). The February 2016 update to the Secretary of the Army on ATFP implementation indicates that new DAMPS templates and instructions for using them were created for 10 U.S.C. 12304a and 12304b mobilization authorities (Deputy Assistant Secretary of the Army, Training, Readiness, and Mobilization, 2016, slide 8). ${ }^{18}$

The ATFP directed the Army to make use of $12304 \mathrm{~b}$ mobilization authority, and the NCFA also recommended greater use of this authority. To measure the Army's use of $12304 \mathrm{~b}$ mobilization authority, we examined the Military Personnel, Army justification books for the FY 2015-2017 base and Overseas Contingency Operations (OCO) budgets. ${ }^{19}$ Table 3.4 shows actual funding and person-years for FY 2014-2015, estimated funding and person-years for FY 2016, and requested funding and person-years for the FY 2017 base budget and OCO budgets. ${ }^{20}$

18 On the related issue of duty status reform, a number of different boards and commissions, including the National Commission on the Guard and Reserves, the Reserve Forces Policy Board, and the Military Compensation and Retirement Modernization Commission, have recommended that DoD work with Congress to reduce the number RC duty statuses from 32 to as few as six. DoD has a working group analyzing this issue. See, for example, Reserve Forces Policy Board, 2014, p. 19; and Military Compensation and Retirement Modernization Commission, 2015, p. 4.

19 We did not find any mention of $12304 \mathrm{~b}$ authority prior to the FY 2015 budget materials.

20 OCO funding that is approved and executed is rolled into the prior-year actuals and estimates in the base budget materials, so it cannot be separately reported. 
Table 3.4

Army Utilization of 10 U.S.C. 12304b Mobilization Authority

\begin{tabular}{|c|c|c|c|c|c|c|c|}
\hline & \multicolumn{4}{|c|}{ Base Budget } & \multicolumn{3}{|c|}{ OCO Budget } \\
\hline & $\begin{array}{c}\mathrm{FY} \\
2014 \\
\text { (actual) }\end{array}$ & $\begin{array}{c}\text { FY } \\
2015 \\
\text { (actual) }\end{array}$ & $\begin{array}{c}\text { FY } \\
2016 \\
\text { (esti- } \\
\text { mate) }\end{array}$ & $\begin{array}{c}\text { FY } \\
2017 \\
\text { (request) }\end{array}$ & $\begin{array}{c}F Y \\
2015 \\
\text { (request) }\end{array}$ & $\begin{array}{c}F Y \\
2016 \\
\text { (request) }\end{array}$ & $\begin{array}{c}F Y \\
2017 \\
\text { (request) }\end{array}$ \\
\hline $\begin{array}{l}12304 b \\
\text { Funding }\end{array}$ & $\begin{array}{c}\$ 11 \\
\text { million }\end{array}$ & $\begin{array}{c}\$ 90 \\
\text { million }\end{array}$ & $\begin{array}{c}\$ 173 \\
\text { million }\end{array}$ & $\begin{array}{c}\$ 182 \\
\text { million }\end{array}$ & $\begin{array}{l}\$ 1.051 \\
\text { billion }\end{array}$ & $\begin{array}{c}\$ 901 \\
\text { million }\end{array}$ & $\begin{array}{l}\$ 1.060 \\
\text { billion }\end{array}$ \\
\hline $\begin{array}{l}\text { Person- } \\
\text { years }\end{array}$ & 139 & 973 & 1,826 & 1,878 & 11,362 & 10,107 & 11,124 \\
\hline
\end{tabular}

SOURCES: Department of the Army, 2014, 2015a, 2016a; DoD, 2014b, 2015, 2016a.

As Table 3.4 indicates, the Army has been ramping up toward utilization of 3,000 person-years of $12304 \mathrm{~b}$ mobilization authority annually in its base budget. NCFA CoC (2016) indicates that the Army has included 3,000 person-years in its Program Objective Memorandum for 2018-2022. The preplanned missions named in the base budgets include U.S Northern Command air defense and chemical, biological, radiological, nuclear, and explosives response missions; U.S. Africa Command counterterrorism partnerships; U.S. Central Command and U.S. European Command peacekeeping support; U.S. Southern Command stability operations; and theater security cooperation for U.S. Africa Command, U.S. Central Command, U.S. European Command, U.S. Southern Command and U.S. Special Operations Command. However, the budget materials do not report which missions the $\mathrm{RC}$ personnel actually supported.

The Army apparently requested large amounts of funding related to 12304b mobilization authority in its OCO budgets for FYs 2015-2017, but it is not clear whether this authority was actually used. In practice, it may be impossible to measure the usage of $12304 \mathrm{~b}$ authority by examining the mobilization orders issued. Some benefits available under 10 U.S.C. 12302 are not available under Section 12304b, so RC personnel may be advised to "volunteer" for these mobilizations under 10 U.S.C. 12301d authority, which does include the additional benefits. ${ }^{21}$ These

21 Benefits that are not available under $12304 \mathrm{~b}$ include reduced age for retirement, Post9/11 GI Bill credit, vocational rehabilitation, voluntary separation pay recoup protection, 
differences in benefits are a potentially contentious issue for RC service members in all the military services, but they can only be dealt with by Congress.

\section{Obstacles to Integration}

The NCFA report indicates that FORSCOM identified 3,000 personyears of missions annually in FYs 2014, 2015, and 2016 that could have met using $12304 \mathrm{~b}$ authority, ${ }^{22}$ but due to funding constraints caused by the Budget Control Act of 2011, the Army only programmed about one-third of this amount for 12304b missions (NCFA, 2016). As a result, some $\mathrm{AC}$ units with less than two years of dwell time performed these missions, even though similar ARNG and USAR units were available. According to the NCFA report, "Off-ramp decisions to avoid costs after scheduling Army National Guard units for deployment increased friction and, in some cases, raised suspicions between components that other motives were in play" (NCFA, 2016, p. 66). USAR interviewees also reported having spent a significant amount of money to train units, only to have the deployments canceled due to funding constraints.

Some stakeholders thought that the Army could use more RC units to support international theater security cooperation exercises at relatively low cost. This could be achieved under $12304 \mathrm{~b}$ authority by combining 15 days of funding for annual training with an additional 15 days of pay from the AC or the combatant command. To their knowledge, $12304 \mathrm{~b}$ funding had not been used for exercises, but this approach could meet the dual purposes of helping combatant commands build partner capacity or support U.S. regional presence and simultaneously training and employing $\mathrm{RC}$ forces.

\footnotetext{
premobilization TRICARE coverage, and federal civilian differential pay. One benefit that was added to $12304 \mathrm{~b}$ by the NDAA for FY 2016 is an exemption from the five-year limit on reemployment rights under the Uniformed Services Employment and Reemployment Rights Act of 1994. See Air Force Reserve Command Force Generation Center, 2016; and Office of the Assistant Secretary of Defense, Reserve Affairs, 2014.

22 These missions included Kosovo peacekeeping; Multi-National Forward Observers (Sinai); the Defense Chemical, Biological, Radiological, Nuclear Response Force; and selected theater security cooperation events.
} 
We also heard some concerns about other NCFA recommendations. Some interviewees thought that $12304 \mathrm{~b}$ authority should not be used to meet short-term demands, because RC units need adequate time to mobilize. Others expressed conflicting views on whether the 365-day limit on RC mobilizations should be extended in order to increase the common boots-on-the-ground time from 270 days to ten months.

\section{Moving Forward}

Following the publication of the NCFA report, the Army appears to be on track to increase utilization of $12304 \mathrm{~b}$ mobilization authority. The NCFA reported that many of the RC soldiers, employers, and state governors who provided testimony would support greater use of RC units to meet combatant command missions. However, all three groups would prefer to have predictability of deployments whenever possible (NCFA, 2016, p. 67).

As part of the implementation of the ATFP and NCFA recommendations, the Army should monitor the types of operations designated for RC units under $12304 \mathrm{~b}$ mobilization authority, and the contributions of these missions to relieving stress on $\mathrm{AC}$ forces and maintaining an operational reserve.

\section{Materiel}

The fifth part of our DOTMMLPF framework is materiel. In this domain, the ATFP states that “The Army's equipping strategy will ensure that procurement and equipping processes enable the Total Force to perform the missions of the Department of the Army" (McHugh, 2012b). The NCFA report includes some more specific recommendations regarding equipment shortages and modernization:

- Recommendation 8: The Army should provide a report to Congress on tactical wheeled vehicle shortages, including the costs and potential trade-offs for closing significant readiness gaps in this area. 
- Recommendation 9: The Army must reassess the risk it is assuming in modernization for aviation survivability; short-range air defense; chemical, biological, radiological, and nuclear equipment; field artillery; and watercraft.

- Recommendation 50: The Army should provide a Predeployment Training Equipment set to Fort Bliss, Texas, for its role as a Mobilization Force Generation Installation.

- Recommendation 60: The Army should implement a more aggressive modernization program for its aviation forces (NCFA, 2016).

\section{What's Being Done}

Unlike some of the other DOTMLPF domains, it is relatively easy to develop objective metrics to identify equipment shortages and measure equipment readiness. The difficulty lies in determining how to allocate scarce resources for equipment modernization across components and types of weapon systems.

DoD produces an annual National Guard and Reserve Equipment Report (NGRER) that provides an overview of RC equipment shortages and the services' equipment procurement plans for their RCs, including the base budget (P-1R) and the National Guard and Reserve Equipment Appropriation (NGREA). It also includes detailed appendixes for the ARNG and USAR describing inventory levels relative to requirements, average age of equipment, planned procurements, equipment transfers and withdrawals, and authorized substitutes for major types of equipment.

The NGRER for FY 2017 indicates that "Due to the impacts of the Budget Control Act of 2011, the Department is witnessing a decline in $\mathrm{RC}$ equipment procurement funding, in some cases falling back to pre-9-11 levels or even lower" (Department of Defense, 2016b). The practice of transferring aging equipment from the $\mathrm{AC}$ to the $\mathrm{RCs}$ can create capability and interoperability gaps between $\mathrm{AC}$ and $\mathrm{RC}$ units. The report also notes a recent practice of labeling transferred and existing RC equipment as "modern" when it was previously considered outdated. This practice may "suppress the demand signal to keep the RC truly modern and compatible" (Department of Defense, 2016b, p. 1-2). The NGRER for FY 2017 reports overall shortages of \$23.9 billion in 
ARNG equipment and $\$ 8.9$ billion in USAR equipment, not including authorized substitutions (Department of Defense, 2016b, p. 1-4).

To supplement the data available in the NGRER by major type of equipment, we compared the equipment assigned to AC, ARNG, and USAR units of similar types using AE2S data as of June 2016. Figure 3.2 shows the median percentage of authorized equipment on hand by dollar value, excluding substitutes, for pacing items and other essential equipment (Equipment Readiness Codes $\mathrm{P}$ and $\mathrm{A})^{23}$ for infantry battalions, military police (MP) companies, and transportation companies in each component. ${ }^{24}$ The number of units of each type is shown above the columns.

We found that infantry battalions have similar equipping rates, excluding substitutes, across components. However, because of differences in the dollar value of authorized equipment across different types of infantry battalions, AC infantry battalions have a median value of $\$ 40$ million in equipment, whereas ARNG and USAR infantry battalions have about $\$ 34$ million in equipment on hand, excluding substitutes. MP companies show the largest differences in equipping rates across components, with the median AC unit having about 90 percent of authorized equipment by value, compared with about 75 percent for the median ARNG and USAR units. Equipping rates for transportation companies were lower for all components, with AC units at a median of about 70 percent and RC units at about 65 percent. ${ }^{25}$

We also compared equipping rates for various sub-types of $\mathrm{MP}$ and transportation companies by component and looked for differences in equipping rates relative to the Dynamic Army Resourcing Pri-

23 We exclude the value of items greater than the number authorized and the value of items whose quantities on hand, no substitutes are above the quantities on hand including substitutes.

24 One caveat to this analysis is that it does not fully reveal differences in equipment modernization across components, because in some cases, multiple national stock numbers can be used to fill the same authorized line item number. Those national stock numbers might represent different generations of equipment, such as different levels of armoring or earlier and later versions of automated systems that are not fully compatible with each other.

25 Note that these results are consistent with the NCFA's concerns about shortages of tactical wheeled vehicles. 
Figure 3.2

Median Percentage of Authorized Equipment on Hand, No Substitutes, by Dollar Value

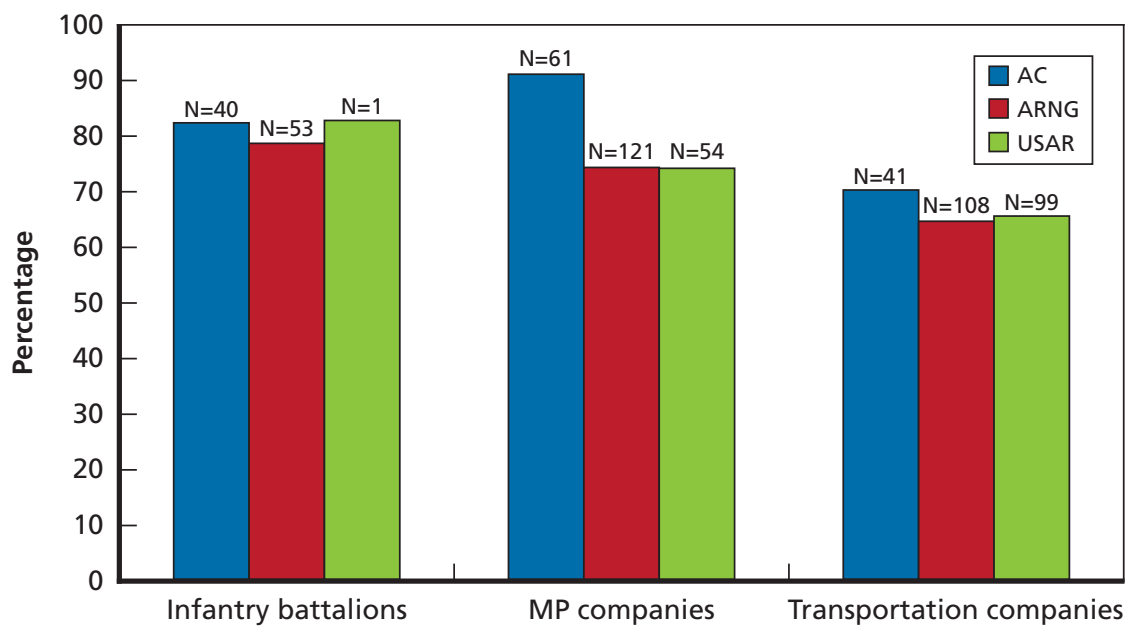

SOURCE: U.S. Army, 2016.

NOTE: Excludes on-hand > authorized.

RAND RR1958-3.2

ority List (DARPL) category of the unit. Additional results are shown in Appendix D. We did not find much variation in equipping rates by DARPL category, although in a few cases, units with low priorities had much lower median equipping rates than those with higher priorities.

\section{National Guard and Reserve Equipment Appropriation}

In 1981, Congress created a separate equipment appropriation for the RCs, called NGREA, in response to past AC budget priorities. It was intended to supplement the services' base budgets for equipment procurement. Total NGREA funding added by Congress has averaged about \$1.1 billion dollars from FY 2009 through FY 2016. However, it has almost doubled as a percentage of total $\mathrm{RC}$ procurement (from 13 percent to 24 percent) as funding for $\mathrm{RC}$ procurement in the base budget has dwindled (DoD, 2016b, pp. 1-1 and 1-5). RC leaders we interviewed for this study agreed that NGREA helps fix some of the smaller equipment deficiencies, particularly with ARNG "critical dual 
use" equipment, which is designated to support both disaster relief/ domestic crisis response and national contingency operations.

\section{Equipment Transparency}

In 2008, the Commission on the National Guard and Reserves recommended that the services provide increased visibility and accountability of equipment designated for the National Guard and Reserves in their annual budget submissions, and for tracing that equipment through the acquisition process from procurement through delivery to units. The Army has complied with this reporting requirement since 2009, although it is largely a manual process because its existing databases were not designed to link deliveries of equipment with the funding used to resource the procurement. DoD has conducted several internal and independent assessments of the Equipment Transparency Report. These assessments have found gaps in the current strategy, business model, culture, and data system and concluded that the Equipment Transparency Report is ineffective at providing the intended transparency and accountability. As a result, DoD is working with departmental stakeholders to develop alternatives to the Equipment Transparency Report that would provide transparency and accountability of the RC equipping process (DoD, 2016b, p. 1-3 and p. 2-5).

\section{Access to Modernized Equipment}

Interviewees mentioned that equipment-sharing between components for training has the potential to reduce both training and shipping costs, while improving $\mathrm{RC}$ access to modernized equipment. For example, the USAR sent engineer equipment to Fort Bliss for ARNG and USAR units to use for training, and the 1st Cavalry Division loaned M1 tanks and Bradley fighting vehicles to the Mississippi National Guard for its Multi-Echelon Integrated Brigade Training exercise on Fort Hood. However, there can be complications because the components receive maintenance funding based on density and usage of equipment, and reimbursement for maintenance costs by the borrowing unit to another component is cumbersome. A Fort Hood Logistics Readiness Center representative said that because each party was concerned about being held accountable for damage and other maintenance costs when they turned over accountability, both sides worked 
hard to identify every possible deficiency before signing for the vehicles. As a result, each party made such significant investments in inspecting and repairing equipment that it might have been less expensive for the ARNG unit to bring its own equipment. There are also concerns that equipment-sharing will lead to lower overall equipping levels across the Army.

Another dilemma in equipment modernization is the trade-off between sending the latest equipment to deployable units and diverting some of it to training sites. While there is an obvious demand for the former, a counterargument can be made that it is important for schoolhouses to have the most current equipment to ensure consistent training for all soldiers, on the assumption that, even if they report to a unit with older technology, they are likely to see the modernized version when they deploy and have a faster learning curve when time matters most. To this end, TRADOC representatives indicated that they are trying to ensure that the training base has modernized equipment. It does this by providing input to the distribution planning process, articulating the need for schools offering One Army School System (OASS) courses to be prioritized to receive modernized equipment.

\section{Obstacles to Integration}

Interviewees noted that the Army heavily relied on OCO funding to modernize RC equipment over the past 15 years and that, with the high operations tempo, the modernization gap between $\mathrm{AC}$ and $\mathrm{RC}$ units shrank over that period. However, these requirements were not incorporated into the base budget, and as OCO and acquisition funding have declined, the ARNG's and USAR's unfunded equipment shortfalls are growing. USAR leaders thought that the Army needs a more balanced investment strategy to comply with ATFP, particularly to ensure that early-deploying enabler units have access to modernized equipment. Communications equipment, where interoperability is essential, is considered one of the most critical areas for synchronized modernization.

In addition to acquisition funding, the RCs also need a steady stream of funding to repair equipment that is being handed down from the $\mathrm{AC}$, and to transport that equipment between units to address 
shortages. While the RCs can be expected to support the delivery of modern equipment to multicomponent training centers, this may have secondary effects if it reduces fielding to RC MTOE units.

Stakeholders we interviewed noted that equipment transparency (the ability to trace procurement from funding to delivery by component) is still a challenge. Interviewees said that equipment intended for the USAR is being diverted to other users (e.g., Chinook helicopters) and that acquisition of new items has been curtailed after the AC has been modernized but before the RC has received the items originally intended. They also noted that the USAR lags behind the other components in fielding plans for the Joint Light Tactical Vehicle. These concerns reflect a deeper assumption that the USAR gets lowest priority in fielding new equipment, especially for items that also go to combat arms units.

Interviewees stated that since the Equipping Program Element Group is centrally managed, the USAR and ARNG do not carry much weight in decisionmaking and have not been able to make a sufficient case to obtain more-modern equipment. In addition, the funding process favors BCTs, which puts the USAR at a disadvantage. As a result, the USAR lags in obtaining modernized equipment (e.g., Joint Light Tactical Vehicles, mission command software) to the point that many items assigned to USAR units are on U.S. Central Command's nondeployable list.

NGREA was mentioned as one way the system tries to minimize such gaps, but interviewees described it as only a partial solution. They voiced concerns that the Army cuts funding in the base budget in anticipation of NGREA funding. There are also difficulties in efficiently using NGREA as a primary funding stream because the RCs only get NGREA funds in the year of execution, not in the Program Objective Memorandum, making it difficult to plan for its use. RC acquisitions also need to fit into broader Army contracts; if these contracts end before the $\mathrm{RC}$ requirements have been met, as they did for M915 trucks, NGREA funds can not be used to fill in the gap. 


\section{Moving Forward}

The Army's procurement funding is likely to remain constrained in future years, so it will be difficult to fill modernization gaps across the board. However, the Army could set higher priorities for early-deploying RC units and measurable goals for equipping those units. An improved process for equipment transparency reporting would also help ensure that equipment designated for RC units is eventually delivered to them. In addition, the Army should make greater use of innovative solutions, such as multicomponent vehicle loans and pre-positioning of modernized equipment at RC training centers and schoolhouses, and establish business processes to provide funding for maintenance of shared equipment.

To the extent that the Army sees all U.S.-based equipment as available for training by any unit, this becomes a much broader field of efficiencies. However, this approach would fly in the face of decades of culture. Every tanker, artilleryman, or driver feels some sense of attachment to their assigned vehicle or piece of equipment, and there is a logical expectation that they would take better care of equipment they plan to go to war with. At the same time, one must question how much this matters during actual operations, because units often fall in on prepositioned or theater-provided equipment rather than deploying with their own equipment. As one observer of the Fort Hood pilot project noted, the "ah-hah moment" for some training units might be seeing what an unfamiliar inspector finds when they do the turn-in inspection on a hard-used vehicle. In the same way that 21 st-century training should reflect the modularity foreseen in U.S. operational doctrine, one could argue that forces should also be equipped the way they will fight - showing up on the battlefield and signing out whatever vehicles are available. Creating a culture of interchangeable training sets would help promote multicomponent training across the United States. However, this approach might require legislation (or some type of reimbursement mechanism) because the RA, ARNG, and USAR each have separate appropriations for operations and maintenance. Thus, it is not only a question of which component is going to operate a particular piece of equipment, but also which one is going to pay for fuel and repair parts. 


\section{Leadership and Education}

The sixth part of our DOTMMLPF framework is leadership and education. This domain goes hand in hand with both the (collective) training and personnel functions, but focuses on tying them together through the development of individual soldiers through formal schooling and sequential assignments. The ATFP simply states that "Standards for qualification and professional development will be the same for AC and RC personnel." (McHugh, 2012b). The NCFA makes several more-specific recommendations:

- Recommendation 40: The Army should retain formal leader development activities as a high priority for all uniformed and civilian personnel.

- Recommendation 41: Congress should direct DoD to review enlisted Joint Professional Military Education requirements and determine which ones should become mandatory.

- Recommendation 42: The Army should conduct an end-to-end review of The Army School System and report to Congress on the efficiencies gained by consolidating under-used capacity.

- Recommendation 43: The Army should establish true regionalization of the Army's school system and continue to consolidate the infrastructure where efficiencies can be gained.

- Recommendation 44: The Army should immediately implement the entire OASS to realize savings sooner (NCFA, 2016).

\section{What's Being Done}

One of the signature initiatives that has been included in ATFP implementation is the OASS. Its precursor was the Total Army School System, which sought to improve the performance and efficiency of the Army's school system by raising standards, improving integration across components, and consolidating facilities. ${ }^{26}$ The program centered on a regional system for RC schools. In 2009, the Army imple-

26 The Army's school system includes initial entry training; Military Occupational Specialty (MOS) reclassification training; officer, warrant officer, NCO, and Department of the Army civilian professional development training; functional training; and education. 
mented OASS to synchronize training for all three components and to further improve the efficiency and effectiveness of the Army's school system (NCFA, 2016, p. 74).

During its site visits, the NCFA found many incidents of underutilized training facilities and inefficient use of training dollars. Many facilities belonging to different components are located on the same installation or in close geographic proximity. These facilities often offer the same courses of instruction and technical training that soldiers travel to other regions to attend. Though fully staffed, many of these schools were not filled to student capacity. In addition, AC soldiers were traveling to AC training facilities at other installations, even though the required course was being taught at an $\mathrm{RC}$ school on or near their home installation (NCFA, 2016, p. 75).

Unlike the prior Total Army School System, which improved the administrative integration of the various schools, OASS focuses on integrating the flow of soldiers to courses to make the school assignment as efficient as possible. For example, an AC soldier on the West Coast might be sent to a USAR or ARNG course in California, instead of the traditional AC course at Fort Bragg or Fort Stewart, reducing travel cost and time away from home, while the reverse could be done for an RC soldier on the east coast. Implied in this effort is ensuring that the different versions of the same course are not only equivalent in content, but are administered in a way that allows soldiers from all components to attend. ${ }^{27}$ During interviews, TRADOC personnel said that they are still working on gaps in the programs of instruction, which often means focusing on what is essential in order to get soldiers back to units faster. Sometimes this includes breaking courses into two-week blocks to facilitate RC attendance. Overall, the organization reports it is making progress on its goal of continuing to expand the number of soldiers trained in OASS-managed courses each year.

The OASS process begins with a site selection team choosing course locations. TRADOC has developed a model to select the best locations based on infrastructure, staffing, equipment, convenience,

27 For example, RC-based courses tend to run six to seven days a week to shorten total course length, while courses developed for the AC assume a five-day classroom week. 
and past performance. The objective results are then adjudicated with the components to account for any subjective differences. One advantage of OASS is the elimination of courses that were being taught at less than capacity. To date, TRADOC has eliminated about 50 percent of excess capacity. The NCFA reported that the Army expects to achieve $\$ 5$ million in annual cost savings and return 77,000 training days to operational units by FY 2018 (NCFA, 2016, p. 75).

To examine trends in cross-component attendance at Army courses, we analyzed ATRRS data, focusing on soldiers in infantry battalions, MP companies, and transportation companies who attended a Basic Leader Course (BLC), an Advanced Leader Course (ALC), or a Senior Leader Course (SLC). ${ }^{28}$ We compared a three-year period prior to the ATFP (FYs 2010-2012) with a more recent two-year period (FYs 2014-2015) to see whether cross-component integration had increased. Our results for BLC are shown in Figure 3.3. Each column shows the percentage of students from one component who attended courses run by the other two components, with AC-run courses shown in shades of green, ARNG-run courses shown in shades of blue, and USAR-run courses shown in shades of red.

We found that RC attendance at AC-run BLC courses had increased in FYs 2014-2015 relative to FYs 2010-2012, particularly for USAR soldiers in these three unit types. However, for the most part, $\mathrm{AC}$ attendance at RC schools had gone down. In part, this occurred because the USAR was offering BLC in Kosovo in FYs 2010-2012, but these courses were no longer available in FYs 2014-2015. ${ }^{29}$ Some RC attendance at AC schools also occurred while soldiers were deployed.

\footnotetext{
28 For branch-specific courses (ALC and SLC), we focused on the primary MOSs in each unit type, $11 \mathrm{~B}$ and $11 \mathrm{C}$ in infantry battalions, $31 \mathrm{~B}$ and $31 \mathrm{E}$ in MP companies, and $88 \mathrm{M}$ in transportation companies.

29 Nevertheless, these figures indicate that increases in cross-component attendance have occurred since 2009, when RAND researchers James C. Crowley, Michael G. Shanley, Christina Panis, and Kristin J. Leuschner found only 22 percent integration overall, and little AC attendance at RC schools. This unpublished research also estimated that if all soldiers attended the closest training course available at that time, this policy would result in 42 percent cross-component integration.
} 
Figure 3.3

Trends in Cross-Component Attendance at Basic Leader Course

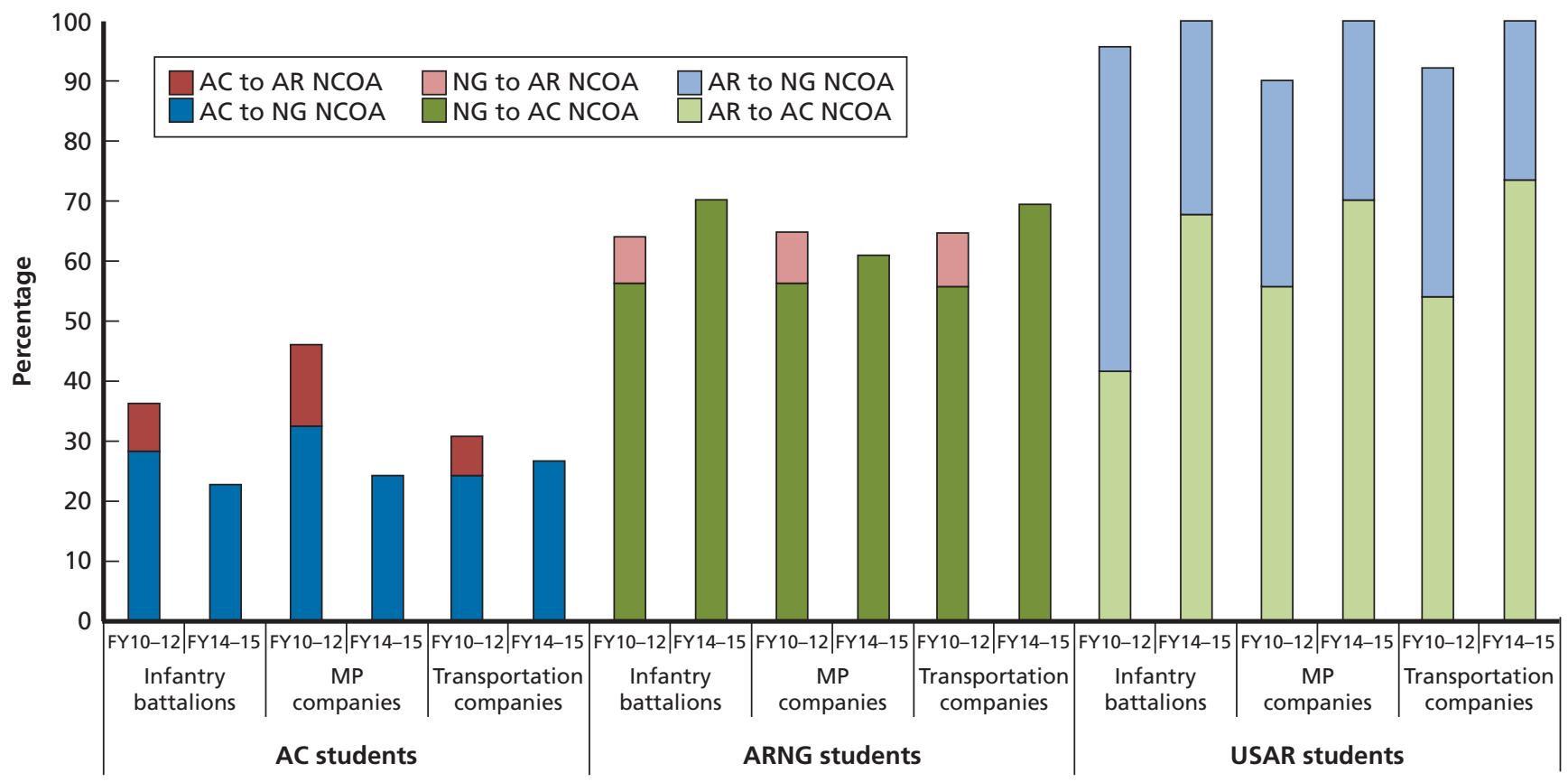

SOURCE: U.S. Army, undated-a. NOTE: NCOA = NCO Academy.

RAND RR1958-3.3 
For more senior NCOs, we found relatively little cross-component attendance at ALCs and SLCs for either AC or RC NCO academies. One exception is an increase in AC attendance at ARNG-run ALCs for infantry. Another is an increase in USAR attendance at AC-run SLCs for MPs and truck drivers. We also found that most ARNG MPs and truck drivers attended USAR-run ALCs and SLCs in both FYs 2010-2012 and FYs 2014-2015, but AC soldiers in the same MOSs exclusively attended AC-run ALCs and SLCs. ${ }^{30}$

Thus, there appears to be room for improvement in crosscomponent integration of BLCs, ALCs, and SLCs. Data provided by TRADOC indicates that AC attendance at RC-run MOS reclassification training, ALCs, and SLCs is projected to increase from 973 soldiers in FY 2016 to 4,444 soldiers in FY 2019.

\section{Obstacles to Integration}

RC leaders we interviewed said that OASS has been a success story, with some caveats. They felt that there has been good progress on standardizing programs of instruction, but some thought that the USAR and ARNG should be more involved in decisions to expand programs of instruction for specific courses. Increasing course length particularly affects the ARNG and USAR, because it increases the pay and allowances needed by RC soldiers to attend these courses. Another problem has been "color of money" issues with paying instructors from one component to teach students that primarily come from other components. For example, there have been some issues with paying RC drill sergeants for ten weeks of summer training because the students are mostly AC soldiers. Overall, interviewees also said that OASS increases contact and understanding between $\mathrm{AC}$ and RC soldiers, but some in the AC still have the attitude that RC schools aren't as good as AC schools.

RC leaders also expressed concerns that individual and institutional training is not getting enough funding due to tight budgets. Limited funding is available to pay for online courses and structured self-development, so RC soldiers must take these courses on their own

30 Detailed results are shown in Table E.1 in Appendix E. 
time. ${ }^{31}$ Due to tight budgets, duty MOS qualification training is the highest priority, followed by professional military education. Relatively little funding is available for functional training (i.e., additional skill identifiers, such as airborne, sapper, or ranger, or special qualification identifiers, such as drill sergeant or foreign language training), which can be valuable to individual soldiers. In addition, there has been no funding in recent budgets to reimburse USAR soldiers who live more than 150 miles from their unit for travel or lodging to attend inactive duty training.

\section{Total Force Leadership}

A recurring topic in our discussions with personnel from both RCs is the critical role of leadership in setting the tone for the ATFP and its component initiatives, and most critically the gap in representative leadership positions. There is at least a perception that RC leaders are generally limited to positions where they are expected to speak just for their component, and this increases as individuals ascend the promotion ladder. For example, in the integrated Human Resources Command, only six of 35 O-6 (colonel) positions are given to USAR officers. These positions are the following:

- Inspector General

- Headquarters Commandant

- Chief, Army Reserve Officer Division

- Chief, Health Services Division, Division Support Branch

- Chief, Army Reserve Enlisted Division

- Chief, Army Personnel Records Division.

Further analysis shows a pattern that is familiar to many RC soldiers. The USAR colonels are well represented in the most common occupational specialty in the headquarters-Adjutant General (three of nine). They hold two of 11 Branch Immaterial positions, close to the overall average. But in all other specialties, they hold just one of

31 There have also been concerns that RC soldiers would no longer receive retirement points for these courses following changes in the military retirement system. 
15 positions. The clear implication is that if there is only one careerenhancing position available, it is usually marked for an AC officer.

A counterexample has been the use of RC general officers on the Joint Staff in the Pentagon. The Army Reserve's floating J5 deputy director position has recently included heading the offices for PoliticalMilitary Affairs in Africa and for the Western Hemisphere, utilizing both the specific experiences of the individuals named to those positions and the RCs' high level of support for operations in both areas of responsibility.

\section{Moving Forward}

As the NCFA recommended, the Army should continue to implement OASS, both to reduce excess capacity and travel costs and to increase contact and understanding between the components. In the course of our interviews, several individuals mentioned that one way to institutionalize total force integration would be to promote integration within the staffs of the schoolhouses. While classes may mix students from different components, as long as the instructors come from a single component, a "pecking order" of perceived quality among the schools will remain. Integrating at the instructor level would ensure both component-neutral content and academic policies and the perception of fully equivalent instruction. It would also give schools the ability to provide a certain amount of training as a year-round baseline and seamlessly surge to a higher level as requirements increased.

One issue that we were not able to address in our analysis is whether RC soldiers are getting required leadership courses before promotion, or whether promotions are being delayed because soldiers are not able to attend required leadership courses. In some cases, ARNG and USAR units must choose between soldiers attending schools or annual training exercises. In addition, some courses are stretched over a year or more in the RC, but completed in weeks or months by AC soldiers. More detailed analysis of ATRRS and other Army personnel data systems would be needed to address these questions.

Multicomponent attendance at training and leadership courses could be pursued more broadly to help break down cultural barriers between components. For example, the Commission on the National 
Guard and Reserves recommended an increase in the number of fully funded slots allocated to RC officers at the National Defense University, senior war colleges, and ten-week Joint Professional Military Education in-residence course, and James Currie (2009) advocated that "Another area where cultural prejudice-or perhaps just lack of informationcan be addressed [is] by incorporating material on the RCs into the curriculum of the senior Service colleges." Currie also noted that most of the RCs service members sent to senior service colleges in residence are AGRs, rather than part-time, drilling USAR and ARNG officers.

\section{Personnel}

The seventh part of our DOTMMLPF framework is personnel. In many ways, the Personnel function is the central hub for the total force. Units, schoolhouses, and installations are only integrated to the extent that the personnel system can and does send the individuals who belong to each component to them in the ways intended. The ATFP has two objectives related to the Personnel domain:

- The Army will employ an integrated personnel management and pay system that contains standardized business processes and authoritative data for military personnel, enabling access to secure and reliable data.

- Personnel policies shall incorporate total force values and facilitate a continuum of service and opportunities for joint experiences (McHugh, 2012).

The NCFA also made several recommendations related to crosscomponent assignments, implementation of an integrated personnel and pay system, and programs to consolidate recruiting and marketing functions:

- Recommendation 27: The Army should review and assess officer and NCO positions for potential designation as integrated positions that could be filled by any component, to foster an Army 
total force culture and expand knowledge about other components.

- Recommendation 28: The Army should develop selection and promotion policies that incentivize AC, ARNG, and USAR assignments across components and within multicomponent units.

- Recommendation 35: Congress should enact legislation to allow assignment of AC officers and enlisted soldiers to ARNG positions without prejudice to their federal standing and the similar assignment of ARNG personnel to AC units.

- Recommendation 36: The Army should implement a pilot program to assign AC officers and enlisted soldiers to USAR fulltime support positions.

- Recommendation 37: Congress, DoD and the Army should continue to support and adequately fund the development and fielding of IPPS-A as the cornerstone to enhanced integration of all components of the Army.

- Recommendation 38: Congress should authorize the Army to establish a substantial multiyear pilot program in which recruiters from all three components are authorized to recruit individuals into any component and receive credit for an enlistee regardless of the component.

- Recommendation 39: Congress should authorize the consolidation of Army marketing functions across components to gain unity of effort (NCFA, 2016).

\section{What's Being Done}

If it is true, in the words of former Chief of Staff Creighton Abrams, that "Soldiers are not in the Army. Soldiers are the Army," then it is to be expected that personnel policies should be leading the way in creating the total force. Ultimately, the success of the ATFP will be judged by the Army's ability to use each soldier for the maximum benefit of the service (and the nation), both at every point in time and over a career. 


\section{Cross-Component Assignments}

As described in the Organization section above, one particular way in which total force objectives are being pursued is in the creation of associated units and other types of multicomponent units. This begins as a structure issue, but then becomes a task for the personnel and training functions to turn the units from theory to reality. The Army plans to begin cross-component assignments of officers and NCOs in FY 2017 as part of the AUPP. While assignment of USAR officers to AC organizations and vice versa is generally not an issue (once the necessary structure has been created), the Army needs to resolve legal issues to assign AC personnel to ARNG units and vice versa (e.g., RA vs. state commission). To address these issues, the NCFA has recommended that Congress enact legislation to facilitate cross-component assignments between the AC and ARNG. To support this effort, the Army Office of General Counsel is reviewing applicable laws and statutes (NCFA CoC, 2016).

Assignment of AC officers and NCOs to full-time support positions in RC units dates back to Title XI of the NDAA for FY 1993. The original intent of the law was that 5,000 AC personnel would be assigned as advisers to RC units. However, the emphasis on assigning AC advisers to RC units faded after a few years, and the NDAA for FY 1996 permitted the Army to count AC personnel assigned to units with the primary mission of providing training support to RC units (such as First Army) as part of the total number of AC advisers required by Title XI. The NDAA for FY 1994 required the Army to submit an annual report on the number of assigned Title XI personnel as part of the Army Posture Statement, including a comparison of the promotion rates of officers assigned as AC advisers with those of all other Army officers (Pint et al., 2015, pp. 18-21). ${ }^{32}$

There is some evidence that AC officers assigned to Title XI positions had lower promotion rates than other Army officers. Figure 3.4 shows the Army's reported figures for in-zone promotion rates to major

32 The NDAA for FY 2005 reduced the required number of AC advisers from 5,000 to 3,500, most of whom are now assigned to First Army. 
and lieutenant colonel from 2000 through 2011..$^{33}$ With the exceptions of 2007-2008 (when there were six or fewer Title XI officers eligible for promotion to major or lieutenant colonel), there is a consistent pattern of lower selection rates. Whether this reflects a bias at the promotion boards or a bias in sending less-qualified officers to serve in Title XI positions, this validates the NCFA's recommendation for the Army to develop selection and promotion policies to incentivize multicomponent assignments.

Figure 3.4

Promotion Rates for Title XI Officers vs. All Army Officers

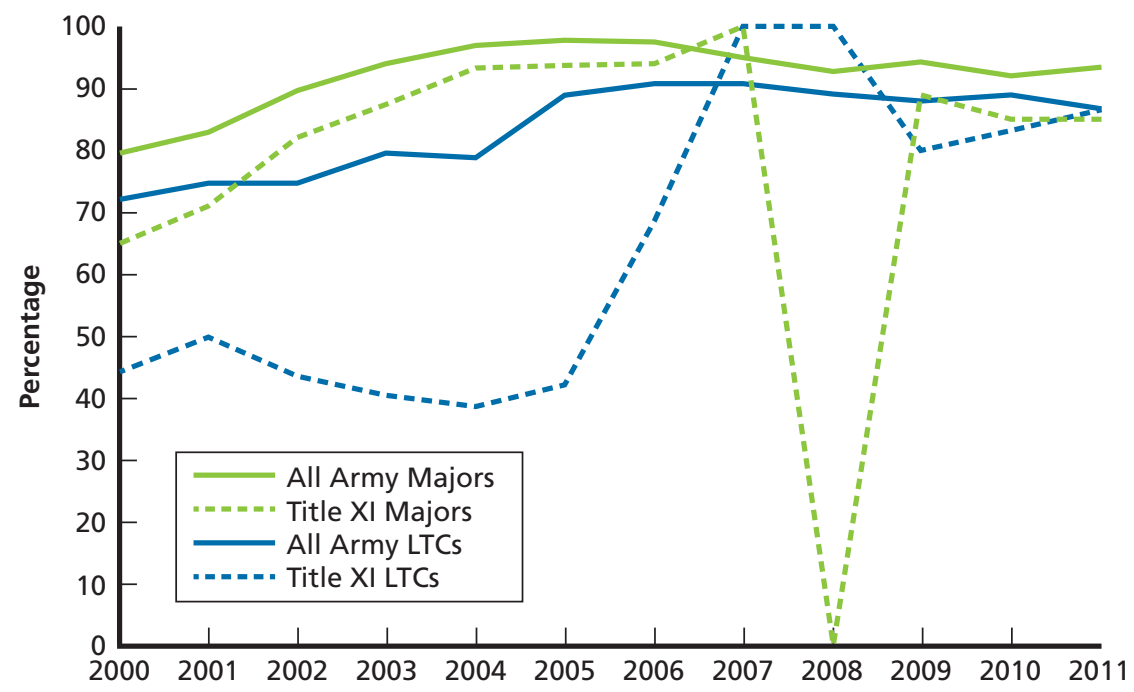

SOURCE: U.S. Army, 2002-2012.

RAND RR1958-3.4

33 In more recent years, the Army has continued to report the required data to Congress in an addendum to the Army Posture Statement, but the addenda are no longer easily accessible on the Army's website. See U.S. Army, undated-b. 


\section{Integrated Personnel and Pay System}

The ATFP directed the Army to employ an integrated personnel management and pay system, and the NCFA recommended that the Army continue to resource and implement IPPS-A. Of all the programs currently identified with the ATFP, none probably had a greater initial handicap than IPPS-A. Seen by many as the heir, if not the descendent, of the much-criticized Defense Integrated Military Human Resources System (DIMHRS), IPPS-A had to show it was not the "disaster" of its predecessor. DIMHRS was intended to create a common personnel and pay system for all the services, including their RCs, but was canceled in 2010 after spending $\$ 1$ billion and 12 years of effort. Required upgrades to the services' individual systems had been postponed for many years in anticipation of DIMHRS. In particular, many ARNG and USAR soldiers activated to serve in Afghanistan and Iraq reported significant pay errors due to inadequacies in legacy personnel and pay systems (Philpott, 2010). ${ }^{34}$

Despite the failure of DIMHRS, the Army still needs an integrated personnel and pay system. The inability of pay and records systems to share information is a fundamental shortcoming in efforts to make personnel management more adaptable and responsive. Interview subjects noted that an interim system, the Interactive Personnel Electronic Records Management System (iPERMS), can be used by soldiers and human resources (HR) personnel to maintain military personnel records and has facilitated access to personnel records across components.

IPPS-A is scheduled to be launched incrementally in five phases. Release One was fielded in three waves by component in 2014 and provides the system infrastructure, as well as access to basic personnel records for soldiers and predefined queries for HR administrators. Release Two will replace the ARNG's personnel system, the Standard Installation/Division Personnel System, scheduled in the second quarter of FY 2018. Release Three will replace the personnel systems used

\footnotetext{
34 For more information on the problems caused by legacy personnel and pay systems and the history of DIMHRS, see U.S. House of Representatives, Committee on Government Reform, 2006; Farrell, 2008, and Connor et al., 2016, pp. 26-27.
} 
by the RA and USAR in the first quarter of FY 2019. Pay capabilities will be added for all components in Release Four, scheduled for the fourth quarter of FY 2019. Remaining personnel services, including personnel evaluations and retention management, will be incorporated into Release Five in the third quarter of FY 2020 (NCFA 2016, p. 70, and Program Executive Office, Enterprise Information Systems, undated). 35

Interviewees said that IPPS-A appears promising. Its primary advantage is that it will not only integrate data for personnel in the different components, it will integrate data and combine functions of several legacy systems, including ATRRS and the Total Army Personnel Database. It will also include civilian employment information for RC personnel, long a shortcoming in the HR records. By giving the Army G-1 visibility of RC data, it will encourage efforts to better match individuals to requirements and allow more-comprehensive analysis of HR trends and processes.

However, the promise of IPPS-A comes at a cost. Fielding a system designed to integrate numerous legacy databases is requiring the Army to halt any changes to the architecture of these legacy systems until IPPS-A takes over. As a result, many smaller initiatives that could improve visibility today are on hold for several years. New programs, designed to improve HR management, may be fielded, but data fields needed to track their implementation and assess their success may not be available. For example, interviewees told us that a group of senior leaders is currently developing reforms to the system of dozens of duty statuses under which RC members serve, but many of the reforms will require database changes that would not take effect until the early 2020s.

\section{Continuum of Service}

The ATFP directed the Army to implement personnel policies that promote a continuum of service. Multicomponent units promote integration by bringing soldiers from different components together into a

35 The IPPS-A website does not provide a planned release schedule, so schedule information is based on NCFA, 2016. Interviewees said that implementation is currently in a three-year data correction phase. 
single organization. In most cases, when they complete these assignments, they return to single-component units and resume their career progression. A different, longer-term form of integration comes as individuals, by their choice or the Army's, leave one component and join another. In the same way that multicomponent units or unit associations attempt to meld different types of organizations together to maximize total capabilities, the intent here is to find the right status for each individual throughout his or her career so the Army gets the right contribution from that individual over time. Facilitating a continuum of service would increase the Army's return on its investment in these soldiers' training and experience.

Army Reserve leaders we interviewed said that the term "continuum of service" has not been well defined until recently. At its simplest level, it focuses on individual transitions between components. How easy is it for an AC soldier to transition to the ARNG or USAR? Or vice versa? Do they keep their rank, MOS, and status within the organization or take a step back? Moving from RC to AC could hurt a soldier's promotion opportunities, as they may not seem to be competitive with peers. There is clearly not a free flow between the AC and $\mathrm{RC}$, and most would agree that some constraints will be needed for the foreseeable future (e.g., there is a finite number of positions in each component and within most "current organizations" within the RCsthe authorized troop program unit, individual mobilization augmentation [IMA] and AGR positions).

ATFP initiatives to promote these kinds of transitions focused on excessive paperwork requirements limiting transfers and were looking for quick wins. The quarterly ATFP Implementation briefing to the Secretary of the Army listed the following tasks as "enablers" for the continuum of service initiative:

- If the separation processing designator requires a waiver into another component and the soldier is approved for transfer to that component, change the separation processing designator to favorable to avoid stigma. 
- Prepare and submit a legislative change to streamline officer appointment (scrolling) processes (e.g., universal appointment into one of the armed forces).

- Prepare and submit a legislative change to extend authorities in Army Directive 2012-19 to warrant officers. ${ }^{36}$

- Convert all hard copy forms required to electronic.

- Make ARNG unit vacancies available on RETAIN with assist from HRC.

- Review/change grade determination rules of engagement when a soldier changes component.

- Review/change/standardize waiver authorities for selected separation processing designator codes to access into another component.

- Standardize incentive policies between components.

- Review/change requirements for the excessive and/or redundant paperwork required for a soldier to change component.

- Eliminate duplication of forms.

- Establish a complete iPERMS record for all soldiers (including derogatory information reports).

- Provide all component HR managers with iPERMS access to review prior service soldier records with assist from ARNG and USAR.

- Standardize eligibility when transferring officers between components (Deputy Assistant Secretary of the Army, Training, Readiness, and Mobilization, 2016, slides 18-23).

Although these steps would reduce the administrative burden of moving between components, they do not address a broader human capital management strategy that would provide greater career flexibility for soldiers. In contrast, DoD's Force of the Future initiatives, announced in 2015-2016, proposed a variety of approaches to increase the flows of personnel and ideas between the military and the private

36 McHugh, John M., "Army Directive 2012-19 (Elimination of the Oath of Office Requirement When Transferring from the Active-Duty List to the Reserve ActiveStatus List)," Washington, D.C., July 16, 2012a. 
sector and improve recruiting and retention. These initiatives included expanding a career intermission program that allows service members to take a sabbatical from military service for a few years to get a degree, learn a new skill, or start a family; creating a more interactive, web-based career management system; and allowing officers to temporarily defer promotion boards so that they would not be penalized for taking careerbroadening assignments that deviate from the typical career path. ${ }^{37}$

\section{Other Ongoing Programs}

In this section, we briefly describe some other initiatives in the Personnel domain that are related to ATFP directives and NCFA recommendations.

The NDAA for FY 2017 directs the Army to consolidate its marketing organizations across components by October 1, 2017, and to establish a three-year pilot program that authorizes recruiters from all three components to recruit individuals into any components and receive credit toward enlistment goals, as recommended by the NCFA. The NCFA CoC (2016) indicates that the Army is assessing three approaches to consolidating the Army's marketing functions. The Army has also established an integrated process team to determine how the One Army recruiting pilot program will be implemented and evaluated. ${ }^{38}$

As discussed in the section on organization, the Army merged its $\mathrm{AC}$ and USAR personnel commands into a multicomponent organization. Separate from the organizational challenges of creating a multicomponent command, once created, its existence opens the door for more integrated management of the personnel being serviced (e.g., within career management fields or branches), and should facilitate assignments to multicomponent units and other types of cross-component assignments. However, HRC personnel we interviewed said that it would not be possible to manage assignments across components until

\footnotetext{
37 See Garamone, 2015; Pellerin, 2016; and Department of Defense, undated-a, undated-b, undated-c, and undated-d.

38 RAND Arroyo Center is assisting the Army with the experimental design and evaluation of this program.
} 
IPPS-A has been fielded. In addition, HRC only directly manages RA and USAR personnel, even if many of its functions include some visibility over and consideration of the ARNG as well.

Interviewees also mentioned making changes to increase promotions to E-5 and E-6. Previously, units were not holding promotion boards frequently enough; combining boards allowed more qualified soldiers to be promoted. Changes also allowed qualified AC soldiers to retain their promotion status if they joined an $\mathrm{RC}$ unit.

\section{Obstacles to Integration}

As was the case with associated units, some of the NCFA's recommendations regarding cross-component assignments hearken back to prior initiatives that were attempted but later abandoned. The question thus arises whether these new initiatives will be able to overcome past problems, particularly with assignment and promotion policies.

Some stakeholders said that the Army's continuum of service initiatives have been focused on reducing administrative barriers, rather than promoting and directing personnel flows between components that might result in improved outcomes for individual soldiers and the Army as a whole. They noted that, while the Army encourages priorservice AC soldiers to join RC units, moving from the RCs to the AC could harm promotion opportunities, because these soldiers may not be competitive with those who served continuously in the AC. The lack of an integrated personnel and pay system also hampers the Army's ability to move toward a broader talent management approach.

Another issue mentioned by USAR interviewees was the sense that the separate USAR personnel command in St. Louis was more responsive to its issues. Under the consolidated command, they have had to educate AC career managers about RC issues, or simply work within separate stovepipes to manage reservists (such as a "mini-reserve directorate" for AGRs and the AR Careers Division for troop program unit career management). Similarly, it remains to be seen whether combining marketing functions and consolidating recruiting efforts across components will allow the Army to use its resources more effectively, or result in neglect of RC interests. One interviewee suggested that it 
would be difficult for recruiters to master all the incentives and other programs that differ by component.

Interviewees also raised other issues that are not directly addressed by the ATFP or the NCFA's recommendations. One of these issues was the difficulty the USAR and ARNG have in attracting soldiers separating from the RA, often due to administrative decisions made by the Army. Among other issues, such soldiers are being required to pay back their separation bonuses at the same time that bonuses for joining an $\mathrm{RC}$ unit are not being funded. In addition, one of the advantages of a pilot program to increase the window for AC-to-RC transfers from 180 to 360 days was to allow soldiers additional time to take MOS reclassification training prior to leaving the AC. One interviewee said that only 32 soldiers so far had been able to utilize that opportunity. ARNG personnel mentioned an "active-first" enlistment program that was supposed to channel AC soldiers back to ARNG units, but the NGB was not able to verify how many soldiers returned to the ARNG because they could not easily be tracked in the personnel systems.

Another interviewee suggested that the IMA program could be used to expand opportunities for joint assignments. However, there would be some administrative difficulties to overcome. For example, AR 140-145 (Individual Mobilization Augmentation [IMA] Program) requires only 12 days of funding for annual training of IMAs (Department of the Army, 2016b). Additional funding for up to 48 inactive duty training periods and 14 days of annual training would help make these positions more valuable to soldiers as well as the joint organizations they would be supporting. Moreover, some joint organizations might want full-time employees, but they would need to provide funding for Active Duty for Operational Support orders unless funding set aside for $12304 \mathrm{~b}$ mobilizations could be used (e.g., for assignments to combatant commands).

\section{DOPMA and ROPMA}

Outside of the Army's direct control are the legal obstacles to personnel integration, promotions, and continuum of service posed by the Defense Officer Personnel Management Act (DOPMA) and Reserve Officer Personnel Management Act (ROPMA). Congress passed DOPMA in 
1980 and ROPMA in 1994 to create a more uniform pyramid of officer ranks that rewarded seniority while eliminating less-qualified officers in an "up or out" system that also ensured continued mobility and accession of younger officers. However, this relatively inflexible system that links time in grade with compensation and promotion also constitutes a barrier to broader multicomponent integration.

The legal barriers from DOPMA and ROPMA affect both specific NCFA recommendations and broader potential ATFP implementation efforts. For example, NCFA recommendations 27 and 28 to designate certain positions as integrated positions and develop selection and promotion policies to incentivize AC, ARNG, and USAR assignments across components face the legal barriers contained within DOPMA and ROPMA. However, aside from a brief mention of laws that shaped the U.S. Army, the NCFA report did not discuss DOPMA and ROPMA.

One way DOPMA and ROPMA potentially hinder ATFP implementation is through disparate retirement systems. While DoD has made efforts to reform the compensation systems, the AC and RC retirement systems remain separate, and the elements of seniority inherent in DOPMA and ROPMA remain intact. The seniority clock for officers starts "ticking" at the time of commissioning, and continues as officers progress through their careers. As AC officers only become eligible for retirement pay after 20 years of service, they have an incentive to ensure their assignments are competitive for promotion. $\mathrm{RC}$ officers also only become eligible for retirement pay after 20 years of qualifying service, but they do not receive benefits until age 60.39 However, RC officers must continue to be promoted on the same "up

\footnotetext{
39 Mattock, Asch, and Hosek (2014) estimated the effects of allowing vested RC soldiers to receive retirement benefits immediately upon retirement. For those with prior AC service, their analysis suggests that this policy change would lead to higher RC participation in midcareer years and lower participation after retirement vesting. For those without prior AC service, RC participation would be largely unchanged. They also estimated that Army personnel costs would decrease by about $\$ 800$ million per year because the AC force would become more junior on average.
} 
or out" timelines as AC officers to reach 20 years of service and become eligible for retirement pay. ${ }^{40}$

The DOPMA and ROPMA timelines, combined with the officer career maps of Department of the Army Pamphlet 600-3 (Department of the Army, 2014a), also demonstrate the larger obstacle to personnel integration. The officer career maps list education, training, and assignments that officers should achieve at the different ranks and years of service. The Army has different career maps for AC and RC officers. The intent is to accommodate the different positions available to $\mathrm{AC}$ and $\mathrm{RC}$ officers based upon force structure differences. The assignments are further divided into "key and developmental assignments" and "developmental and broadening assignments." Key and developmental assignments are considered "required" for promotion; developmental and broadening assignments are considered "as time permits." Thus, when officers choose assignments, the key and developmental assignments are valued for promotion over the developmental and broadening assignments, regardless of the knowledge gained. For example, an ARNG engineer officer assigned as a chief financial management officer is in a key and developmental assignment, but not so an AC or USAR engineer officer. An AC officer serving as an AC-RC observer controller for training is only in a developmental and broadening assignment — not a key and developmental assignment. For RC engineer officers, no AC-RC assignments are listed in any category.

For AC officers to be incentivized to serve in RC units, the position must be "key and developmental," and the same goes for RC officers. However, there are a limited number of "key and developmental positions," so components often "fence" those positions for officers from within their own components to ensure their officers remain competitive for promotion. The competition for these assignments is

\footnotetext{
40 Note that separate AC and RC retirement systems are also an impediment to a continuum of service. There is little long-term incentive for mid- or late-career soldiers to consider an AC-RC or RC-AC transfer, because of the effects on their retirement benefits. For example, a soldier completing a 20-year career could serve an additional eight to ten years in an RC unit, but only by delaying his or her AC retirement pay. An RC soldier transferring to the $\mathrm{AC}$ would receive a full-time salary in the short term, but might only get the incremental increase in $\mathrm{RC}$ retirement pay that comes from the additional days of active duty.
} 
thus a barrier to integration, as is the limited time officers have to complete these assignments under DOPMA and ROPMA. The Commission on the National Guard and Reserves proposed an alternative to the assignment dilemma by replacing it with "knowledge, skills and abilities." Recommendation 11 required

Conduct[ing] an analysis of the Service promotion systems to determine if the requirements of DOPMA and ROPMA are hindering the Services' ability to meet the need for officers with the required knowledge, skills and abilities to fill mission requirements. The analysis shall consider the effects on the force of varying the timing of promotions among various competitive categories (Commission of the National Guard and Reserves, 2008).

Despite this recommendation, no system to date has been developed to quantify "knowledge, skills and abilities" to fill mission requirements. Thus, the current system of assignments remains the Army's best indicator of an officer's qualifications. An alternative to quantifying "knowledge, skills and abilities" is to rewrite Department of the Army Pamphlet 600-3 to integrate the AC and RC officer career maps and to allow key and developmental positions to be allocated evenly among the components, incentivizing integration.

\section{Moving Forward}

Most initiatives in the Personnel domain are in the process of being implemented and will need to be carefully monitored and evaluated to ensure the desired results. Particular concerns include whether multicomponent assignments will have negative effects on promotion opportunities, the timeline for fielding IPPS-A and achieving expected benefits, and whether combining recruiting and marketing functions across components will have beneficial and equitable outcomes for all three components.

One area where the ATFP implementation guidance may not have gone far enough is in its discussion of the continuum of service. As noted above, initiatives have focused on easing the movement of personnel from the RA to the RCs. One can also see a more strategic meaning to the term, going beyond the specific transactions to a 
broader concept of careers spent moving among varying levels of participation. Under this definition, a soldier might start in the ARNG, then decide to join the RA. At some point, he or she may want to leave active duty for a defined period to start a family or attend school fulltime, during which period he or she could be in the Individual Ready Reserve or a local RC unit. Then he or she might choose to come back on active duty and resume an RA career. In an ideal world, proponents argue, the Army could find a place for these soldiers at each step, and their ability to change status would only be limited by the need to catch up on objective skills and experiences appropriate for their new positions. In reality, soldiers attempting to have such a career would likely find themselves frustrated both by regulations and policies (not just for transfers, but also for promotions, retirement, and other actions) and by attitudes and biases in each component.

In a 2008 article, then-President of the Reserve Officers Association Dennis M. McCarthy defined continuum of service as

a human capital strategy that views active (full-time) and reserve (part-time) military service as two elements of valuable service that a qualified individual can provide. Some service members may provide exclusively active service from initial accession until discharge or retirement. However, many others will provide a mixture of active and reserve service. The continuum of service concept could be extended to include civilians who serve in various national security roles (McCarthy, 2008).

He listed the key principles of the continuum of service as follows:

Personnel policies should enable members to serve as frequently as they are available, under circumstances that meet their capabilities, provided those circumstances are useful to national security .... An individual's availability almost certainly will change throughout his career. The nation should use those changes in a positive way to distribute the total force across the entire spectrum of national defense requirements. Policymakers must recognize that there is value to the nation at every point along the individual continuum. The nation needs high-skill, highreadiness units; it needs long-lead-time individual replacements; 
and it needs a variety of individuals and units at varying levels of readiness between these two extremes. In providing for a variety of service opportunities, we must recognize that one may provide valuable reserve service as part of a large formation, a smaller crew or an individual augmentee" (McCarthy, 2008).

This expansive view of continuum of service seems markedly different from the scope of current continuum of service initiatives.

Another area requiring consideration is the effect that DOPMA and ROPMA may have on existing initiatives and future efforts at ATFP implementation. The Army should take these current legal requirements into account in creating and implementing its various ATFP and NCFA initiatives and recommendations. Framing Army implementation efforts to comply with DOPMA and ROPMA is one answer. However, it may be necessary to engage stakeholders in the other services, DoD, and Congress and revise DOPMA and ROPMA to better achieve the goals of the ATFP.

\section{Facilities}

The eighth part of our DOTMMLPF framework is facilities. While most observers would find it hard to tell the difference between an RA and an ARNG soldier, or between a High Mobility Multipurpose Military Vehicle (Humvee) from the USAR or the RA based on their appearance, there is a clear difference between facilities belonging to the AC and the RCs. While the stereotypical AC installation is a sprawling city, with acres of maneuver space and a wide range of housing, maintenance, offices, and other buildings, ARNG and USAR units pride themselves on being part of their communities, and include approximately 2,300 Guard armories and 1,100 reserve centers scattered around the country and worldwide, including the Pacific Islands, Japan, and Europe. Even large RC facilities will often be lightly manned during much of the year, waiting for units to arrive and begin weekend, annual, or premobilization training. What does it mean to manage these disparate facilities as part of a total force? 
The ATFP and NCFA do not have any specific objectives or recommendations regarding facilities, except that the NCFA mentions Base Realignment and Closure as a potential source of savings that could be used to fund other initiatives. However, installations, armories, and reserve centers are important enablers for training; in addition, some Army installations serve as mobilization platforms for $\mathrm{RC}$ units.

\section{What's Being Done}

ARNG and USAR stakeholders mentioned concerns about funding for their installations and other facilities. For example, one interviewee noted that the ARNG has 30 percent of the Army's force structure, but only gets 20 percent of installation funding. We were able to compare funding across commands using FY 2016 data obtained from the Office of the Assistant Chief of Staff for Installation Management, Army budget materials, and the Installation Status Report. The results are summarized in Table 3.5. Both the ARNG and the USAR appear to receive a higher share of funding than their shares of total acreage and building square footage, based on various measures of infrastructure spending.

USAR representatives indicated that the USAR provides funding for six large installations, but they are commanded by Installation Management Command (IMCOM). Its current position is that it would like to bring command back under USARC, and personnel are currently documenting the implications of this change. Because some IMCOM requirements are not relevant to the USAR, they believe this change could save on personnel and overhead costs. The USAR also manages approximately 1,100 reserve centers worldwide, and does set policy for those.

ARNG and USAR interviewees said that military construction funding is more equitable, and as a result, they have been able to allocate funding to the highest priority projects. In FY 2016, the ARNG received 22 percent of total Army military construction funding, while the USAR got 13 percent (Assistant Secretary of the Army, Financial Management and Comptroller, 2016). Because the USAR can set its own investment priorities, it has been able to consolidate facilities in some metropolitan areas to modernize and reduce costs. Similarly, the 
Table 3.5

Installation Funding by Command

\begin{tabular}{|c|c|c|c|c|c|c|}
\hline Command & Acres (thousands) & $\begin{array}{l}\text { Building Square } \\
\text { Feet (thousands) }\end{array}$ & $\begin{array}{l}\text { Installation } \\
\text { Status Report } \\
\text { Services Costs }\end{array}$ & $\begin{array}{c}\text { Military } \\
\text { Construction }\end{array}$ & $\begin{array}{c}\text { Base Operations } \\
\text { Support }\end{array}$ & $\begin{array}{c}\text { Facility } \\
\text { Sustainment, } \\
\text { Restoration and } \\
\text { Modernization }\end{array}$ \\
\hline $\begin{array}{l}\text { Army Materiel } \\
\text { Command }\end{array}$ & $\begin{array}{c}461 \\
(3.4 \%)\end{array}$ & $\begin{array}{l}94,980 \\
(9.9 \%)\end{array}$ & $\begin{array}{c}\$ 2,332 \text { million } \\
(18.0 \%)\end{array}$ & \multicolumn{3}{|c|}{ (All AC funding included under IMCOM) } \\
\hline ARNG & $\begin{array}{c}934 \\
(6.9 \%)\end{array}$ & $\begin{array}{c}48,843 \\
(5.1 \%)\end{array}$ & $\begin{array}{c}\$ 1,391 \text { million } \\
(10.8 \%)\end{array}$ & $\begin{array}{l}\$ 249 \text { million } \\
(22.1 \%)\end{array}$ & $\begin{array}{c}\$ 1,044 \text { million } \\
(11.3 \%)\end{array}$ & $\begin{array}{l}\$ 707 \text { million } \\
(18.9 \%)\end{array}$ \\
\hline IMCOM & $\begin{array}{c}11,684 \\
(87.1 \%)\end{array}$ & $\begin{array}{l}774,288 \\
(80.4 \%)\end{array}$ & $\begin{array}{c}\$ 8,460 \text { million } \\
(65.4 \%)\end{array}$ & $\begin{array}{l}\$ 728 \text { million } \\
(64.8 \%)\end{array}$ & $\begin{array}{c}\$ 7,583 \text { million } \\
(82.3 \%)\end{array}$ & $\begin{array}{c}\$ 2,763 \text { million } \\
(73.9 \%)\end{array}$ \\
\hline USAR & $\begin{array}{c}342 \\
(2.6 \%)\end{array}$ & $\begin{array}{l}44,484 \\
(4.6 \%)\end{array}$ & $\begin{array}{l}\$ 755 \text { million } \\
(5.8 \%)\end{array}$ & $\begin{array}{l}\text { \$148 million } \\
(13.1 \%)\end{array}$ & $\begin{array}{l}\$ 584 \text { million } \\
(6.4 \%)\end{array}$ & $\begin{array}{l}\$ 267 \text { million } \\
(7.2 \%)\end{array}$ \\
\hline
\end{tabular}

SOURCE: FY 2016 data obtained from Office of the Assistant Chief of Staff for Installation Management, 2016; Installation Status Report, Department of the Army (2017a, 2017b, 2017c); and Assistant Secretary of the Army, Financial Management and Comptroller, 2016. Installation Status Report data are not publicly available. 
ARNG has developed an Armory Facilities Master Plan to manage and prioritize its military construction funding.

\section{Obstacles to Integration}

The ARNG also highlighted that the Army's environmental resourcing model has been a problem, and they are working with the Office of the Assistant Chief of Staff for Installation Management and IMCOM to revise it. The model was originally based on one "virtual installation" per state, regardless of the number of separate ARNG facilities. Delaying environmental remediation due to underfunding (e.g., threatened and endangered species) could cause problems in the future, and there is a possibility that installations would have to shut down training if not in compliance. Environmental manning models have also been a problem, because they are based on GS-level positions, but the ARNG works with state employees, not federal ones.

Another example is that many support services are installationbased, which makes them less accessible and less adaptable to the RCs.

\section{Moving Forward}

Facility management may be another case where "one size fits all" policies are not appropriate across components. The Army should ensure that funding is equitable and facilities are right-sized across components, but allow the components some discretion on how best to maintain and invest in facilities.

\section{Summary}

In this chapter, we reviewed the Army's implementation of the ATFP across the DOTMMLPF domains, using objective metrics where feasible, but also based on the perceptions of stakeholders we interviewed. We also discussed obstacles to integration and ways the Army can move forward with total force integration. In the next chapter, we summarize our findings and recommendations. 



\section{Conclusions and Recommendations}

In our review of ATFP implementation, some common themes emerged. The Army has made progress in implementing the ATFP across the DOTMLPF domains, but more work remains to be done. In many areas, the NCFA has provided recommendations that are more specific and has created a new impetus for the Army to move forward with ATFP implementation. However, budget constraints have limited implementation of some objectives, particularly multicomponent training, RC equipment modernization, and use of $12304 \mathrm{~b}$ mobilization authority. Another important issue to address, as noted by the NCFA, is breaking down cultural barriers and distrust between components. In addition, several initiatives focus on BCTs and tend to neglect enabler units that are also needed to conduct contingency operations. Finally, some interviewees noted that ATFP implementation emphasizes policy changes, not execution and enforcement of changes that promote greater total force integration.

Since the Army's budget is likely to remain constrained in the future, innovative solutions are needed to achieve the intent of the ATFP. For example, the Army can reduce the cost of multicomponent training through initiatives such as the Nationwide Move program, multicomponent vehicle loans, and positioning modernized equipment at regional training and mobilization sites. Another example is the consolidation and integration of individual training and professional military education under OASS. The NCFA recommended that the Army free up funding for initiatives that promote total force integration through such efficiency initiatives as reforming the military health 
care system, reducing energy consumption, and closing unneeded military facilities.

One lingering question remains: How will the Army know when it has achieved total force integration, or what is the right balance of resources across components to maximize the Army's readiness to fight and win the nation's wars? A partial answer is to set goals for force integration and to establish metrics to monitor progress toward achieving those goals, such as the number of units and soldiers participating in multicomponent training events, use of $12304 \mathrm{~b}$ mobilization authority, equipping of early-deploying enabler units, and the fielding schedule and functionality of IPPS-A. In addition, the Army has started several pilot programs that will need to be evaluated to determine whether they are meeting the intent of the ATFP and whether combining functions across components results in the neglect of ARNG and USAR interests. These programs include the AUPP, multicomponent headquarters organizations, the One Army recruiting pilot, and combining marketing functions.

In the remainder of this chapter, we review our findings and recommendations in each of the DOTMLPF domains, plus mobilization. We also identify ongoing research that will help evaluate progress toward implementing the ATFP and the NCFA's recommendations.

\section{Doctrine}

The ATFP required that the Army change three regulations, including AR 71-11 (Department of the Army, 1995), AR 525-29 (Department of the Army, 2011), and AR 500-5 (Department of the Army, 2015b) and consolidate or eliminate Series 135 (Army National Guard and Army Reserve), Series 140 (Army Reserve), Series 350 (Training), and Series 600 (Personnel-General). We found that only a few had been updated since 2012, and in some cases, the changes did not address ATFP requirements. Therefore, we recommend that the Army assess the status of the regulatory changes required by the ATFP and set a firm timeline to publish the remaining changes. 


\section{Organization}

The Army has several initiatives related to multicomponent units, including the AUPP, the corps and division multicomponent headquarters program, and other multicomponent sustainment and support units. Most of these programs have only recently been implemented and have yet to be evaluated to determine whether they are meeting the intent of the ATFP. Some are similar to past initiatives that were intended to increase AC-RC integration but fell into neglect or were abandoned when $\mathrm{RC}$ forces were not deemed ready to deploy with their AC counterparts. Therefore, we recommend that the Army develop goals and metrics for these programs and adjust policies and practices as necessary to meet those goals.

\section{Training}

Initiatives to increase multicomponent collective training include the Total Force Partnership Program, participation of RC units in CTC rotations and other multicomponent training exercises, and development of a new Army EXORD on validating predeployment readiness. However, no additional funding has been provided to transport $\mathrm{RC}$ units to CTCs or AC installations or AC units to $\mathrm{RC}$ training facilities. In addition, some initiatives focus on BCTs, which tend to exclude or provide only limited opportunities for enabler units to participate. Innovative solutions, such as the Nationwide Move program, multicomponent vehicle loans, and positioning equipment at training centers, can reduce transportation costs, but the Army should also consider increasing transportation funding to support multicomponent training.

\section{Mobilization}

The ATFP and the NCFA both call for greater use of the mobilization authority in Title 10, Section $12304 \mathrm{~b}$, which allows the service secretaries to involuntarily mobilize up to $60,000 \mathrm{RC}$ personnel for a 
maximum of 365 days. To use this authority, the services are required to detail manpower, costs, and intended missions in the budget materials submitted to Congress. Based on recent Army budget materials, we found that the Army is gradually ramping up toward the 3,000 person-years of $12304 \mathrm{~b}$ utilization recommended by the NCFA. The Army should monitor the types of operations designated for RC units under this authority, and the contributions of these missions to relieving stress on $\mathrm{AC}$ forces and maintaining an operational reserve.

\section{Materiel}

DoD produces an annual National Guard and Reserve Equipment Report that provides an overview of RC equipment shortages and the services' equipment procurement plans for their RCs. The most recent report notes that budget constraints are causing a decline in RC equipment procurement funding, and the practice of transferring aging equipment from $\mathrm{AC}$ to $\mathrm{RC}$ units can create capability and interoperability gaps. We used Army equipping data to compare the equipment assigned to AC, ARNG, and USAR units of similar types and found some evidence of discrepancies in assignment of modernized equipment. The Army's procurement funding is likely to remain constrained, but it could set higher priorities for early-deploying RC units and measurable goals for equipping those units. In addition, greater multicomponent sharing of equipment or positioning of equipment at training centers could increase $\mathrm{RC}$ access to modernized equipment.

\section{Leadership and Education}

The OASS is consolidating individual training facilities across components, standardizing programs of instruction, and integrating the flow of soldiers to the closest location offering the course they need, regardless of component. To assess this initiative, we examined crosscomponent attendance at BLC, ALC, and SLC for soldiers in selected unit types. We found that $\mathrm{RC}$ attendance at AC-run courses had 
increased in recent years, but not $\mathrm{AC}$ attendance at $\mathrm{RC}$-run courses. As recommended by the NCFA, the Army should continue to implement OASS and monitor cross-component attendance. Multicomponent attendance at training and leadership courses could be pursued more broadly to help break down cultural barriers between components, for example, by increasing the number of fully funded slots allocated to $\mathrm{RC}$ officers at the National Defense University, senior war colleges, and Joint Professional Military Education in-residence courses.

\section{Personnel}

The ATFP directs the Army to employ an integrated personnel management and pay system and to facilitate continuum of service and opportunities for joint experiences, while the NCFA added an emphasis on cross-component assignments and programs to consolidate recruiting and marketing functions across components. The Army is making progress in implementing IPPS-A, but full implementation is not expected until 2020. So far, initiatives to promote a continuum of service have focused on reducing the paperwork requirements limiting transfers between components. These initiatives have not yet moved toward a broader vision of an Army human capital strategy that allows soldiers to move more flexibly between components, depending on their personal circumstances and the needs of the Army. DOPMA and ROPMA create additional constraints and disincentives for continuum of service and cross-component assignments. Other concerns that will need to be monitored and evaluated include whether multicomponent assignments will have negative effects on promotion opportunities, and whether combining recruiting and marketing functions across components will have equitable outcomes for all three components.

\section{Facilities}

The ATFP and the NCFA's recommendations do not directly address facilities, but they are important enablers for training and mobilization. 
Concerns in this area focus on equitable funding for facility operations and maintenance and military construction. Facility management may be a case where "one size fits all" policies are not appropriate, and the components should be given some latitude on how best to maintain and invest in facilities.

\section{Related Research}

This research project has provided an overview of the Army's progress in implementing the ATFP, but these efforts include many complex initiatives that merit more in-depth assessments of their strengths and weaknesses. As of this writing, RAND Arroyo Center has several other studies examining some of these initiatives, including:

- Support to the NCFA and Army Assessment and Implementation of NCFA Recommendations

- Tailored Equipping Strategies for USAR Units

- Principles for Successful Multicomponent Approaches

- Multicomponent Units and Division Headquarters Readiness

- Implementation and Evaluation of the One Army Recruiting Pilot

- Aligning Full-Time Support to Achieve Desired RC Readiness Levels

- Understanding and Estimating Unit Effectiveness as a Function of Permanent and Temporary Duty Manning Choices

- Supporting Implementation of Objective-T Performance Measures.

The Army should also conduct evaluations of other initiatives to determine whether they are meeting the intent of the ATFP. These include:

- the AUPP

- the Total Force Partnership Program

- use of section $12304 \mathrm{~b}$ mobilization authority 
- implementation of the OASS and increasing multicomponent attendance at other leadership and training courses

- expanding the continuum-of-service concept into a broader human capital strategy that allows soldiers to serve more flexibly across components. 

We provided interviewees a one-page summary of the ATFP and used the question list that follows it to guide our discussions.

The ATFP specifies several policy objectives and regulatory changes that must be implemented by various organizations in the Army.

- The Army will integrate AC and RC forces and capabilities at the tactical level (division and below). This will include some predeployment collective training of tactical-level organizations, including those that will routinely deploy as multicomponent forces (e.g., sustainment brigades and other multifunctional support brigades).

- Procedures and processes for validating the predeployment readiness of assigned forces are uniform for AC and RC units and soldiers. Standards for qualification and professional development will be the same for AC and RC personnel.

- The Army will streamline the voluntary and involuntary call to active duty of RC personnel and units to rapidly expand and sustain Total Army capabilities.

- The Army's equipping strategy will ensure that procurement and equipping processes enable the total force to perform its missions.

- The Army will employ an integrated personnel management and pay system that contains standardized business processes and authoritative data for military personnel. Personnel policies shall incorporate total force values and facilitate continuum of service and opportunities for joint experiences. 
- Amend AR 71-11 (Total Army Analysis) to include an annual analysis of force structure options, including the mix of operating and generating force capabilities between the AC and RC, and to require the Army to report any military capabilities that are insufficient in numbers or type.

- Amend AR 525-29 (Army Force Generation) to direct that available forces (mission force and surge force) are prepared to deploy as integrated expeditionary forces and to require a common set of standards and procedures for the validation of readiness. The Army shall use a common deployment cycle to facilitate the integration of $\mathrm{AC}$ and $\mathrm{RC}$ forces in support of operations.

- Amend AR 500-5 (Army Mobilization) to conform with this policy and to streamline the mobilization process to rapidly provide $\mathrm{RC}$ capabilities to perform Army missions.

- Consolidate or eliminate Army publications Series 135 (Army National Guard and Army Reserve), Series 140 (Army Reserve), Series 350 (Training) and Series 600 (Personnel-General) to conform with the guidance in this directive. All components will collaborate in the development, administration, and execution of publications.

- The Army will use the new authority in 10 U.S.C. 12304b, which allows the Secretary of the Army to order RC units to active duty under certain conditions.

Questions for Army subject matter experts:

1. What is your role in implementing the ATFP?

a. Which of the policy objectives and regulatory changes does this include?

2. For each of the relevant policy objectives:

a. To what extent has this objective been implemented to date?

b. What additional implementation activities are currently ongoing?

c. Are there any data sources you would recommend to help create metrics for the Army's progress in meeting this objective? 
d. Are there any legal, policy, regulatory, cultural, or other types of barriers to implementing this policy objective?

e. Are there any legal, policy, regulatory, cultural or other types of changes that are needed to enable the Army to meet this policy objective?

f. Should this policy objective be modified or adjusted to better fit the Army's current operating and budgetary environment or to better meet the overall objective of a more integrated total force?

3. For each of the regulatory changes:

a. Has the regulation been changed as indicated?

b. If so, what was the substance of the change?

i. What was the process for changing the regulation?

ii. What Army organizations were involved?

iii. How long did it take?

iv. Is the regulatory change actually changing the way things are done?

c. If not, is there any current activity ongoing to make or approve changes to the regulation?

i. What are the reasons for this delay, e.g., difficulty reaching consensus on the changes, slow approval process, etc.?

ii. Does this regulatory change still make sense in the Army's current operating and budgetary environment? If not, how should it be modified to better meet the overall objective of a more integrated total force?

4. Has the Army used the authority in 10 U.S.C. 12304 b that allows the Secretary of the Army to order RC units to active duty under certain conditions?

a. If yes, please give some examples of when it has been used. How many individuals have been mobilized under this authority?

b. If no, why has it not yet been used?

5. Are you familiar with any recommendations of the National Commission on the Future of the Army that are related to the policy objectives of the ATFP? 
a. To what extent do these recommendations reinforce or contradict the policy objectives of the ATFP?

b. Do you think that any changes to the ATFP are needed in light of these recommendations?

6. Are there any other changes to the ATFP that you would recommend to better meet the overall objective of a more integrated total force? 


\title{
Department of Defense Directive 1200.17, Managing the RCs as an Operational Force
}

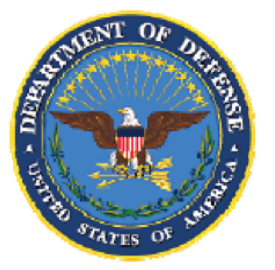

\author{
Department of Defense \\ DIRECTIVE
}

SUBJECT: Managing the Reserve Components as an Operational Force

References: (a) Title 10, United States Code

(b) Title 32, United States Code

(c) Joint Publication 1-02, "Department of Defense

Dictionary of Military and Associated Terms," as amended

1. PURPOSE. This Directive establishes the overarching set of principles and policies to promote and support the management of the Reserve Components (RCs) as an operational force.

2. APPLICABILITY. This Directive applies to OSD, the Military Departments, the Office of the Chairman of the Joint Chiefs of Staff and the Joint Staff, the Combatant Commands, the Office of the 
Inspector General of the Department of Defense, the Defense Agencies, the DoD Field Activities, and all other organizational entities in the Department of Defense.

\section{DEFINITIONS. See Glossary.}

4. POLICY. It is DoD policy that:

a. The RCs provide operational capabilities and strategic depth to meet U.S. defense requirements across the full spectrum of conflict including under sections 12301, 12302, 12304, and 12306 of Reference (a).

b. The Active Components (ACs) and RCs are integrated as a total force based on the attributes of the particular component and individual competencies.

c. Homeland Defense and Defense Support to Civil Authorities (DSCA) are total force missions. Unity of effort is maintained consistent with statutory responsibilities in operations involving Federal forces and non-federalized National Guard forces with Federal forces under Federal command and control and non-federalized National Guard forces under State command and control.

d. The RCs provide connection to and commitment of the American public.

e. The continuum of service is utilized to enhance the effectiveness of and sustain the all- volunteer force with flexible service options that are attractive to a broad population.

f. Utilization rules are implemented to govern frequency and duration of activations. Since expectation management is critical to the success of the management of the RCs as an operational force, these rules enhance predictability and judicious and prudent use of the RCs. 
g. Voluntary duty, per section 12301(d) of Reference (a) and section 502(f)(2) of title 32, United States Code (Reference (b)), is encouraged to meet mission requirements.

h. The RCs are resourced to meet readiness requirements per sections 3013, 5013, and 8013 of Reference (a). RC resourcing plans shall ensure visibility to track resources from formulation, appropriation, and allocation through execution.

i. Outreach services are established and available for RC members, their families, and employers from pre-activation through reintegration.

5. RESPONSIBILITIES. See Enclosure.

6. RELEASABILITY. Unlimited. This Directive is approved for public release. Copies may be obtained through the Internet from the DoD Issuances Web Site at http://www.dtic.mil/whs/directives.

7. EFFECTIVE DATE. This Directive is effective immediately.

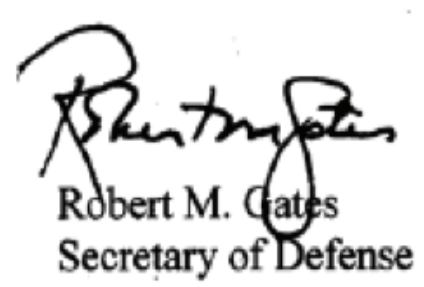

Enclosure

Responsibilities

Glossary 


\section{ENCLOSURE}

\section{RESPONSIBILITIES}

\section{UNDER SECRETARY OF DEFENSE FOR PERSONNEL AND READINESS (USD(P\&R)). The USD(P\&R) shall:}

a. Ensure DoD policies support the planning, organization, and utilization of the RCs to provide operational capabilities and strategic depth across the full spectrum of conflict.

b. Provide guidance and oversight for the development of programs.

c. Provide guidance and oversight for employer and family support programs that fully integrate $\mathrm{AC}$ and $\mathrm{RC}$ requirements.

d. Ensure that total force policies encourage optimum integration of AC and RC personnel to provide the most efficient training opportunities to all personnel, allow for shared use of resources, and provide the most operational benefits and mission capability.

e. Ensure that total force assignment policies encourage the consideration of RC members to serve in key senior leadership positions throughout the Department of Defense.

f. Develop performance targets (measures and milestones) in conjunction with the Secretaries of the Military Departments for the Reserve operating forces in the development of the DoD annual performance budget.

2. ASSISTANT SECRETARY OF DEFENSE FOR RESERVE AFFAIRS (ASD(RA)). The ASD(RA), under the authority, direction, and control of the USD $(P \& R)$, shall: 
a. Develop policies for managing the RCs as an operational force, which is a necessity in an era of persistent conflict and global engagement.

b. Coordinate and develop policies that promote use of total force capabilities in support of domestic disaster response without interference with core defense missions.

c. Ensure that sufficient guidance exists to guide Service implementation of the continuum of service concept.

d. Develop policies that provide compensation, benefits, and incentives to sustain the all-volunteer force that are commensurate with the service provided and encourage Service members to continue to serve.

e. Ensure that family and employer support outreach programs are sufficient to sustain the all-volunteer force.

\section{ASSISTANT SECRETARY OF DEFENSE FOR HEALTH} AFFAIRS (ASD(HA)). The ASD(HA), under the authority, direction, and control of the USD(P\&R), shall:

a. Ensure policies are in place to support medical and dental readiness such that RC members comply with required medical and dental standards pre-activation through deactivation.

b. Ensure policies are in place to provide RC members and their families appropriate medical, dental, and mental health services consistent with DoD programs to provide support to America's wounded, ill, and injured Service members.

\section{UNDER SECRETARY OF DEFENSE FOR POLICY (USD(P)).} The USD $(\mathrm{P})$ shall establish policies and develop procedures to ensure the RCs have operational capabilities and strategic depth to meet U.S. defense requirements across the full spectrum of conflict. 
5. ASSISTANT SECRETARY OF DEFENSE FOR HOMELAND DEFENSE AND AMERICAS' SECURITY AFFAIRS (ASD(HD\&ASA)). The ASD(HD\&ASA), under the authority, direction, and control of the USD $(\mathrm{P})$, shall:

a. Develop policies and procedures and provide guidance and oversight to ensure the RCs have operational capabilities and strategic depth to meet U.S. homeland defense and DSCA requirements across the full spectrum of missions while preserving unity of effort consistent with applicable law and authority.

b. Advocate resource requirements identified with homeland defense and DSCA.

6. UNDER SECRETARY OF DEFENSE (COMPTROLLER)/ CHIEF FINANCIAL OFFICER, DEPARTMENT OF DEFENSE (USD(C)/CFO). The USD(C)/CFO shall:

a. Provide requirements and instructions to the Department of Defense and Services regarding program and budget justification materials for Program/Budget Review and submission to the Congress.

b. Assess Military Department compliance against the performance targets throughout the planning, programming, budgeting, and execution (PPBE) process.

7. UNDER SECRETARY OF DEFENSE FOR ACQUISITION, TECHNOLOGY, AND LOGISTICS (USD(AT\&L)). The USD(AT\&L) shall establish policies and develop procedures to ensure the RCs are managed as an effective operational force for all matters related to the DoD Acquisition System; research and development; advanced technology; integrated test and evaluation; production; logistics; installation management; military construction; procurement; environmental security; and nuclear, chemical, and biological matters. 
8. UNDER SECRETARY OF DEFENSE FOR INTELLIGENCE (USD(I)). The USD(I) shall provide guidance and oversight to the intelligence elements of the RCs and establish practices and develop procedures to ensure RCs are managed as an effective operational force.

9. DIRECTOR, PROGRAM ANALYSIS AND EVALUATION (PA\&E). The Director, PA\&E, shall:

a. Prepare programmatic guidance on which the Future Years Defense Program is based. Prepare fiscal guidance in coordination with the USD(C)/CFO.

b. Manage the program review phase of the PPBE system, including serving as the Executive Secretary to the senior group advising the Secretary and Deputy Secretary of Defense on program review issues and as Chair of the group charged with overseeing the development of those issues.

10. SECRETARIES OF THE MILITARY DEPARTMENTS. The Secretaries of the Military Departments shall:

a. Implement the provisions of this Directive.

b. Manage their respective RCs as an operational force such that the RCs provide operational capabilities while maintaining strategic depth to meet U.S. military requirements across the full spectrum of conflict.

c. Ensure that the RCs participate across the full spectrum of missions at home and abroad in providing operational capabilities according to the national defense strategy, their Service force management plans, and operational requirements. To the extent practicable and consistent with the Services' organizational constructs, ensure unit integrity is maintained, to include unit leadership positions when RC units are utilized to fulfill operational requirements. 
d. Ensure that, while providing strategic depth, RC units and individuals train and are available for missions in accordance with the national defense strategy.

e. Ensure the total force and non-federalized National Guard forces, through coordination with the National Guard Bureau, have capabilities useful for domestic disaster response and are utilized in accordance with applicable Federal rules, without interference with defense missions.

f. Ensure RC forces meet operational readiness requirements as identified by the President and the Secretary of Defense.

g. Ensure sufficient depth of RC unit and individual capabilities to meet established DoDforce utilization goals.

h. Ensure force rebalancing is conducted on a continuing basis to adjust force structure and individual skill inventories to meet full spectrum operations while moderating excessive utilization of the total force. Such rebalancing shall result in a force mix that takes into account AC and RC capabilities and capacities.

i. Integrate $\mathrm{AC}$ and $\mathrm{RC}$ organizations to the greatest extent practicable, including the use of cross-component assignments, both AC to RC and RC to AC. Such assignments should be considered as career enhancing and not detrimental to a Service member's career progression.

j. Align, to the extent practicable, force structure with established DoD goals for frequency and duration of utilization for unit and individuals.

k. Ensure the appropriate level of full-time support personnel -AC, Active Guard and Reserve, military technicians (dual-status), nondual status technicians, and other Federal civilian employees -- to meet the readiness requirements of the RCs. 
1. Implement the continuum of service construct in ways that sustain the all-volunteer force and the willingness of individuals to serve.

(1) Provide flexible service options, consistent with DoD policies, making military duty attractive to a broad population.

(2) Execute the appropriate range of compensation, benefits, and incentives to sustain the all-volunteer force commensurate with the service provided. This encourages Service members to continue to serve.

(3) Implement utilization rules for voluntary and involuntary service that are clear and effectively communicated. Implement related expectation management programs to provide members, families, and employers maximum predictability and planning consistent with operational requirements.

m. To facilitate the sustainment of volunteerism:

(1) Provide opportunities for and encourage the performance of military duty beyond minimum participation requirements, consistent with Service needs.

(2) Provide flexible participation options that conform to mission requirements.

(a) As appropriate, provide monetary and non-monetary incentives to increase the level of participation above and beyond minimum requirements.

(b) Offer choices among available incentives according to individual preferences to accomplish force management objectives. 
(c) Execute Military Service agreements and incentives to ensure the availability of individuals who may be needed on short notice to meet mission requirements.

n. Program and execute resources where required to support a "train-mobilize-deploy" construct. Funds for training and equipment must be provided to coincide with the Services' force planning cycle and enable an effective pre- and post-mobilization training and deployment process.

(1) Ensure that resources support medical and dental readiness such that RC members comply with required medical and dental standards pre-activation through deactivation.

(2) Ensure resources are provided in a timely manner to ensure effective execution to meet mission requirements.

(3) Ensure procurement programs and processes provide visibility and accountability of RC equipment in the Program/ Budget justification materials through the timely execution of funds and distribution of procured assets.

(4) Ensure facilities and training areas are available to support $\mathrm{RC}$ training requirements.

(5) Ensure legal assistance resources are available to support the activation of military personnel.

o. Accelerate modernization while balancing the need for restoring immediate readiness through recapitalization with the imperative to prepare for future conflicts with more advanced adversaries.

p. Ensure RC forces have been considered for sourcing Combatant Commands' requests for forces. 


\section{GLOSSARY}

\section{DEFINITIONS}

Unless otherwise noted, these terms and their definitions are for the purposes of this Directive.

Continuum of service. Management policies supported by appropriate statutes, benefit and compensation options, and agreements that facilitate transparent movement, to the extent possible, of individuals between active military, reserve military, and civilian service. These management policies provide variable and flexible service options and levels of participation, and are consistent with DoD manpower requirements and each individual's ability to serve over the course of a lifetime of service.

Homeland defense. The protection of United States sovereignty, territory, domestic population, and critical defense infrastructure against external threats and aggression or other threats as directed by the President. As defined in Joint Publication 1-02 (Reference (c)).

RCs as an operational force. The RCs provide operational capabilities and strategic depth to meet U.S. defense requirements across the full spectrum of conflict. In their operational roles, RCs participate in a full range of missions according to their Services' force generation plans. Units and individuals participate in missions in an established cyclic or periodic manner that provides predictability for the combatant commands, the Services, Service members, their families, and employers. In their strategic roles, $\mathrm{RC}$ units and individuals train or are available for missions in accordance with the national defense strategy. As such, the RCs provide strategic depth and are available to transition to operational roles as needed.

Reserve Components. The Reserve Components of the armed forces are: (1) The Army National Guard of the United States. (2) The 
Army Reserve. (3) The Navy Reserve. (4) The Marine Corps Reserve. (5) The Air National Guard of the United States. (6) The Air Force Reserve. (7) The Coast Guard Reserve. (As defined in section 10101 of Reference (a).)

Total force. The AC and RC military elements of the total force.

Train-mobilize-deploy construct. A Service implemented model designed to train and certify individual skills and limited unit collective training prior to mobilization to achieve a prescribed level of readiness in order to limit post-mobilization training and maximize operational deployment time.

Voluntary duty. Duty performed by RC members who request or indicate willingness to accept orders for active duty beyond any active duty obligation. 


\section{Army Total Force Policy}

SUBJECT: Army Directive 2012-08 (Army Total Force Policy)

1. References:

a. Title 5, United States Code (Government Organizations and Employees).

b. Title 10, United States Code (Armed Forces).

c. Title 32, United States Code (National Guard).

d. Memorandum, Secretary of Defense, 19 Jan 07, subject: Utilization of the Total Force.

e. Department of Defense (DoD) Directive 1200.17 (Managing the Reserve Components as an Operational Force), 29 Oct 08. 
f. DoD Directive 1235.10 (Activation, Mobilization, and Demobilization of the Ready Reserve), Incorporating Change 1, 21 Sep 11.

g. DoD Directive 5100.01 (Functions of the Department of Defense and Its Major Components), 21 Dec 10.

2. This directive establishes policy for the integration of the Army's active component (AC) and reserve component (RC) as a "Total Force." DoD policies require the military departments to organize, man, train and equip their active and reserve components as an integrated operational force to provide predictable, recurring and sustainable capabilities. The Total Force must be part of Army strategy and planning to fulfill national military needs.

3. Army policy is that:

a. As one Total Force, the Active Army, Army National Guard and U.S. Army Reserve provide operating and generating forces to support the National Military Strategy and Army commitments worldwide.

b. The Army will ensure that the Total Force is organized, trained, sustained, equipped and employed to support combatant commander requirements as force packages tailored to achieve anticipated objectives.

c. As appropriate, the Army will integrate AC and RC forces and capabilities at the tactical level (division and below), consistent with the Secretary of Defense's policies for use of the Total Force (reference 1d). This will include some predeployment collective training of tactical-level organizations, including for those organizations that will routinely deploy as multicomponent forces (for example, sustainment brigades and other multifunctional support brigades).

d. Army Commands and Army Service Component Commands will ensure that the procedures and processes for validating the predeployment readiness of assigned forces are uniform for AC and RC 
units and Soldiers. Army commanders will be responsible for certifying personnel readiness and individual training for assigned personnel. Standards for qualification and professional development will be the same for AC and RC personnel.

e. The Army will streamline the voluntary and involuntary call to active duty of RC personnel and units to rapidly expand and sustain Total Army capabilities.

f. The Army's equipping strategy will ensure that procurement and equipping processes enable the Total Force to perform the missions of the Department of the Army.

g. The Army will employ an integrated personnel management and pay system that contains standardized business processes and authoritative data for military personnel, enabling access to secure and reliable data. Personnel policies shall incorporate Total Force values and facilitate continuum of service and opportunities for joint experiences.

4. Implementation of this policy requires the following actions:

a. Amend Army Regulation (AR) 71-11 (Total Army Analysis) to include an annual analysis of force structure options, including the mix of operating and generating force capabilities between the AC and RC, for the Secretary of the Army to consider and approve in support of the Army's future force and to meet Secretary of Defense planning objectives. The amended regulation shall require that the Assistant Secretary of the Army (Manpower and Reserve Affairs), in coordination with the Deputy Chief of Staff, G-3/5/7, report any military capabilities that are insufficient in numbers or type to meet Secretary of Defense planning objectives for the Total Force and provide recommendations to the Secretary of the Army. In accordance with AR 71-11, the Secretary of the Army and Chief of Staff, Army annually approve the Army's Program Objective Memorandum Force. 
b. Amend AR 525-29 (Army Force Generation) to direct that available forces (mission force and surge force) are prepared to deploy as integrated expeditionary forces, to the maximum extent possible, in accordance with Global Force Management requirements. The amended regulation shall require that the Assistant Secretary of the Army (Manpower and Reserve Affairs), in coordination with the Deputy Chief of Staff, G-3/5/7, develop a common set of standards and procedures for the validation of readiness. Within the parameters of global security conditions and combatant commander requirements, the Army shall use a common deployment cycle (Army Deployment Period) for named operations, approved by the Secretary of the Army, to facilitate the integration of AC and RC forces in support of operations. The Chief of Staff, Army provides advice to the Secretary with regard to such plans and, after approval of the plans or recommendations, acts as the agent of the Secretary in carrying them into effect.

c. Amend AR 500-5 (Army Mobilization) and the Army Mobilization Operations, Planning and Execution System to conform with this policy. The amended regulation shall require that the Assistant Secretary of the Army (Manpower and Reserve Affairs), in coordination with the Deputy Chief of Staff, G-3/5/7, streamline the mobilization process to rapidly provide RC capabilities to support the Total Force and perform Army missions.

d. Consolidate or eliminate Department of the Army publications (Series 135 (Army National Guard of the United States and Army Reserve), Series 140 (Army Reserve), Series 350 (Training) and Series 600 (Personnel-General) to conform with the guidance in this directive. All components will collaborate in the development, administration and execution of publications to ensure streamlining while addressing the uniqueness of the component and leveraging their subject matter expertise.

e. To help achieve these ends, the Army will use the new authority provided by 10 United States Code section 12304b, which allows the Secretary of the Army to order RC units to active duty under cer- 
tain conditions. This directive, coupled with this new Reserve call-up authority, will allow the Army to benefit from the shared experiences of the last decade of war.

5. This policy is effective immediately and applies to all components.

6. The Assistant Secretary of the Army (Manpower and Reserve Affairs) is the proponent for this policy.

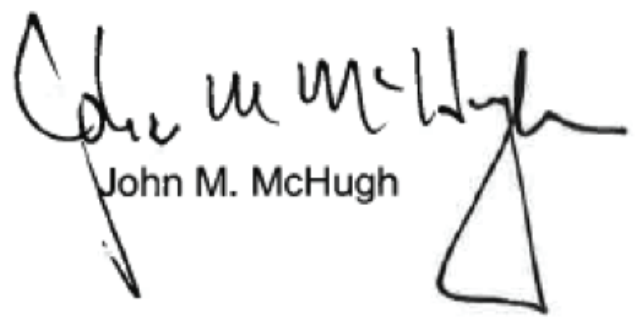

\section{DISTRIBUTION:}

Principal Officials of Headquarters, Department of the Army Commander

U.S. Army Forces Command

U.S. Army Training and Doctrine Command

U.S. Army Materiel Command

U.S. Army Europe

U.S. Army Central

U.S. Army North

U.S. Army South

U.S. Army Pacific

U.S. Army Africa

U.S. Army Special Operations Command Military Surface Deployment and Distribution Command 
U.S. Army Space and Missile Defense Command/Army Strategic Command

U.S. Army Network Enterprise, Technology Command/9th Signal Command (Army)

U.S. Army Medical Command

U.S. Army Intelligence and Security Command

U.S. Army Criminal Investigation Command

U.S. Army Corps of Engineers

U.S. Army Military District of Washington

U.S. Army Test and Evaluation Command

U.S. Army Installation Management Command

Superintendent, United States Military Academy

Director, U.S. Army Acquisition Support Center

CF:

Commander, U.S. Army Cyber Command

Director, Business Transformation

Director, Army National Guard 


\section{Additional Data on Equipping Rates for Selected Unit Types}

This appendix provides additional comparisons of equipment assigned to AC, ARNG, and USAR infantry battalions, MP companies, and transportation companies using data from the AE2S as of June 2016. Figure D.1 shows the median percentage of authorized equipment on hand by dollar value, excluding substitutes, for pacing items and other essential equipment (Equipment Readiness Codes $\mathrm{P}$ and $\mathrm{A})^{1}$ for various types of MP companies. ${ }^{2}$ The number of units of each type is shown above the columns. The total number of items and dollar value of authorized equipment for each unit type is shown at the bottom of the figure. The authorized equipment for the three types of MP companies is fairly similar across components, but combat support MP companies have both more and higher-valued authorized equipment than guard and internment/resettlement companies. Equipping rates are also higher for combat support MP companies than the other two types, and higher for AC units than for ARNG and USAR units.

Figure D.2 shows the median percentage of authorized equipment on hand by dollar value, excluding substitutes, for various types of transportation companies. Except for composite heavy and heavy

\footnotetext{
1 We exclude the value of items greater than the number authorized and the value of items whose quantities on hand, no substitutes are above the quantities on hand including substitutes.

2 One caveat to this analysis is that it does not fully reveal differences in equipment modernization across components, because in some cases, multiple national stock numbers can be used to fill the same authorized line item number. Those national stock numbers might represent different generations of equipment, such as different levels of armoring or earlier and later versions of automated systems that are not fully compatible with each other.
} 


\section{Figure D.1}

Median Percentage of Authorized Equipment on Hand, No Substitutes, by Dollar Value for Different Types of MP Companies

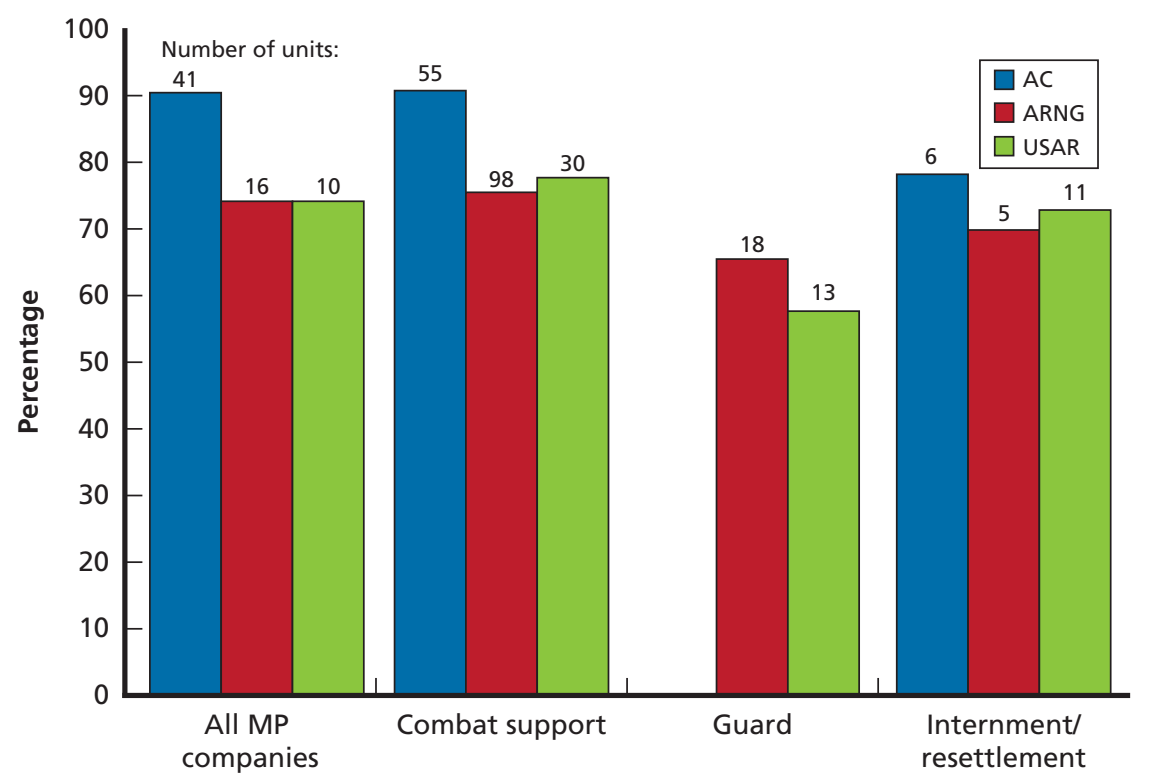

\begin{tabular}{|l|c|c|c|}
\hline $\begin{array}{l}\text { Authorized } \\
\text { number of items }\end{array}$ & $1,980-2,090$ & 1,250 & $530-550$ \\
\hline Authorized value & $\$ 31-33$ million & $\$ 9.1$ million & $\$ 2.8-4.4$ million \\
\hline
\end{tabular}

SOURCE: U.S. Army, 2016.

NOTE: Excludes on-hand > authorized.

RAND RR1958-D.1

equipment transport companies, the authorized amount and value of equipment is fairly similar across components for each unit type. However, equipping rates vary substantially by unit type and component, ranging from 84 percent for the median AC cargo transportation company to 51 percent for the median USAR palletized load system company. In addition, some types of transportation companies are found exclusively in one component or primarily in the RCs, such as cargo transportation companies; light-medium truck companies; palletized load system companies; and petroleum, oil, and lubricants companies. 
Figure D.2

Median Percentage of Authorized Equipment on Hand, No Substitutes, by Dollar Value for Different Types of Transportation Companies

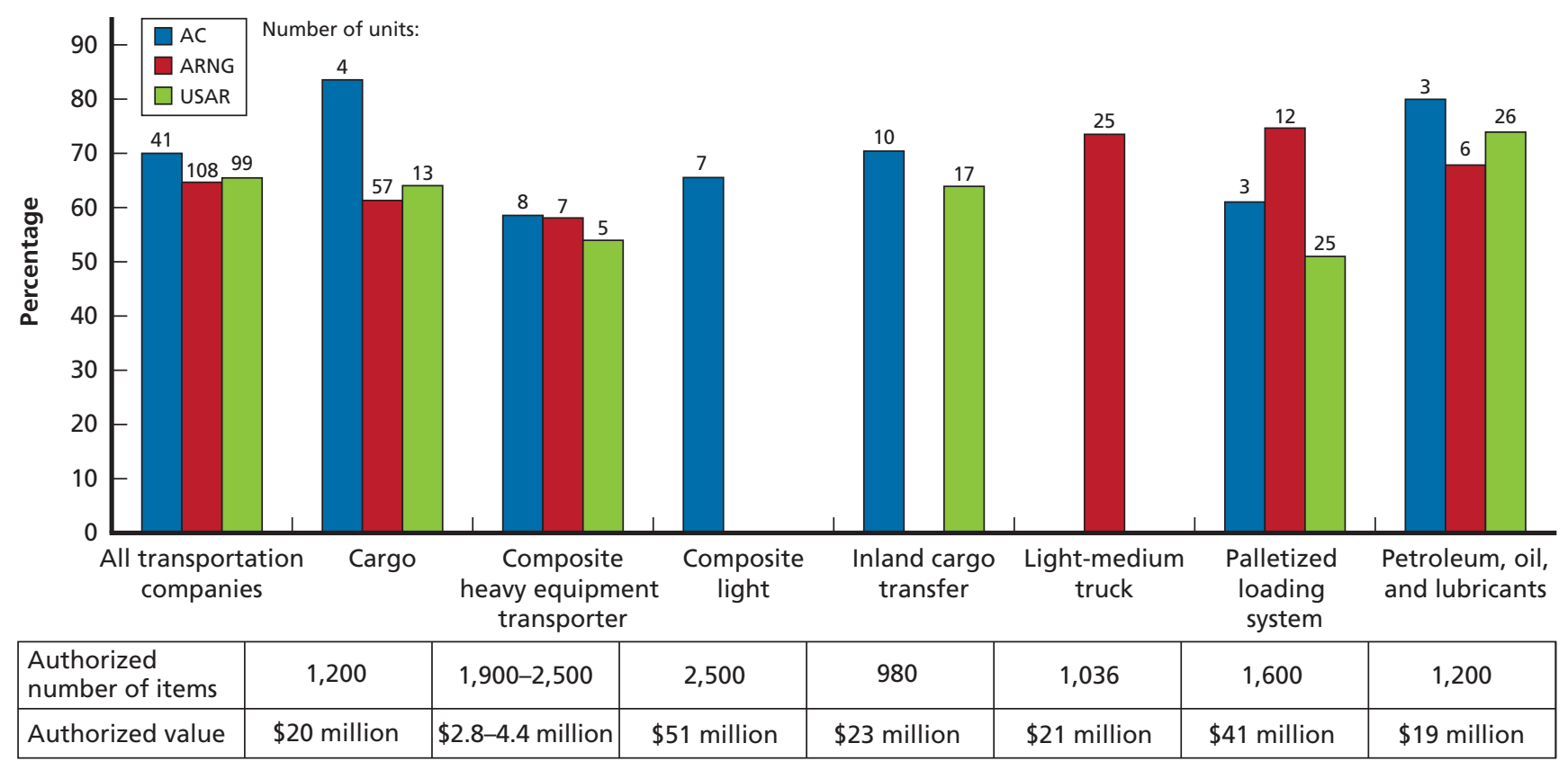

SOURCE: U.S. Army, 2016.

NOTE: Excludes on-hand > authorized.

RAND RR1958-D.2 
AE2S also provides information on the resourcing priority of units in a field called "DARPL BIN." A lower value of DARPL BIN indicates that the unit has higher priority for resources, including equipment, manning levels, and training. ${ }^{3}$ Therefore, we examined whether median equipping rates varied by component and DARPL BIN. The results of this analysis are shown in Figure D.3 for infantry battalions, Figure D.4 for MP companies, and Figure D.5 for transportation companies. We did not find any clear indication of higher equipping rates for higher-priority units, but some units with low priority (such as two AC MP companies in DARPL BIN 4 and one ARNG transportation company in DARPL BIN 9) had very low equipping rates.

Figure D.3

Median Percentage of Authorized Equipment on Hand, No Substitutes, by Dollar Value for Infantry Battalions by DARPL BIN

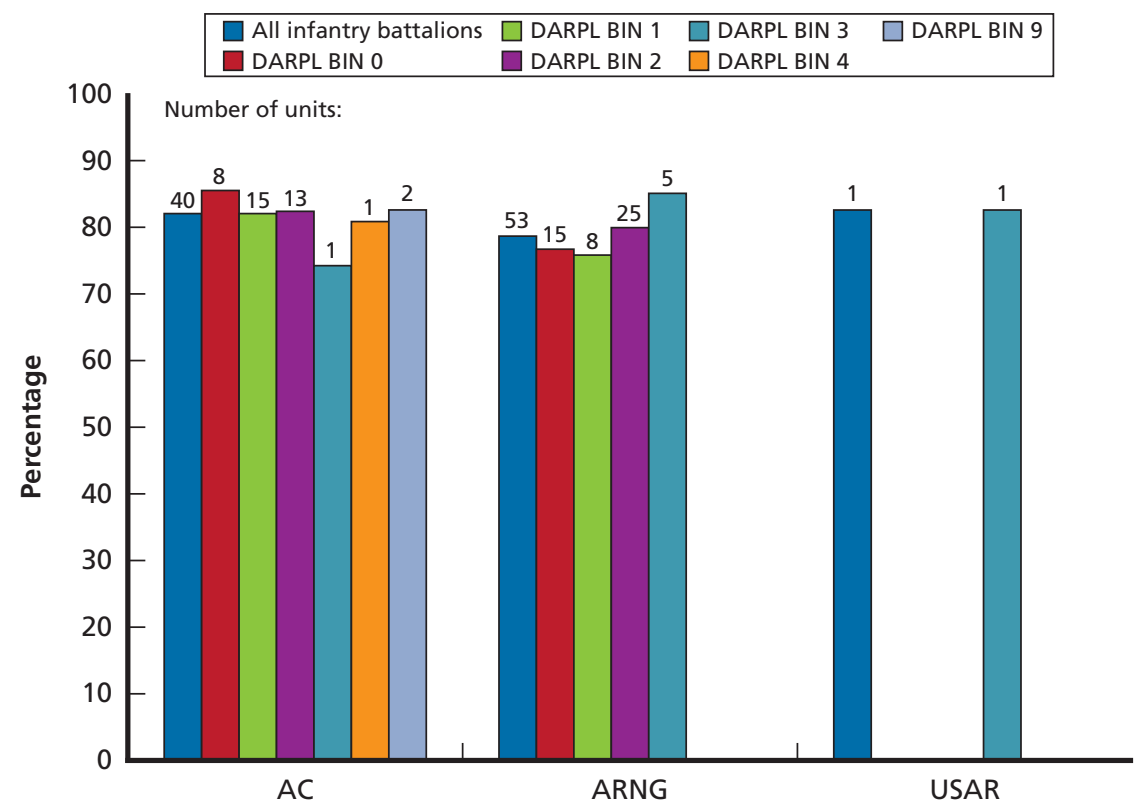

SOURCE: U.S. Army, 2016.

NOTE: Excludes on-hand > authorized.

RAND RR1958-D.3

3 Based on email communication with USAR G-4, September 14, 2016. 
Figure D.4

Median Percentage of Authorized Equipment on Hand, No Substitutes, by Dollar Value for MP Companies by DARPL BIN

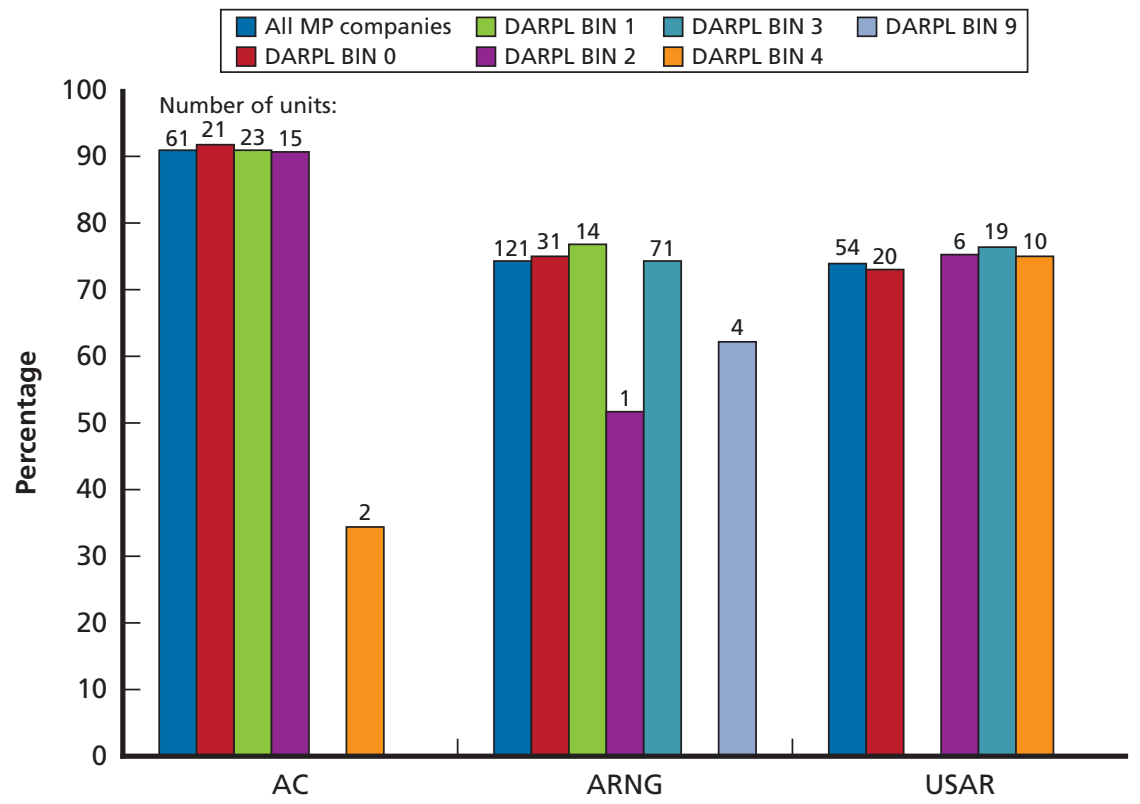

SOURCE: U.S. Army, 2016.

NOTE: Excludes on-hand > authorized.

RAND RR1958-D.4 


\section{Figure D.5}

Median Percentage of Authorized Equipment on Hand, No Substitutes, by Dollar Value for Transportation Companies by DARPL BIN

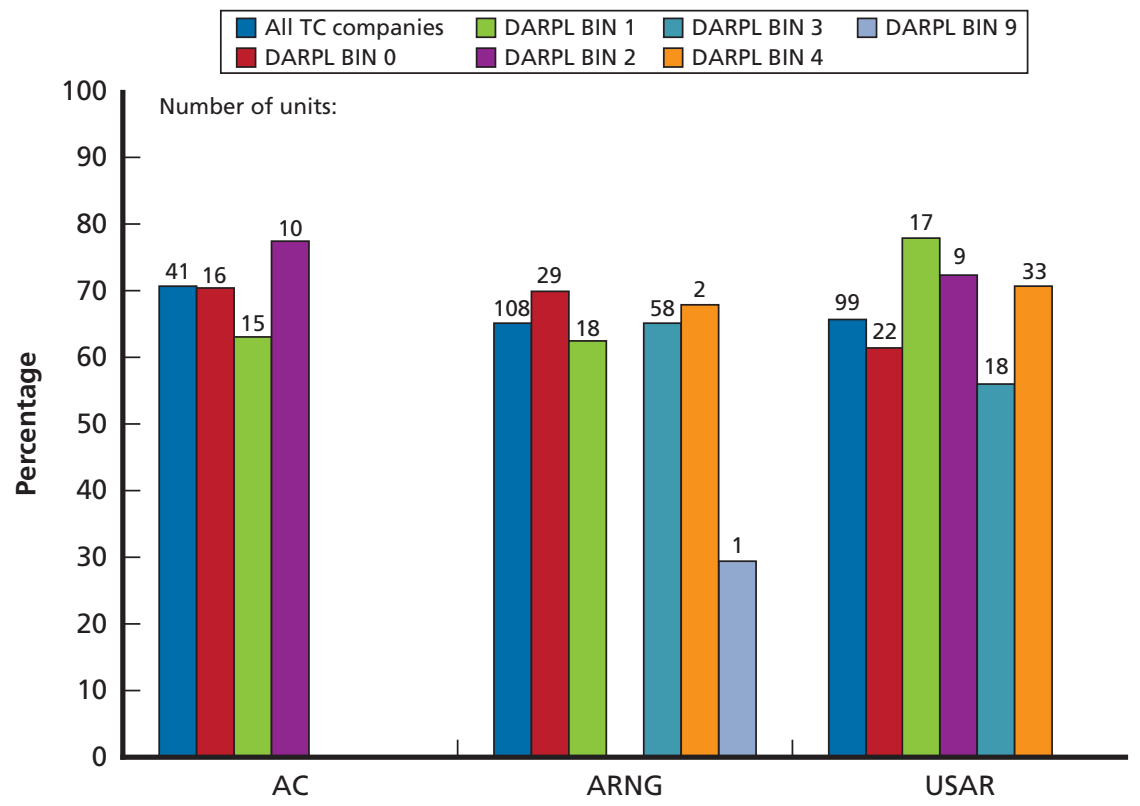

SOURCE: U.S. Army, 2016.

NOTE: Excludes on-hand > authorized.

RAND RR1958-D.5 


\section{Additional Data on Cross-Component Attendance at ALC and SLC}

In this appendix, we provide additional information on trends in crosscomponent attendance at ALCs and SLCs, based on our analysis of ATRRS data. Since ALCs and SLCs are branch-specific, we focus on soldiers in MOSs 11B and $11 \mathrm{C}$ in infantry battalions, MOSs 31B and $31 \mathrm{E}$ in MP companies, and MOS $88 \mathrm{M}$ in transportation companies. We compared a three-year period prior to the ATFP (FYs 2010-2012) with a more recent two-year period (FYs 2014-2015) to see whether cross-component integration had increased. Our results are summarized in Table E.1. The component of the soldiers is indicated by rows, while the component running the course and the time periods are shown in columns. For example, in FYs 2010-2012, 93.9 percent of AC soldiers in MOSs $11 \mathrm{~B}$ and $11 \mathrm{C}$ attended an AC-run course, and 6.1 percent attended an ARNG-run course. There were no USAR-run courses for these MOSs. 
Table E.1

Trends in Cross-Component Attendance at ALC and SLC

\begin{tabular}{|c|c|c|c|c|c|c|c|c|c|c|c|c|}
\hline & \multicolumn{4}{|c|}{ AC NCO Academy } & \multicolumn{4}{|c|}{ ARNG NCO Academy } & \multicolumn{4}{|c|}{ USAR NCO Academy } \\
\hline & \multicolumn{2}{|c|}{ ALC } & \multicolumn{2}{|c|}{ SLC } & \multicolumn{2}{|c|}{ ALC } & \multicolumn{2}{|c|}{ SLC } & \multicolumn{2}{|c|}{ ALC } & \multicolumn{2}{|c|}{ SLC } \\
\hline & $\begin{array}{c}\text { FYs } \\
2010- \\
2012\end{array}$ & $\begin{array}{c}\text { FYs } \\
2014- \\
2015\end{array}$ & $\begin{array}{c}\text { FYs } \\
2010- \\
2012\end{array}$ & $\begin{array}{c}\text { FYs } \\
2014- \\
2015\end{array}$ & $\begin{array}{c}\text { FYs } \\
2010- \\
2012\end{array}$ & $\begin{array}{c}\text { FYs } \\
2014- \\
2015\end{array}$ & $\begin{array}{c}\text { FYs } \\
2010- \\
2012\end{array}$ & $\begin{array}{c}\text { FYs } \\
2014- \\
2015\end{array}$ & $\begin{array}{c}\text { FYs } \\
2010- \\
2012\end{array}$ & $\begin{array}{c}\text { FYs } \\
2014- \\
2015\end{array}$ & $\begin{array}{c}\text { FYs } \\
2010- \\
2012\end{array}$ & $\begin{array}{c}\text { FYs } \\
2014- \\
2015\end{array}$ \\
\hline \multicolumn{13}{|c|}{ Infantry (MOS 11B and 11C) } \\
\hline$A C$ & 93.9 & 77.8 & 100 & 99.6 & 6.1 & 22.2 & 0 & 0.4 & 0 & 0 & 0 & 0 \\
\hline ARNG & 0 & 0.4 & 1.8 & 0.5 & 99.8 & 99.6 & 98.2 & 99.5 & 0 & 0 & 0 & 0 \\
\hline \multicolumn{13}{|c|}{ MP (MOS 31B and 31E) } \\
\hline$A C$ & 100.0 & 100.0 & 100.0 & 100.0 & 0 & 0 & 0 & 0 & 0 & 0 & 0 & 0 \\
\hline ARNG & 0 & 0 & 0 & 2.4 & 0 & 11.7 & 0 & 0 & 100.0 & 88.3 & 99.4 & 97.6 \\
\hline USAR & 0.7 & 0.9 & 11.9 & 14.8 & 0 & 5.6 & 0 & 0 & 99.3 & 93.5 & 88.1 & 85.2 \\
\hline \multicolumn{13}{|c|}{ Transportation (MOS 88M) } \\
\hline$A C$ & 100.0 & 100.0 & 100.0 & 100.0 & 0 & 0 & 0 & 0 & 0 & 0 & 0 & 0 \\
\hline ARNG & 1.2 & 1.3 & 1.9 & 1.8 & 0 & 1.3 & 0 & 0 & 98.8 & 97.4 & 98.1 & 98.2 \\
\hline USAR & 0.0 & 7.0 & 13.6 & 27.7 & 0 & 7.6 & 0 & 0 & 100 & 85.4 & 86.4 & 72.3 \\
\hline
\end{tabular}

SOURCE: U.S. Army, undated-a.

a Since the USAR has only one infantry battalion, there were ten or fewer soldiers attending ALCs or SLCs in each time period.

Therefore, we did not find any consistent trends and do not report the data. 
In comparison with BLCs, we found very little $\mathrm{AC}$ attendance at RC-run ALCs and SLCs, except for an increase in AC attendance at ARNG-run ALCs for infantry MOSs, from 6.1 percent of trainees in FYs 2010-2012 to 22.2 percent of trainees in FYs 2014-2015. Similarly, we found very little RC attendance at AC-run ALCs and SLCs. The exceptions are an increase in USAR attendance at AC-run courses for MOSs 31B, 31E, and 88M, particularly at SLCs for MOS $88 \mathrm{M}$, where 27.7 percent of USAR NCOs were trained at AC academies in FYs 2014-2015. In addition, most ARNG MPs and truck drivers attended USAR-run ALCs and SLCs (see lower right of table). However, in the FY 2014-2015 time period, the ARNG began to conduct some ALC training for these MOSs, so we begin to see some USAR attendance at ARNG courses during this period. 



\section{References}

AcqNotes, "DOTMLPF-P Analysis," September 17, 2014a. As of February 15, 2017:

http://www.acqnotes.com/acqnote/acquisitions/dotmlpf-analysis?print=1

AcqNotes, "Functional Solutions Analysis (FSA)," September 17, 2014b. As of February 15, 2017:

http://www.acqnotes.com/acqnote/acquisitions/

functional-solutions-analysis?print $=1$

AcqNotes, "JCIDS Process Overview," September 17, 2014c. As of February 15, 2017:

http://www.acqnotes.com/acqnote/acquisitions/jcids-overview?print=1

Air Force Reserve Command Force Generation Center, "Changes to DoD Mobilization Authority Could Impact Reservists," March 21, 2016. As of November 16, 2016:

http://www.arpc.afrc.af.mil/News/ArticleDisplay/tabid/267/Article/698148/ changes-to-dod-mobilization-authority-could-impact-reservists.aspx

APD—See Army Publishing Directorate.

Army Publishing Directorate, "APD: Army Publishing Directorate," undated. As of June 5, 2017:

http://www.apd.army.mil

Assistant Secretary of the Army, Financial Management and Comptroller, "FY 2017 President's Budget Highlights," February 2016.

Bailey, Ronald C., and Benjamin Crane, "100th Missile Defense Brigade: A Decade of Transformation and Missile Success," press release, Colorado Springs, Col., September 30, 2014. As of November 3, 2016:

https://www.army.mil/article/134856/

The_100th_Missile_Defense_Brigade_A_deade_of_transformation_and_ mission_success 
Barrows, James, "Evolution of Partnership," Fort Hood Sentinel, March 10, 2016. As of September 29, 2016:

http://www.forthoodsentinel.com/editorial/

evolution-of-partnership/article_631662cc-e611-11e5-964b-f78cd6cea513.html

Chairman of the Joint Chiefs of Staff, Instruction 5120.02D, Joint Doctrine

Development System, January 5, 2015. As of November 16, 2016 :

http://www.dtic.mil/doctrine/new_pubs/cjcsi5120_02d.pdf

Commission on the National Guard and Reserves, Commission on the National Guard and Reserves: Transforming the National Guard and Reserves into a 21st

Century Operational Force, Final Report to Congress and the Secretary of Defense, January 31, 2008. As of February 24, 2017:

https://www.loc.gov/rr/frd/pdf-files/CNGR_final-report.pdf

Connor, Kathryn, Carra S. Sims, Rianne Laureijs, Jaime L. Hastings, Kristin Van Abel, Kayla M. Williams, and Michael Schwille, Sustaining Service Members and Their Families: Exploring Opportunities for Efficiency and Joint Provision of Services Using Nonappropriated Funds, Santa Monica, Calif.: RAND Corporation, RR-1175-OSD, 2016. As of November 30, 2016:

http://www.rand.org/pubs/research_reports/RR1175.html

Correll, John T., "Origins of the Total Force" Air Force Magazine, February 2011, pp. 94-97. As of November 14, 2016:

http://www.airforcemag.com/MagazineArchive/Documents/2011/February\%20 2011/0211force.pdf

Cronk, Terri M., "DoD Official Endorses Army Plan to Train All Components," DoD News, October 14, 2014.

Currie, James T. "Senior Officer Professional Military Education as an Equalizer," Joint Forces Quarterly, Issue 59, 4th Quarter 2010, pp. 30-34. As of November 22, 2016:

http://www.dtic.mil/doctrine/jfq/jfq-59.pdf

Department of the Army, Army Regulation 71-11, Total Army Analysis (TAA), Washington, D.C., December 29, 1995. As of August 30, 2017: http://www.apd.army.mil/epubs/DR_pubs/DR_a/pdf/web/r71_11.pdf

Department of the Army, Army Regulation 71-32, Force Development and Documentation -Consolidated Policies, Washington, D.C., March 3, 1997. As of September 1, 2017:

http://www.apd.army.mil/epubs/DR_pubs/DR_a/pdf/web/r71_32.pdf

Department of the Army, Army Regulation 525-29, Army Force Generation, Washington, D.C., March 14, 2011. As of August 30, 2017 : http://www.apd.army.mil/epubs/DR_pubs/DR_a/pdf/web/r525_29.pdf

Department of the Army, Fiscal Year (FY) 2015 President's Budget Submission, Military Personnel, Army Justification Book, Washington, D.C., March 2014 a. 
Department of the Army, Pamphlet 600-3, "Commissioned Officer Professional Development and Career Management," Washington, D.C., December 3, 2014 b. As of July 18, 2017:

https://www.army.mil/e2/c/downloads/376665.pdf

Department of the Army, Fiscal Year (FY) 2016 President's Budget Submission, Military Personnel, Army Justification Book, Washington, D.C., February 2015a.

Department of the Army, Army Regulation 500-5, Army Mobilization, Washington, D.C., April 16, 2015b. As of February 24, 2017: http://www.apd.army.mil/pdffiles/r500_5.pdf

Department of the Army, Fiscal Year (FY) 2017 President's Budget Submission, Military Personnel, Army Justification Book, Washington, D.C., February 2016a.

Department of the Army, Army Regulation 140-145, Individual Mobilization Augmentation, Washington, D.C., March 21, 2016b. As of August 30, 2017: http://www.apd.army.mil/epubs/DR_pubs/DR_a/pdf/web/r525_29.pdf

Department of the Army, Fiscal Year (FY) 2018 Budget Estimates, Volume I: Operation and Maintenance, Army, Justification of Estimates, Washington, D.C. May 2017a. As of July 18, 2017: https:/www.asafm.army.mil/documents/BudgetMaterial/fy2018/oma-v1.pdf

Department of the Army, Fiscal Year (FY) 2018 Budget Estimates, Volume I: Operation and Maintenance, Army National Guard, Justification of Estimates, Washington, D.C. May 2017b. As of July 18, 2017: https://www.asafm.army.mil/documents/BudgetMaterial/fy2018/omng-vl.pdf

Department of the Army, Fiscal Year (FY) 2018 Budget Estimates, Volume I: Operation and Maintenance, Army Reserve, Justification of Estimates, Washington, D.C. May 2017c. As of July 18, 2017: https://www.asafm.army.mil/documents/BudgetMaterial/fy2018/omar-v1.pdf Deputy Assistant Secretary of the Army, Training, Readiness, Mobilization, "Army Total Force Policy Implementation: Secretary of the Army Quarterly Update," February 26, 2016.

Dunn, Richard J. III, “America’s Reserve and National Guard Components: Key Contributors to U.S. Military Strength," 2016 Index of U.S. Military Strength, Washington, D.C.: Heritage Foundation, October 2015. As of February 14, 2017: http://index.heritage.org/military/2016/essays/ americas-reserve-and-national-guard-components/

Fanning, Eric K., "Memorandum: Removal of the 100th Battalion, 442nd Infantry Regiment from the Associated Units Pilot," Washington, D.C., December 5, 2016. 
Farrell, Brenda S., "DoD Systems Modernization: Maintaining Effective Communication Is Needed to Help Ensure the Army's Successful Deployment of the Defense Integrated Military Human Resource System," Washington, D.C.: U.S. Government Accountability Office, GAO-08-927R, September 8, 2008. As of November 30, 2016:

http://www.gao.gov/products/GAO-08-927R

Feickert, Andrew, National Commission on the Future of the Army (NCFA): Background and Issues for Congress, Washington, D.C., Congressional Research Service, February 5, 2016. As of February 14, 2017: https://fas.org/sgp/crs/natsec/R44366.pdf

FORSCOM-See U.S. Army Forces Command.

Freedberg, Sydney J. Jr., "Guard Cheers Army Chief Milley: Budget Civil War Seems Over," Breaking Defense, September 12, 2016. As of March 3, 2017: http://breakingdefense.com/2016/09/ guard-chiefs-army-chief-milley-budget-civil-war-seems-over/

Garamone, Jim, "Carter Details Force of the Future Initiatives," press release, U.S. Department of Defense, Washington, D.C., November 18, 2015. As of February 14, 2017: https://www.defense.gov/News/Article/Article/630400/ carter-details-force-of-the-future-initiatives

Greenhill, Jim, “General Milley: 'There Is Only One Army,”” press release, Washington, D.C., September 25, 2015. As of October 24, 2016: https://www.army.mil/article/155850/ General_Milley___There_is_only_one_Army_/

Headquarters, Department of the Army, Execution Order 042-014, "Certification, Confirmation, and Validation Process for Employing Army Forces (Active Component and Reserve Component)," January 2014.

Henry, Devin, "Lean Times at the Pentagon Pit Active-Duty Army Against National Guard,” MinnPost, March 27, 2015. As of February 14, 2017: https:/www.minnpost.com/dc-dispatches/2015/03/ lean-times-pentagon-pit-active-duty-army-against-national-guard

Howlett, Darryl, First Army, "First Army Provides Training Support During 2016 MIBT Exercise at Fort Hood,” press release, Rock Island Arsenal, Ill., June 2, 2016. As of November 7, 2016: https://www.army.mil/article/169071/ first_army_provides_training_support_during_2016_mibt_exercise_at_fort_hood Judson, Jen, "U.S. Army Tests Combined Active-Reserve Aviation Units," Defense News, January 30, 2016. As of August 29, 2017: https://www.defensenews.com/land/2016/01/30/ us-army-tests-active-reserve-aviation-units/ 
Knotts, John R., “Assessing Your Organization Using the Military's DOTMLPFFREE Assessment," February 8, 2014. As of February 15, 2017:

https://johnrknotts.wordpress.com/2014/02/08/

assessing-your-organization-using-the-militarys-dotmlpf-free-assessment/

Marlow, W. Wayne, "First Army-Designed Exercise Replicates Combat Training

Center Rotation,” press release, Fort Drum, N.Y., June 23, 2015. As of November 7, 2016:

https://www.army.mil/article/151005/

First_Army_designed_exercise_replicates_combat_training_center_rotation

Mattock, Michael G., Beth J. Asch, and James Hosek, Making the Reserve

Retirement System Similar to the Active System: Retention and Cost Estimates, Santa

Monica, Calif.: RAND Corporation, RR-530-A, 2014. As of December 2, 2016:

http://www.rand.org/pubs/research_reports/RR530.html

McCarthy, Dennis M., "A Continuum of Service," Armed Forces Journal,

September 1, 2008. As of November 22, 2016:

http://armedforcesjournal.com/a-continuum-of-service/

McHugh, John M., "Army Directive 2012-19 (Elimination of the Oath of Office Requirement When Transferring from the Active-Duty List to the Reserve ActiveStatus List)," Washington, D.C., July 16, 2012 a.

McHugh, John M., "Army Directive 2012-08 (Army Total Force Policy)," Washington, D.C., September 4, 2012 b.

McHugh, John M., "Memorandum: Implementation of Army Total Force Policy," memorandum to U.S. Army Forces Command et al., Washington, D.C., September 25, 2013. As of September 1, 2017:

http://www.apd.army.mil/epubs/DR_pubs/DR_a/pdf/web/ad2012_08.pdf

McHugh, John M., "Memorandum: Army Total Force Policy (ATFP)

Implementation Guidance," memorandum to U.S. Army Forces Command et al., Washington, D.C., October 16, 2014. As of September 1, 2017:

http://www.apd.army.mil/epubs/DR_pubs/DR_a/pdf/web/ad2012_08.pdf

Military Compensation and Retirement Modernization Commission, Final Report, Washington, D.C., January 29, 2015. As of November 21, 2016: http://www.ngaus.org/sites/default/files/MCRMC\%202015_0.pdf

Murphy, Patrick, Acting Secretary of the Army, "Memorandum: Designation of Associated Units in Support of Army Total Force Policy,” March 21, 2016.

Nagl, John A. and Travis Sharp, "Operational for What? The Future of the Guard and Reserves," Joint Forces Quarterly, Issue 59, 4th Quarter 2010, pp. 21-29. As of November 17, 2016:

http://www.dtic.mil/doctrine/jfq/jfq-59.pdf 
National Commission on the Future of the Army, Report to the President and the Congress of the United States, Arlington, Va., January 28, 2016. As of

November 16, 2016:

http://www.ncfa.ncr.gov/sites/default/files/NCFA_Full\%20Final\%20Report_0.pdf

National Commission on the Future of the Army Council of Colonels, "National

Commission on the Future of the Army Council of Colonels," briefing, August 10, 2016.

National Commission on the Future of the Army Force Generation

Subcommittee, "Force Generation Subcommittee Meeting Minutes," Arlington, Va., August 18, 2015. As of July 18, 2017:

http://www.ncfa.ncr.gov/sites/default/files/Force\%20Generation $\% 20$

subcommittee\%2018\%20Aug\%2015\%20Minutes.pdf

National Commission of the Future of the Army Operation Subcommittee, "The Total Force Policy and Integration of Active and Reserve Units (Multiple Component Units-MCU)," December 17, 2015. As of September 29, 2016: http://www.ncfa.ncr.gov/sites/default/files/

Operational $\% 20$ Subcommittee $\% 20$ Multicomponent $\% 20$ Units $\% 20$ paper $\% 20$ $17 \% 20 \mathrm{DEC} \%$

2015_0.pdf

National Training Center, “FY16 NTC Rotational Schedule,” June 30, 2016.

NCFA - See National Commission on the Future of the Army.

NCFA CoC_-See National Commission on the Future of the Army Council of Colonels.

Ochoa, Fernando, 311th Sustainment Command, "The 729th TC Drive

Nationwide Move,” press release, Fresno, Calif., May 19, 2016. As of November 7, 2016:

http://www.usar.army.mil/News/Display/Article/776659/

the-729th-tc-drive-nationwide-move/

Office of the Assistant Chief of Staff for Installation Management, "Army Universe Chart," briefing, September 30, 2016.

Office of the Assistant Secretary of Defense, Reserve Affairs, "America's National Guard and Reserve Force: An Indispensable, Valuable, and Operational Force for the 21st Century," briefing, undated. As of November 17, 2016:

http://www.people.mil/Portals/56/Documents/OSDRACommandBrief.pptx

Office of the Assistant Secretary of Defense, Reserve Affairs, "Guidance on Service Implementation of 10 U.S.C. $\$ 12304$ b Order to Active Duty for Preplanned Missions in Support of Combatant Commands, Memorandum for Assistant Secretaries of the Military Departments (Manpower and Reserve Affairs)," May 1, 2014. 
Office of the ASA (M\&RA)_See Office of the Assistant Secretary of the Army for Manpower and Reserve Affairs.

Office of the Assistant Secretary of the Army for Manpower and Reserve Affairs, "Memorandum: FY17 Army Total Force Policy (ATFP) Implementation Guidance," draft dated April 27, 2016.

Office of the Deputy Chief of Staff, G-3/5/7, Department of the Army Management Office, Mobilization Division, "Department of the Army Mobilization Processing System (DAMPS)," power point briefing, January 2008. As of July 19, 2017: http://www.people.mil/Portals/56/Documents/rtm/Army\%20G-3\%20 Mobilization\%20Processing\%20System\%20(DAMPS).ppt

Office of the Deputy Chief of Staff, G-3/5/7, Department of the Army Management Office-Force Management, "Associated Units Pilot Overview, Implementation Forum,” briefing, May 25, 2016.

Office of the Secretary of Defense, Public Affairs, "Secretary Cohen Signs Memorandum Emphasizing Increased Reliance on the Reserve Components," press release, Arlington, Va., 1997. As of October 24, 2016:

https:/www.legistorm.com/stormfeed/view_rss/588965/organization/31751.html

Owens, Dallas D., Jr., AC/RC Integration: Today's Success and Transformation's Challenge, Carlisle, Penn.: Strategic Studies Institute, U.S. Army War College, 2001. As of October 24, 2016:

http://www.strategicstudiesinstitute.army.mil/pdffiles/PUB255.pdf

Pellerin, Cheryl, "Carter Unveils Next Wave of Force of the Future Initiatives," press release, U.S. Department of Defense, Washington, D.C., June 9, 2016. As of February 14, 2017:

https://www.defense.gov/News/Article/Article/795625/

carter-unveils-next-wave-of-force-of-the-future-initiatives

Philpott, Tom, "Mullen Pulls Plug On Problem-Plagued DIMHRS Pay Program," Newport News Daily Press, February 22, 2010. As of November 11, 2016: http://articles.dailypress.com/2010-02-21/news/ dp-local_milupdate_0222feb22_1_military-personnel-payroll-navy-and-air-force Pint, Ellen M., Matthew W. Lewis, Thomas F. Lippiatt, Philip Hall-Partyka, Jonathan P. Wong, and Tony Puharic, Active Component Responsibility in Reserve Component Pre-and Postmobilization Training, Santa Monica, Calif.: RAND Corporation, RR-738-A, 2015. As of November 30, 2016: http://www.rand.org/pubs/research_reports/RR738.html

Pressnell, Ricky C., DOTMLPF Implications for an Operational Army National Guard, thesis, U.S. Army War College, March 2013. As of February 15, 2017: http://www.dtic.mil/get-tr-doc/pdf?AD=ADA590219 
Price, Dakota, 210th Mobile Public Affairs Detachment, "Nationwide Move 15 Gives Reservists Experience, Confidence,” press release, Fort Drum, N.Y., May 26, 2015. As of November 7, 2016:

https://dvidshub.net/news/165462/

nationwide-move-2015-gives-reservists-experience-confidence

Program Executive Office, Enterprise Information Systems, "IPPS-A System:

Capabilities Released Over Time,” undated. As of November 11, 2016:

https://www.ipps-a.army.mil/about-2/system/

Randolph, Addie, 76th U.S. Army Reserve Operational Response Command, "US PACOM Army Reserve Element Stands Up," press release, November 19, 2014. As of November 30, 2014:

https:/www.dvidshub.net/news/148283/us-pacom-army-reserve-element-stands-up

Reserve Forces Policy Board, Reserve Component Use, Balance, Cost and Savings: A Response to Questions from the Secretary of Defense, Final Report to the Secretary of Defense, Falls Church, Va., February 11, 2014. As of November 21, 2016: http://www.ngaus.org/sites/default/files/ RFPB_Report_RC_Use_Mix_Cost_Savings_Web.pdf

Schnaubelt, Christopher M., Raphael S. Cohen, Molly Dunigan, Gian Gentile, Jaime Hastings, Joshua Klimas, Jefferson P. Marquis, Agnes Gereben Schaefer, Bonnie Triezenberg, Michelle D. Ziegler, Sustaining the Army's Reserve Components as an Operational Force, Santa Monica, Calif.: RAND Corporation, RR-1495-A, 2017.

Tan, Michelle, "Army Pilot Links Active, Guard and Reserve Units for Training, Deployments," Army Times, March 22, 2016. As of September 29, 2016: https://www.armytimes.com/story/military/pentagon/2016/03/22/ army-pilot-links-active-guard-and-reserve-units-training-deployments/82128968/

U.S. Army, Army Training Requirements and Resources System, data system, undated-a. Not available to general public.

U.S. Army, "References: Army Strategic Documents and Resources," undated-b. As of June 5, 2017: https://www.army.mil/info/references/

U.S. Army, "Addendum," Posture Statement 2002, February 2002. As of July 31, 2017:

https://www.army.mil/aps/02/html/addendum.html

U.S. Army, “Addendum A,” 2003 Posture Statement, February 2003. As of July 31, 2017:

https://www.army.mil/aps/2003/extras/pdfs/addendum.pdf

U.S. Army, “Addendum A,” 2004 Posture Statement, February 2004. As of July 31, 2017:

https:/www.army.mil/aps/04/addendumA.html 
U.S. Army, "Addendum A: (Data Required by NDAA 1994)," 2005 Posture Statement, February 2005. As of July 31, 2017: https:/www.army.mil/aps/05/addenduma.html

U.S. Army, “Addendum A: Data Required by NDAA 1994," 2006 Posture Statement, February 2006. As of July 31, 2017:

https://www.army.mil/aps/06/15_addendums.html

U.S. Army, "Addendum E: (Data Required by the National Defense Authorization Act for 1994)," 2007 Posture Statement, February 2007. As of July 31, 2017: https:/www.army.mil/aps/07/addendum/e.html

U.S. Army, "Addendum A: Reserve Components Readiness," 2008 Army Posture Statement, February 2008, pp. 15-28. As of July 31, 2017:

https://www.army.mil/aps/08/APS2008.pdf

U.S. Army, "Addendum D: Reserve Component Readiness," 2009 Army Posture Statement, May 2009. As of July 31, 2017: https://www.army.mil/aps/09/addenda/addenda_d.html

U.S. Army, "Addendum E: Reserve Component Readiness," 2010 Army Posture Statement, February 2010.

U.S. Army, "Addendum E: Reserve Component Readiness," 2011 Army Posture Statement, March 2011.

U.S. Army, "Addendum F: Reserve Component Readiness," 2012 Army Posture Statement, February 2012.

U.S. Army, Army Equipping Enterprise System, database, files obtained May, July, and September 2016. Not available to public.

U.S. Army Chief of Staff, "U.S. Army Mission Command Strategy, FY 13-19," Washington, D.C. June 12, 2013. As of February 15, 2017: https://www.army.mil/e2/c/downloads/312724.pdf

U.S. Army Chief of Staff, “Army Readiness Guidance, Calendar Year 2016-17,” memorandum for all Army leaders, January 20, 2016. As of November 9, 2016 : https://www.army.mil/e2/downloads/rv7/standto/docs/

army_readiness_guidance.pdf

U.S. Army Force Management Support Agency, Force Management System Web Site, undated. As of September 1, 2017: https://fmsweb.fms.army.mil/unprotected/splash/

U.S. Army Forces Command, "Memorandum of Agreement Between Commander, U.S. Army Forces Command and Chief, Army Reserve for Implementation of the XVIII Airborne Corps Multiple-Component Unit (MCU) Pilot,” Ft. Bragg, N.C., May 8, 2015. 
U.S. Army Forces Command, "Memorandum of Agreement Between Commander, U.S. Army Forces Command (FORSCOM) and Commander, U.S. Army Reserve (CDR, USARC) and Director, Army National Guard (DARNG) and The Adjutant General, Wisconsin National Guard (TAG WING) and The Adjutant General, Utah National Guard (TAG UTNG) for Implementation of the 101st Airborne Division Multiple-Component Unit (MCU) Pilot," Ft. Bragg, N.C., January 29, 2016 a.

U.S. Army Forces Command, "Objective T-level (OBJ T) - The Future for Measuring the Training (T-level) and Assigned Mission Training (AMT-level) in Unit Status Report," information paper, June 16, 2016 b.

U.S. Army Reserve, "76th Operational Response Command: Salt Lake City, Utah,” website, undated. As of November 30, 2016:

http://www.usar.army.mil/Commands/Operational-Functional/76th-ORC/

U.S. Army Reserve G-4, email communication, September 14, 2016.

U.S. Army War College, How the Army Runs: A Senior Leader Reference Handbook, 2015-2016, Carlisle, Pa., August 2015. As of November 21, 2016:

http://www.carlisle.army.mil/orgs/SSL/dclm/pubs/HTAR.pdf

U.S. Code, Title 10, Section 12302, "Partial Involuntary Mobilization,” January 3, 2012a.

U.S. Code, Title 10, Section 12304b, "Selected Reserve: Order to Active Duty for Preplanned Missions in Support of the Combatant Commands," January 3, 2012b.

U.S. Department of Defense, "Fact Sheet: Building the First Link to the Force of the Future," undated-a. As of February 14, 2017:

https:/www.defense.gov/Portals/1/features/2015/

0315_force-of-the-future/documents/FotF_Fact_Sheet_-_FINAL_11.18.pdf

U.S. Department of Defense, "Fact Sheet: Building the Second Link to the Force of the Future, Strengthening Comprehensive Family Benefits" undated-b. As of February 14, 2017:

https://www.defense.gov/Portals/1/Documents/pubs/

Fact_Sheet_Tranche_2_FOTF_FINAL.pdf

U.S. Department of Defense, "Fact Sheet: The Next Two Links to the Force of the Future," undated-c. As of February 14, 2017:

https:/www.defense.gov/Portals/1/features/2015/0315_force-of-the-future/ Fact-Sheet-The-Next-Two-Links-to-the-Force-of-the-Future.pdf

U.S. Department of Defense, "Fact Sheet: Forging Two New Links to the Force of the Future," undated-d. As of February 14, 2017:

https://www.defense.gov/Portals/1/Documents/pubs/Fact_Sheet_-_The_Fifth_ and_Sixth_Links_to_the_Force_of_the_Future.pdf 
U.S. Department of Defense, 1200.17, Managing the Reserve Components as an Operational Force, Washington, D.C., October 29, 2008a. As of August 29, 2017: https://www.hsdl.org/?view\&did=233708

U.S. Department of Defense, Directive 1235.10, Activation, Mobilization, and Demobilization of the Ready Reserve, Washington, D.C., November 26, 2008b. As of February 24, 2017:

https://cryptome.org/dodi/dodd-1235-10.pdf

U.S. Department of Defense, Instruction 1235.12, Accessing the Reserve

Components (RC), Washington, D.C., February 4, 2010. As of February 24, 2017: https://cryptome.org/dodi/dodi-1235-12.pdf

U.S. Department of Defense, Directive 5124.09, "Assistant Secretary of Defense for Readiness and Force Management (ASD(R\&FM))," Washington, D.C., June 12, 2014a. As of November 22, 2016:

http://www.esd.whs.mil/Portals/54/Documents/DD/issuances/dodd/512409p.pdf

U.S. Department of Defense, Fiscal Year 2015 Overseas Contingency Operations Request for Operation Enduring Freedom, Military Personnel, Army Justification Book, Washington, D.C.., June 2014b.

U.S. Department of Defense, Fiscal Year 2016 Overseas Contingency Operations Request, Military Personnel, Army Justification Book, Washington, D.C., February 2015.

U.S. Department of Defense, Fiscal Year (FY) 2017 Overseas Contingency Operations Request, Military Personnel, Army Justification Book, Washington, D.C., February 2016a.

U.S. Department of Defense, National Guard and Reserve Equipment Report for Fiscal Year 2017, Washington, D.C., March 2016b. As of November 9, 2016: http://prhome.defense.gov/Portals/52/Documents/PR\%20Docs/NGRER\%20 FY2017.pdf

U.S. Department of Defense, Instruction 1235.12, Accessing the Reserve Components (RC), June 7, 2016c. As of February 24, 2017: http://www.dtic.mil/whs/directives/corres/pdf/123512p.pdf

U.S. Government Accountability Office, Problems in Implementing the Army's CAPSTONE Program To Provide All Reserve Components With a Wartime Mission, Washington, D.C., FPCD-82-59, September 22,1982. As of August 30, 2017: http://www.gao.gov/products/FPCD-82-59

U.S. Government Accountability Office, Military Personnel: DoD Actions Needed to Improve the Efficiency of Mobilizations for Reserve Forces, GAO-03-921, Washington, D.C., August 2003. As of February 24, 2017: http://www.gao.gov/assets/240/239290.pdf 
U.S. Government Accountability Office, Military Personnel: DoD Needs to Address Long-term Reserve Force Availability and Related Mobilization and Demobilization Issues, GAO-04-1031, Washington, D.C., September 2004. As of February 24, 2017:

http://www.gao.gov/assets/250/244151.pdf

U.S. Government Accountability Office, Force Structure: Army's Analyses of Aviation Alternatives, GAO-15-430R, Washington, D.C., April 27, 2015. As of July 18, 2017:

http://www.gao.gov/assets/670/669857.pdf

U.S. House of Representatives, Committee on Government Reform, "Financial Friendly Fire: A Review of Persistent Military Pay Problems," Washington, D.C., U.S. Government Printing Office 2006.

U.S. Senate, "National Commission on the Future of the Army Act," Washington, D.C., U.S. Government Printing Office, 2014.

Vergun, David, “Army Total Force Partnerships Improving Readiness,” Army News Service, June 9, 2016. As of September 29, 2016:

https://www.army.mil/article/169416/

army_total_force_partnerships_improving_readiness

Wada, Debra S., "The Force of the Future," press release, October 1, 2015. As of October 24, 2016:

https://www.army.mil/article/156474/

Winkler, John D., "Developing an Operational Reserve," Joint Forces Quarterly, Issue 59, 4th Quarter 2010, pp. 14-20. As of November 17, 2016:

http://www.dtic.mil/doctrine/jfq/jfq-59.pdf 
This report reviews the implementation of the Army's Total Force Policy (ATFP). It presents an analysis of the extent to which the Army has implemented the actions directed by the ATFP, how these efforts benefitted the different components and enhanced the total force, whether implementation actions to date caused negative unintended consequences, and how the Army might improve the ATFP to achieve a more cost effective, integrated and capable total force. We find that, in general, the Army has made progress in implementing the policy and improving the integration of the Regular Army, Army National Guard, and U.S. Army Reserve. However, budget constraints have limited implementation of some objectives, such as multicomponent training, reserve component equipment modernization, and use of $12304 \mathrm{~b}$ mobilization authority. Since the Army's budget is likely to remain constrained in the future, we recommend that it continue to pursue and develop innovative solutions, such as multicomponent vehicle loans, positioning modernized equipment at regional training and mobilization sites, and integrating individual training and professional military education under the One Army School System. We also recommend that the Army set measurable goals for total force integration and establish metrics to monitor progress, and evaluate pilot programs such as associated units and combining recruiting and marketing functions to determine whether they are meeting their intent.

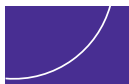

RAND ARROYO CENTER

\section{wWw.rand.org}

ISBN-10 0-8330-9821-7

ISBN-13 978-0-8330-9821-4 